AUTARQUIA ASSOCIADA À UNIVERSIDADE DE SÃO PAULO

DESENVOLVIMENTO E CARACTERIZAÇÃO DE CÂMARAS DE IONIZAÇÃO ESPECIAIS PARA FEIXES DE TOMOGRAFIA COMPUTADORIZADA

Maysa Costa de Castro

Dissertação apresentada como parte dos requisitos para obtenção do Grau de Mestre em Ciências na Área de Tecnologia Nuclear Aplicações

Orientadora:

Profa. Dra. Linda V. E. Caldas

São Paulo 2016 
INSTITUTO DE PESQUISAS ENERGÉTICAS E NUCLEARES

Autarquia associada à Universidade de São Paulo

\title{
DESENVOLVIMENTO E CARACTERIZAÇÃO DE CÂMARAS DE IONIZAÇÃO ESPECIAIS PARA FEIXES DE TOMOGRAFIA COMPUTADORIZADA
}

Maysa Costa de Castro

Dissertação apresentada como parte dos requisitos para obtenção do Grau de Mestre em Ciências na Área de Tecnologia Nuclear Aplicações

Orientadora:

Profa. Dra. Linda V. E. Caldas

\author{
Versão Corrigida \\ Versão Original Disponível no IPEN
}

São Paulo

2016 


\section{Dedicatória}

Aos meus pais e a minha irmã, com muito amor e carinho. 


\section{Agradecimentos}

À Dra. Linda V. E. Caldas, pela orientação, sabedoria, disponibilidade, paciência durante o desenvolvimento deste trabalho, e acima de tudo pela confiança depositada em mim desde o princípio. Agradeço também por todo cuidado, carinho e conselhos durante toda a trajetória, pois eles foram muito importantes não somente no meu crescimento acadêmico como pessoal.

Ao Sr. Marcos Xavier, por toda disponibilidade, ensinamentos e questionamentos durante todo o tempo, e principalmente no desenvolvimento das câmaras de ionização e auxílio técnico na parte experimental deste projeto.

Ao Dr. Vitor Vivolo e à Dra. Maria da Penha Albuquerque Potiens, pelos esclarecimentos e colaboração no decorrer deste trabalho.

À Dra. Denise Yanikian Nersissian, por compartilhar seus conhecimentos da parte clínica, além de toda disponibilidade, prestatividade e ajuda nos experimentos desenvolvidos no Hospital Veterinário da USP.

À Profa. Dra. Ana Carolina Fonseca Pinto, por disponibilizar o uso do tomógrafo do Hospital Veterinário da Faculdade de Medicina Veterinária e Zootecnia da Universidade de São Paulo (FMVZ/USP).

Ao Dr. Roberto Sakuraba, à Sra. Elaine Cristina Godoy Artuzo e à Sra. Camila dos Santos Silva (Coordenadora Biomédica da Tomografia) do Hospital Israelita Albert Einstein, por todo o suporte e ajuda durante as realizações dos testes clínicos na instituição.

Ao Hospital Israelita Albert Einstein, por ceder seus equipamentos e proporcionar um melhor aprendizado para a utilização do equipamento construído neste trabalho.

À Oficina Mecânica do IPEN pela colaboração no desenvolver deste trabalho. 
À MSc. Natália Fiorini da Silva e ao MSc. Tallyson Sarmento Alvarenga, por todo companheirismo desde sempre nos bons momentos e nos desesperadores também, pelas conversas e gordices realizadas.

À Natalia Cravo Costa, por me ajudar com suas habilidades arquitetônicas a fazer as figuras do projeto das câmaras de ionização que foram desenvolvidas. Obrigada pela amizade e pelos momentos de descontração.

À Sra. Deise Aparecida Dias dos Santos e à Sra. Donata C. Zanin, pela disponibilidade em resolver problemas administrativos sempre que necessários.

À Dra. Patricia de Lara Antônio e à MSc. Elaine Wirney Martins por toda colaboração e ajuda prestada durante o desenvolvimento deste trabalho.

Aos amigos do grupo, pelos momentos de descontração.

À minha mãe, Eliane Maria Santos Cravo Costa de Castro e ao meu pai, Ary Estevam de Castro, agradeço por toda a dedicação durante toda a minha caminhada, pelo amor, compreensão, incentivo, apoio em todos os momentos e até pelas broncas e choques de realidade. Quero que saibam que vocês são pessoas maravilhosas e indispensáveis e que dedico a vocês toda a minha admiração e respeito.

Agradeço à minha irmã Mayara Castro, e às minhas irmãs que a vida me deu, Hortência Maria Xavier de Sousa e Beatriz Helena Cano, por toda amizade e companheirismo desde sempre nos bons e maus momentos. À toda minha família por estar sempre presente em minha vida.

Ao Instituto de Pesquisas Energéticas e Nucleares IPEN-CNEN/USP, na pessoa do Sr. Superintendente, Dr. José Carlos Bressiani, por proporcionar toda a infraestrutura necessária para o desempenho do projeto.

À Comissão Nacional de Energia Nuclear, pela concessão da bolsa de estudos. 
À Fundação de Apoio à Pesquisa do Estado de São Paulo e ao Conselho Nacional de Desenvolvimento Científico e Tecnológico, no projeto INCT em Metrologia das Radiações na Medicina, pelo auxílio financeiro nas participações em congressos. 


\section{Epígrafe}

"O bem só é apreciado quando uma pessoa ganha isso através do trabalho duro.

Quanto mais forte for o esforço, mais doce o sabor do fruto."

Rav Berg 


\title{
Desenvolvimento e Caracterização de Câmaras de lonização Especiais para Feixes de Tomografia Computadorizada
}

\section{Maysa Costa de Castro}

\begin{abstract}
Resumo
O uso de Tomografia Computadorizada (CT) para procedimentos de imagiologia vem crescendo cada vez mais devido aos avanços da tecnologia dos equipamentos de CT, que permitem a obtenção de imagens com melhor resolução do que por outras técnicas, sendo consequentemente responsável pelo aumento da dose de radiação no paciente durante o procedimento. Isso acarretou uma maior preocupação com as doses recebidas pelos pacientes que se submetem a esse tipo de exame. Para a realização da dosimetria de feixes de CT, o instrumento mais utilizado é a câmara de ionização do tipo lápis, pois este dosímetro apresenta uma resposta uniforme ao feixe de radiação incidente em todos os ângulos. A câmara convencional que se encontra disponível no mercado apresenta um comprimento de volume sensível de $10 \mathrm{~cm}$; entretanto, alguns estudos têm mostrado que esse dosímetro tem subestimado os valores de dose. Portanto, neste trabalho optouse por desenvolver no Laboratório de Calibração de Instrumentos do Instituto de Pesquisas Energéticas e Nucleares (LCI-IPEN/CNEN) duas câmaras de ionização, fazendo uso de materiais nacionais de baixo custo, com comprimentos de volume sensível de $10 \mathrm{~cm}$ e $30 \mathrm{~cm}$. A caracterização destas câmaras foi realizada e os resultados se apresentaram dentro dos limites recomendáveis internacionais. Como uma aplicação, as câmaras desenvolvidas, juntamente com uma câmara comercial, foram testadas em um tomógrafo clínico. As câmaras de ionização desenvolvidas foram analisadas de maneira completa, para os seus possíveis usos.
\end{abstract}




\title{
Development and Characterization of Special lonization Chambers for Computed Tomography Beams
}

\section{Maysa Costa de Castro}

\begin{abstract}
The use of computed tomography (CT) for imaging procedures is growing due to advances in the CT equipment technology, because they allow the obtention of images with better resolution than through other techniques. Therefore, they are responsible for increasing the dose radiation of patients during the procedure. This fact led to a greater concern about the doses received by patients who undergo this type of examination. To perform the dosimetry in CT beams, the most widely used instrument is the pencil type ionization chamber, because this dosimeter has a uniform response to the incident radiation beam for all angles. The conventional ionization chamber, which is available on the market, has a sensitive volume length of $10 \mathrm{~cm}$; however, some studies have shown that this dosimeter has underestimated the dose values. Therefore, in this study two ionization chambers with sensitive volume lengths of $10 \mathrm{~cm}$ and $30 \mathrm{~cm}$, making use of low cost national materials, were developed at the Calibration Laboratory of Instruments (LCI-IPEN/CNEN). The characterization of these chambers was performed, and the results were obtained within the international recommended limits. As an application, the developed ionization chambers and a commercial chamber were tested in a clinical tomographer. The developed ionization chambers were analyzed in a complete way for their possible uses.
\end{abstract}




\section{Sumário}

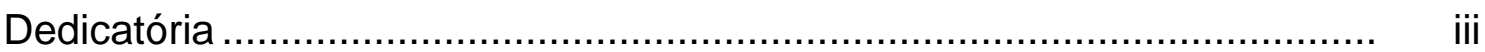

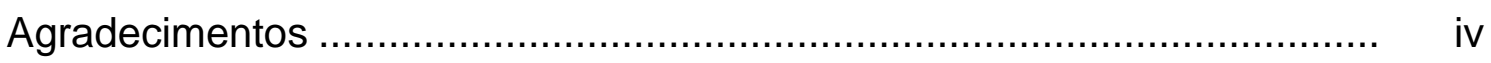

Epígrafe ................................................................................ vii

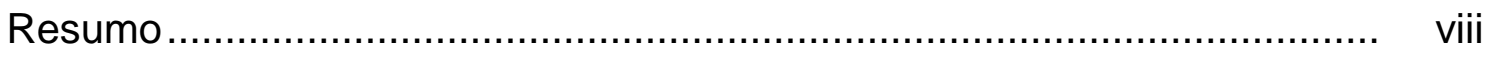

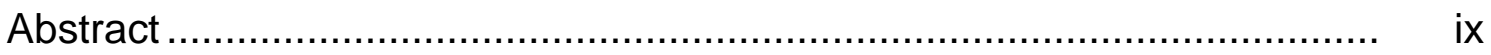

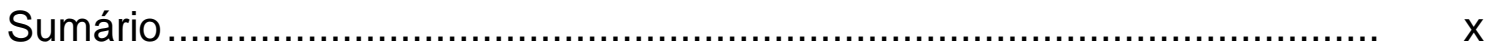

Lista de Figuras ................................................................... $x$ iii

Lista de Tabelas ...........................................................................

Lista de Siglas .................................................................. $x$ xiii

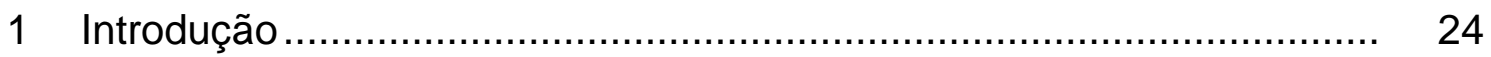

2 Objetivos ................................................................................. 29

3 Fundamentos Teóricos .............................................................. 30

3.1 Interação da Radiação com a Matéria ......................................................... 30

3.1.1 Efeito Fotoelétrico .............................................................................. 30

3.1.2 Efeito Compton ................................................................................ 30

3.1.3 Espalhamento Compton Coerente ou Efeito Rayleigh ......................... 31

3.1.4 Produção de Pares ................................................................................. 31

3.2 Grandezas Dosimétricas............................................................................ 31

3.2.1 Exposição ................................................................................................ 31

3.2.2 Dose Absorvida ............................................................................. 32

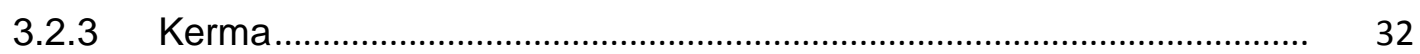

3.3 Fundamentos de Tomografia Computadorizada........................................... 33

3.3.1 Histórico ............................................................................................ 33

3.3.2 Principais Componentes do Tomógrafo .............................................. 35

3.3.3 Grandezas Dosimétricas Específicas para Tomografia Computadorizada ............................................................................ 36

3.4 Câmaras de lonização ............................................................................ 38

3.4.1 Características Gerais ............................................................................. 38

3.4.2 Câmara de lonização para Tomografia Computadorizada................... 39

3.5 Testes de Caracterização e Controle de Qualidade...................................... 39

3.5.1 Teste de Estabilidade ............................................................................. 40

3.5.2 Teste de Tempo de Estabilização ......................................................... 40 
3.5.3 Teste de Corrente de Fuga......................................................................... 40

3.5.4 Teste de Saturação ............................................................................... 40

3.5.5 Teste de Linearidade da Resposta......................................................... 40

3.5.6 Teste de Dependência Angular................................................................... 41

3.5.7 Teste de Dependência Energética ........................................................... 41

3.6 Determinação do Fator de Correção das Medições para as Condições Ambientais de Referência............................................................................ 41

3.7 Conversão de Carga e Corrente em Taxa de Kerma no Ar ......................... 41

3.8 Calibração de Instrumentos............................................................................... 42

3.8.1 Objetivos e Técnicas de Calibração .......................................................... 43

3.8.2 Intercomparação e Rastreabilidade......................................................... 44

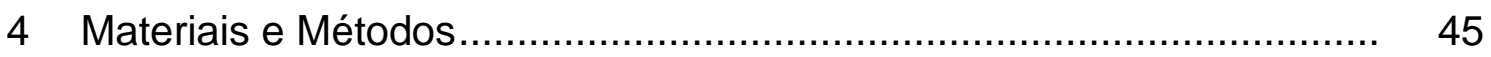

4.1 Sistemas de Radiação .................................................................................... 45

4.2 Sistemas de Medição ................................................................................. 47

4.3 Sistemas Auxiliares ...................................................................................... 49

$4.4 \quad$ Estimativas das Incertezas ...................................................................... 50

5 Resultados: Projeto, Construção e Caracterização Experimental das Câmaras de lonização ............................................................. 52

5.1 Construção das Câmaras de lonização ........................................................ 52

5.1.1 Conectores ................................................................................... 52

5.1.2 Corpo das Câmaras de lonização ......................................................... 52

5.1.3 Eletrodo Coletor ...................................................................................... 53

5.1.4 Capa da Câmara de lonização ............................................................. 53

5.1.5 Montagem das Câmaras de ionização ................................................... 53

5.2 Caracterização Experimental das Câmaras de lonização............................ 54

5.2.1 Corrente de Fuga ..................................................................................... 56

5.2.2 Tempo de Estabilização ........................................................................ 56

5.2.3 Teste de Estabilidade em Curto e Longo Prazos................................... 57

5.2.4 Curva de Saturação, Efeito de Polaridade e Eficiência de Coleção de Íons ........................................................................................... 62

5.2.5 Linearidade da Resposta ............................................................... 79

5.2.6 Dependência Energética .......................................................................... 87

5.2.7 Dependência Angular ........................................................................... 92 
5.2.8 Avaliação da Resposta em Função do Comprimento do Volume Sensível da Câmara de lonização .......................................................... 100

6 Testes Realizados em Feixes Clínicos .............................................. 103

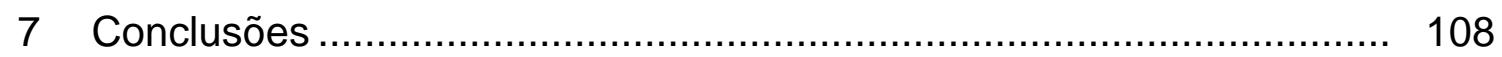

8 Referências .......................................................................... 110 


\section{Lista de Figuras}

Figura 3.1: Componentes de um tomógrafo. Imagem adaptada (TOSHIBA, 2010)

Figura 4.1: Foto dos sistemas de radiação utilizados na execução deste trabalho: (a) Equipamento de raios $\mathrm{X}$, marca Pantak/Seifert e (b) Tomógrafo Philips

Figura 4.2: Foto dos sistemas de medição, (a) Eletrômetro PTW (modelo UNIDOS E) e (b) Câmara de ionização Radcal (modelo RC3CT).

Figura 4.3: Foto das câmaras de ionização C2, C3 e C4 desenvolvidas no LCl

Figura 5.1: Corpo da câmara de ionização de $10 \mathrm{~cm}$, antes da pintura com spray de grafite

Figura 5.2: Eletrodo coletor antes da pintura com spray de grafite

Figura 5.3: Câmaras de ionização prontas, com comprimentos de volume sensível de $10 \mathrm{~cm}$ e $30 \mathrm{~cm}$.

Figura 5.4: Arranjo experimental para realização dos testes de estabilidade a curto e longo prazos, tempo de estabilização e corrente de fuga

Figura 5.5: Arranjo experimental (a) completo; (b) evidenciando a posição da câmara de ionização.

Figura 5.6: Teste de estabilidade para a câmara de ionização C1........ 59

Figura 5.7: Teste de estabilidade para a câmara de ionização C2. ....... 59

Figura 5.8: Teste de estabilidade para a câmara de ionização C3........ 60

Figura 5.9: Teste de estabilidade para a câmara de ionização C4........ 60

Figura 5.10: Teste de estabilidade para a câmara de ionização C5. ........ 61

Figura 5.11: Teste de estabilidade para a câmara de ionização C6. ........ 61

Figura 5.12: Teste de estabilidade para a câmara de ionização C7. ....... 62 
Figura 5.13: Curvas de saturação da câmara de ionização $C 1$ para as qualidades dos feixes padronizados de radiação $X$ para $C T$ no LCl. A incerteza máxima das medições de todas as figuras foi de $0,01 \%$, não visível nos gráficos. Aberturas do colimador: (a) $2 \mathrm{~cm} \times 2 \mathrm{~cm}$ e (b) $5 \mathrm{~cm} \times 2 \mathrm{~cm}$.

Figura 5.14: Curvas de saturação da câmara de ionização $C 2$ para as qualidades dos feixes padronizados de radiação $X$ para $C T$ no LCl. A incerteza máxima das medições de todas as figuras foi de $0,01 \%$, não visível nos gráficos. Aberturas do colimador: (a) $0,5 \mathrm{~cm} \times 2 \mathrm{~cm}$ e (b) $2 \mathrm{~cm} \times 2 \mathrm{~cm}$.

Figura 5.15: Curvas de saturação da câmara de ionização $C 3$ para as qualidades dos feixes padronizados de radiação $X$ para CT no LCl. A incerteza máxima das medições de todas as figuras foi de $0,01 \%$, não visível nos gráficos. Aberturas do colimador: (a) $1,5 \mathrm{~cm} \times 2 \mathrm{~cm} \mathrm{e} \mathrm{(b)} 2 \mathrm{~cm} \times 2 \mathrm{~cm}$.

Figura 5.16: Curvas de saturação da câmara de ionização $C 4$ para as qualidades dos feixes padronizados de radiação $X$ para CT no LCl. A incerteza máxima das medições de todas as figuras foi de $0,01 \%$, não visível nos gráficos. Aberturas do colimador: (a) $2 \mathrm{~cm} \times 2 \mathrm{~cm}$ e (b) $5 \mathrm{~cm} \times 2 \mathrm{~cm}$.

Figura 5.17: Curvas de saturação da câmara de ionização C5 para as qualidades dos feixes padronizados de radiação $X$ para $C T$ no LCl. A incerteza máxima das medições de todas as figuras foi de $0,01 \%$, não visível nos gráficos. Aberturas do colimador: (a) $2 \mathrm{~cm} \times 2 \mathrm{~cm} \mathrm{e} \mathrm{(b)} 5 \mathrm{~cm} \times 2 \mathrm{~cm}$.

Figura 5.18: Curvas de saturação da câmara de ionização $C 7$ para as qualidades dos feixes padronizados de radiação $X$ para $C T$ no LCl. A incerteza máxima das medições de todas as figuras foi de $0,01 \%$, não visível nos gráficos. Aberturas do colimador: (a) $2 \mathrm{~cm} \times 2 \mathrm{~cm} \mathrm{e} \mathrm{(b)} 5 \mathrm{~cm} \times 2 \mathrm{~cm}$. 
Figura 5.19: Curvas de saturação para as qualidades dos feixes padronizados de radiação $X$ para $\mathrm{CT}$ no $\mathrm{LCl}$. A incerteza máxima das medições de todas as figuras foi de $0,01 \%$, não visível nos gráficos. Abertura do colimador de (15 cm $\times 2 \mathrm{~cm}$ ) para as câmaras de ionização: (a) C6 e (b) $\mathrm{C} 7$

Figura 5.20: Linearidade da resposta da câmara de ionização $C 1$ para a qualidade de referência de CT no LCI (RQT 9). A incerteza máxima das medições das figuras foi de $0,02 \%$, não visível nos gráficos. Aberturas do colimador: (a) $2 \mathrm{~cm} \times 2 \mathrm{~cm}$ e (b) $5 \mathrm{~cm} \times 2 \mathrm{~cm}$. $O$ ajuste de reta obtido foi de $R^{2}=0,9999$

Figura 5.21: Linearidade da resposta da câmara de ionização $C 2$ para a qualidade de referência de CT no LCI (RQT 9). A incerteza máxima das medições das figuras foi de $0,02 \%$, não visível nos gráficos. Aberturas do colimador: (a) $0,5 \mathrm{~cm} \times 2 \mathrm{~cm}$ e (b) $2 \mathrm{~cm} \times 2 \mathrm{~cm}$. O ajuste de reta obtido foi de $R^{2}=0,9999$.

Figura 5.22: Linearidade da resposta da câmara de ionização C3 para a qualidade de referência de CT no LCI (RQT 9). A incerteza máxima das medições das figuras foi de 0,02 \%, não visível nos gráficos. Aberturas do colimador: (a) $1,5 \mathrm{~cm} \times 2 \mathrm{~cm} \mathrm{e}$ (b) $2 \mathrm{~cm} \times 2 \mathrm{~cm}$. Os ajustes de reta obtidos foram de: (a) $R^{2}=0,9999$ e (b) $R^{2}=1,0000$.

Figura 5.23: Linearidade da resposta da câmara de ionização $C 4$ para a qualidade de referência de CT no LCI (RQT 9). A incerteza máxima das medições das figuras foi de $0,02 \%$, não visível nos gráficos. Aberturas do colimador: (a) $2 \mathrm{~cm} \times 2 \mathrm{~cm}$ e (b) $5 \mathrm{~cm} \times 2 \mathrm{~cm}$. Os ajustes de reta obtidos foram de: (a) $R^{2}=0,9999$ e (b) $R^{2}=0,9998$. 
Figura 5.24: Linearidade da resposta da câmara de ionização C5 para a qualidade de referência de CT no LCI (RQT 9). A incerteza máxima das medições das figuras foi de $0,02 \%$, não visível nos gráficos. Aberturas do colimador: (a) $2 \mathrm{~cm} \times 2 \mathrm{~cm}$ e (b) $5 \mathrm{~cm} \times 2 \mathrm{~cm}$. Os ajustes de reta obtidos foram de: (a) $R^{2}=0,9999$ e (b) $R^{2}=0,9999$.

Figura 5.25: Linearidade da resposta da câmara de ionização $C 7$ para a qualidade de referência de CT no LCI (RQT 9). A incerteza máxima das medições das figuras foi de $0,02 \%$, não visível nos gráficos. Aberturas do colimador: (a) $2 \mathrm{~cm} \times 2 \mathrm{~cm}$ e (b) $5 \mathrm{~cm} \times 2 \mathrm{~cm}$. Os ajustes de reta obtidos foram de: (a) $R^{2}=0,9999$ e (b) $R^{2}=1,0000$

Figura 5.26: Linearidade da resposta para a qualidade RQT 9, com a abertura do colimador de $(15 \mathrm{~cm} \times 2 \mathrm{~cm})$. A incerteza máxima das medições foi de $0,01 \%$, não visível nos gráficos, para as câmaras de ionização: (a) C6 e (b) C7. O ajuste de reta obtido foi de $R^{2}=1,0000$ para os dois casos .

Figura 5.27: Dependência angular, para a qualidade de referência (RQT 9) dos feixes padronizados de radiação $X$ para CT no $\mathrm{LCl}$ e para a câmara de ionização $\mathrm{C} 1$. A incerteza máxima das medições foi de $0,01 \%$, não visível nos gráficos. Aberturas do colimador: (a) $2 \mathrm{~cm} \times 2 \mathrm{~cm}$ e (b) $5 \mathrm{~cm} \times 2 \mathrm{~cm}$..

Figura 5.28: Dependência angular, para a qualidade de referência (RQT 9) dos feixes padronizados de radiação $X$ para CT no LCl e para a câmara de ionização C2. A incerteza máxima das medições foi de $0,01 \%$, não visível nos gráficos. Aberturas do colimador: (a) $0,5 \mathrm{~cm} \quad x \quad 2 \mathrm{~cm} \quad \mathrm{e}$ (b) $2 \mathrm{~cm} \times 2 \mathrm{~cm}$ 
Figura 5.29: Dependência angular, para a qualidade de referência (RQT 9) dos feixes padronizados de radiação $X$ para CT no $\mathrm{LCl}$ e para a câmara de ionização $\mathrm{C} 3$. A incerteza máxima das medições foi de $0,01 \%$, não visível nos gráficos. Aberturas do colimador: (a) $1,5 \mathrm{~cm} \times 2 \mathrm{~cm} \quad \mathrm{e}$ (b) $2 \mathrm{~cm} \times 2 \mathrm{~cm}$.

Figura 5.30: Dependência angular, para a qualidade de referência (RQT 9) dos feixes padronizados de radiação $X$ para CT no LCl e para a câmara de ionização C4. A incerteza máxima das medições foi de $0,01 \%$, não visível nos gráficos. Aberturas do colimador: (a) $2 \mathrm{~cm} \times 2 \mathrm{~cm}$ e (b) $5 \mathrm{~cm} \times 2 \mathrm{~cm}$..

Figura 5.31: Dependência angular, para a qualidade de referência (RQT 9) dos feixes padronizados de radiação $X$ para CT no LCl e para a câmara de ionização C5. A incerteza máxima das medições foi de $0,01 \%$, não visível nos gráficos. Aberturas do colimador: (a) $2 \mathrm{~cm} \times 2 \mathrm{~cm}$ e (b) $5 \mathrm{~cm} \times 2 \mathrm{~cm}$.

Figura 5.32: Dependência angular, para a qualidade de referência (RQT 9) dos feixes padronizados de radiação $X$ para CT no $\mathrm{LCl}$ e para a câmara de ionização $\mathrm{C} 7$. A incerteza máxima das medições foi de $0,01 \%$, não visível nos gráficos. Aberturas do colimador: (a) $2 \mathrm{~cm} \times 2 \mathrm{~cm}$ e (b) $5 \mathrm{~cm} \times 2 \mathrm{~cm}$.

Figura 5.33: Dependência angular, para a qualidade de referência (RQT 9) dos feixes padronizados de radiação $X$ para CT no LCl e para as câmaras de ionização C6 (a) e C7 (b). A incerteza máxima das medições foi de 0,01 \%, não visível nos gráficos.

Figura 5.34: Esquema das posições utilizadas para o teste de avaliação da resposta em função do comprimento do volume sensível das câmaras de ionização $\mathrm{C} 6$ e C7. 
Figura 5.35: Avaliação da resposta em função da posição no comprimento do volume sensível, para a qualidade de referência (RQT 9) dos feixes estabelecidos de radiação $X$ para CT no $\mathrm{LCl}$, com campo de irradiação de $2 \mathrm{~cm}^{2}$; a incerteza máxima das medições foi de 0,01 \%, não visível nos gráficos, para as câmaras de ionização: (a) C6 e (b) C7.

Figura 6.1: Posicionamento da câmara de ionização C7 para a determinação da taxa de kerma no ar no tomógrafo clínico Philips: (a) imagem geral e (b) imagem focada no posicionamento da câmara no centro do gantry

Figura 6.2: $\quad$ Arranjo experimental para o posicionamento das câmaras no simulador na posição central do tomógrafo clínico Philips

Figura 6.3: Imagens da câmaras de ionização na posição central no interior do simulador: (a) cabeça e (b) abdômen 


\section{Lista de Tabelas}

Tabela 4.1: $\quad$ Características dos feixes padronizados de radiação $X$ para tomografia computadorizada no LCI (IEC, 2005) ................. 47

Tabela 4.2: Características das câmaras de ionização C2, C3 e C4 ....... 48

Tabela 5.1: Características das câmaras de ionização C5, C6 e C7 ....... 54

Tabela 5.2: Teste de corrente de fuga para as câmaras de ionização .... 56

Tabela 5.3: Teste do tempo de estabilização para as câmaras de ionização.

Tabela 5.4: Teste de estabilidade a curto prazo para as câmaras de ionização.................................................................. 58

Tabela 5.5: Abertura do colimador utilizada para cada câmara de ionização, nos testes de curva de saturação, efeito de polaridade e eficiência de coleção de íons.

Tabela 5.6: Efeito de polaridade (\%) para a câmara de ionização $C 1$ em todas as qualidades dos feixes padronizados de radiação $X$ para CT no $\mathrm{LCl}$, para as aberturas do colimador de $(2 \mathrm{~cm} \times 2 \mathrm{~cm})$ e $(5 \mathrm{~cm} \times 2 \mathrm{~cm})$

Tabela 5.7: Efeito de polaridade (\%) para a câmara de ionização C2 em todas as qualidades dos feixes padronizados de radiação $X$ para CT no $\mathrm{LCl}$, para as aberturas do colimador de $(0,5 \mathrm{~cm} \times 2 \mathrm{~cm})$ e $(2 \mathrm{~cm} \times 2 \mathrm{~cm})$.

Tabela 5.8: Efeito de polaridade (\%) para a câmara de ionização $\mathrm{C} 3 \mathrm{em}$ todas as qualidades dos feixes padronizados de radiação $X$ para CT no $\mathrm{LCl}$, para as aberturas do colimador de $(1,5 \mathrm{~cm} \times 2 \mathrm{~cm})$ e $(2 \mathrm{~cm} \times 2 \mathrm{~cm})$.

Tabela 5.9: Efeito de polaridade (\%) para a câmara de ionização $\mathrm{C} 4 \mathrm{em}$ todas as qualidades dos feixes padronizados de radiação $X$ para CT no $\mathrm{LCl}$, para as a aberturas do colimador de $(2 \mathrm{~cm} \times 2 \mathrm{~cm})$ e $(5 \mathrm{~cm} \times 2 \mathrm{~cm})$ 
Tabela 5.10: Efeito de polaridade (\%) para a câmara de ionização C5 em todas as qualidades dos feixes padronizados de radiação $X$ para CT no $\mathrm{LCl}$, para as aberturas do colimador de $(2 \mathrm{~cm} \times 2 \mathrm{~cm})$ e $(5 \mathrm{~cm} \times 2 \mathrm{~cm})$.

Tabela 5.11: Efeito de polaridade (\%) para a câmara de ionização $\mathrm{C} 7 \mathrm{em}$ todas as qualidades dos feixes padronizados de radiação $X$ para CT no $\mathrm{LCl}$, para as aberturas do colimador de $(2 \mathrm{~cm} \times 2 \mathrm{~cm})$ e $(5 \mathrm{~cm} \times 2 \mathrm{~cm})$.

Tabela 5.12: Efeito de polaridade (\%) para as câmaras de ionização C6 e $\mathrm{C} 7 \mathrm{em}$ todas as qualidades dos feixes padronizados de radiação $\mathrm{X}$ para $\mathrm{CT}$ no $\mathrm{LCl}$. Para a abertura do colimador de $(15 \mathrm{~cm} \times 2 \mathrm{~cm})$.

Tabela 5.13: Eficiência de coleção de íons da câmara de ionização C1 $(\%)$ em todas as qualidades dos feixes padronizados de radiação $X$ para $\mathrm{CT}$ no $\mathrm{LCl}$. Aberturas do colimador: $(2 \mathrm{~cm} \times 2 \mathrm{~cm})$ e $(5 \mathrm{~cm} \times 2 \mathrm{~cm})$

Tabela 5.14: Eficiência de coleção de íons da câmara de ionização C2 (\%) em todas as qualidades dos feixes padronizados de radiação $X$ para $\mathrm{CT}$ no $\mathrm{LCl}$. Aberturas do colimador: $(0,5$ $\mathrm{cm} \times 2 \mathrm{~cm})$ e $(2 \mathrm{~cm} \times 2 \mathrm{~cm})$.

Tabela 5.15: Eficiência de coleção de íons da câmara de ionização C3 (\%) em todas as qualidades dos feixes padronizados de radiação $\mathrm{X}$ para $\mathrm{CT}$ no $\mathrm{LCl}$. Aberturas do colimador: $(1,5 \mathrm{~cm} \times 2 \mathrm{~cm})$ e $(2 \mathrm{~cm} \times 2 \mathrm{~cm})$.

Tabela 5.16: Eficiência de coleção de íons da câmara de ionização C4 (\%) em todas as qualidades dos feixes padronizados de radiação $X$ para $\mathrm{CT}$ no $\mathrm{LCl}$. Aberturas do colimador: $(2 \mathrm{~cm} \times 2 \mathrm{~cm})$ e $(5 \mathrm{~cm} \times 2 \mathrm{~cm})$.

Tabela 5.17: Eficiência de coleção de íons da câmara de ionização C5 (\%) em todas as qualidades dos feixes padronizados de radiação $X$ para $\mathrm{CT}$ no $\mathrm{LCl}$. Aberturas do colimador: $(2 \mathrm{~cm} \times 2 \mathrm{~cm})$ e $(5 \mathrm{~cm} \times 2 \mathrm{~cm})$. 
Tabela 5.18: Eficiência de coleção de íons da câmara de ionização C7 (\%) em todas as qualidades dos feixes padronizados de radiação $X$ para $\mathrm{CT}$ no $\mathrm{LCl}$. Aberturas do colimador: $(2 \mathrm{~cm} \times 2 \mathrm{~cm})$ e $(5 \mathrm{~cm} \times 2 \mathrm{~cm})$.

Tabela 5.19: Eficiência de coleção de íons (\%) das câmaras de ionização $\mathrm{C} 6$ e $\mathrm{C} 7 \mathrm{em}$ todas as qualidades dos feixes padronizados de radiação $\mathrm{X}$ para $\mathrm{CT}$ no $\mathrm{LCl}$. Abertura do colimador: $(15 \mathrm{~cm} \times 2 \mathrm{~cm})$.

Tabela 5.20: Abertura do colimador utilizada para cada câmara de ionização nos testes de linearidade da resposta

Tabela 5.21: Abertura do colimador utilizada para cada câmara de ionização nos testes de dependência energética.

Tabela 5.22: Coeficientes de calibração e fatores de correção para a câmara de ionização $\mathrm{C} 1$ nas qualidades de radiação de $\mathrm{CT}$. Aberturas do colimador: $(2 \mathrm{~cm} \times 2 \mathrm{~cm})$ e $(5 \mathrm{~cm} \times 2 \mathrm{~cm})$

Tabela 5.23: Coeficientes de calibração e fatores de correção para a câmara de ionização $\mathrm{C} 2$ nas qualidades de radiação de $\mathrm{CT}$. Aberturas do colimador: $(0,5 \mathrm{~cm} \times 2 \mathrm{~cm})$ e $(2 \mathrm{~cm} \times 2 \mathrm{~cm}) \ldots .$.

Tabela 5.24: Coeficientes de calibração e fatores de correção para a câmara de ionização C3 nas qualidades de radiação de CT. Aberturas do colimador: $(1,5 \mathrm{~cm} \times 2 \mathrm{~cm})$ e $(2 \mathrm{~cm} \times 2 \mathrm{~cm}) \ldots .$.

Tabela 5.25: Coeficientes de calibração e fatores de correção para a câmara de ionização $\mathrm{C} 4$ nas qualidades de radiação de $\mathrm{CT}$. Aberturas do colimador: $(2 \mathrm{~cm} \times 2 \mathrm{~cm})$ e $(5 \mathrm{~cm} \times 2 \mathrm{~cm}) \ldots \ldots .$.

Tabela 5.26: Coeficientes de calibração e fatores de correção para a câmara de ionização $C 5$ nas qualidades de radiação de $C T$. Aberturas do colimador: $(2 \mathrm{~cm} \times 2 \mathrm{~cm})$ e $(5 \mathrm{~cm} \times 2 \mathrm{~cm}) \ldots \ldots \ldots$

Tabela 5.27: Coeficientes de calibração e fatores de correção para a câmara de ionização $\mathrm{C} 7$ nas qualidades de radiação de $\mathrm{CT}$. Aberturas do colimador $(2 \mathrm{~cm} \times 2 \mathrm{~cm})$ e $(5 \mathrm{~cm} \times 2 \mathrm{~cm}) \ldots \ldots \ldots$ 
Tabela 5.28: Coeficientes de calibração e fatores de correção nas qualidades de radiação de $\mathrm{CT}$. Abertura do colimador: $15 \mathrm{~cm} \times 2 \mathrm{~cm}$. Para as câmaras de ionização: (a) C6 e (b) $\mathrm{C} 7$

Tabela 5.29: Abertura do colimador utilizado para cada câmara de ionização nos testes de dependência angular.

Tabela 6.1 Abertura do colimador para os tomógrafos utilizados 103

Tabela 6.2: Índice de kerma ar no ar obtido com as câmaras C1, C5 e C7, sem capa e com capa, para os feixes do tomógrafo do Hospital FMVZ/USP para o campo de radiação de $24 \mathrm{~mm}^{2}$

Tabela 6.3 Índice de kerma ar no ar obtido com as câmaras C1, C5 e C7, sem capa e com capa, para os feixes do tomógrafo do Hospital HIAE para o campo de radiação de $32 \mathrm{~mm}^{2}$

Tabela 6.4 Índice de dose em tomografia computadorizada (CTDI) obtido para as câmaras $\mathrm{C} 1, \mathrm{C} 5$ e C7, para os simuladores de cabeça e abdômen no Hospital HIAE para os tomógrafos de 64 e 320 canais no campo de radiação de $32 \mathrm{~mm}^{2}$

Tabela 6.5 Diferença percentual (\%) entre o CTDI obtido e o nominal para o simuladores de cabeça e de abdômen para as câmaras $\mathrm{C} 1$, C5 e C7 no Hospital HIAE para os tomógrafos de 64 e 320 canais no campo de radiação de $32 \mathrm{~mm}^{2}$ 


\section{Lista de Siglas}

BNC British Naval Connector

CT Tomografia Computadorizada

CTDI Computed Tomography Dose Index

CNEN Comissão Nacional de Energia Nuclear

FMVZ/USP Faculdade de Medicina Veterinária e Zootecnia da Universidade de São Paulo

HIAE Hospital Israelita Albert Einstein

IAEA International Atomic Energy Agency

ICRU International Commission on Radiation Units and Measurements

IEC International Electrotechnical Commission

INMETRO Instituto Nacional de Metrologia, Normalização e Qualidade Industrial

IPEN Instituto de Pesquisas Energéticas e Nucleares

LCI Laboratório de Calibração de Instrumentos

MSAD Multi Slice Average Dose

PMMA Polimetilmetacrilato

PTB Physikalisch-Technische Bundesanstalt

PTW Physikalisch-Technische Werkstätten

SI Sistema Internacional 


\section{Introdução}

O uso de radiação ionizante para tratamento e diagnóstico médico cresceu muito ao longo dos anos, e com isso ocorreu o surgimento e a evolução de equipamentos para esses fins. Por exemplo, para radioterapia eram muito usados os equipamentos de cobalto, porém hoje em dia se faz mais uso de aceleradores lineares. Para o radiodiagnóstico não foi diferente, antes se usava radiografia convencional para todo e qualquer exame, até que surgiu a necessidade de um equipamento que proporcionasse uma melhor visualização de tecidos que apresentassem densidades próximas, e que poderiam mostrar com mais detalhes as estruturas. Assim surgiram os tomógrafos.

O uso de Tomografia Computadorizada (CT) para procedimentos de imagiologia vem crescendo cada vez mais devido aos avanços da tecnologia dos equipamentos de $\mathrm{CT}$, pois estes apresentam a capacidade de realização de digitalizações rápidas. Porém, isso acarretou uma maior preocupação com as doses recebidas pelos pacientes que se submetem a esse tipo de exame. Por isso, a verificação das doses de radiação nos procedimentos dos exames de tomografia deve ser realizada com a melhor precisão possível (BOONE, 2007).

É importante saber quais são os fatores que afetam a dose e a distribuição de dose nos pacientes, quais são os descritores de dose e suas vantagens.

A dose e a distribuição de dose podem ser afetadas em três níveis diferentes (equipamento, operador e características dos pacientes). Quando se considera o equipamento, as características como geometria, colimação, ponto focal, eficiência do detector, entre outras, devem ser levadas em conta. A respeito do operador, são importantes os parâmetros que serão utilizados, ou seja, tensão de pico $(k V p)$, corrente elétrica $(m A)$, tempo de digitalização e 
outros. Em relação ao paciente, suas características físicas, como tamanho, espessura, densidade, etc, devem ser consideradas (FEARON, 2002).

O descritor de dose que mais tem sido usado é o Índice de Dose em Tomografia Computadorizada (CTDI). Sua vantagem é que apresenta reprodutibilidade geométrica, e é de fácil execução com câmaras de ionização e objetos simuladores (FEARON, 2002).

Os tomógrafos submetem os pacientes a doses maiores para a obtenção de suas imagens em relação aos equipamentos de radiologia convencional. Portanto, surgiu uma preocupação em relação às doses, apesar de não se saber as reais contribuições a longo prazo. Devido a este fato é necessário que os equipamentos passem periodicamente por testes de controle de qualidade, de forma a assegurar que pacientes não tomem doses desnecessárias.

Para a dosimetria de feixes de radiação ionizante são necessários equipamentos específicos e especializados para cada caso. Para feixes de tomografia computadorizada (CT), o instrumento dosimétrico utilizado é a câmara de ionização do tipo lápis. Uma de suas características importantes é que este tipo de câmara apresenta uma resposta uniforme à radiação incidente em todos os ângulos, sua leitura normalmente é fornecida em unidade de dose absorvida vezes o comprimento do volume ativo (mGy.cm), facilitando portanto a medição de CTDI. Esta câmara deve atender a requisitos especiais para calibração, para que se possa realizar os testes de controle de qualidade dos equipamentos.

As medições são realizadas no centro e na periferia dos objetos simuladores cilíndricos de polimetilmetacrilato (PMMA), com uma câmara de ionização lápis de comprimento ativo de $10 \mathrm{~cm}$. Embora a leitura da câmara de ionização não seja dose, ela pode ser utilizada para obter a dose acumulada (NAKONECHNY et al, 2005; MAIA, 2005).

A câmara de ionização tipo lápis com comprimento de $10 \mathrm{~cm}$ pode obter a dose acumulada com precisão para um comprimento de varredura (digitalização) de $10 \mathrm{~cm}$. Para varreduras de comprimentos superiores, ela pode subestimar os valores da dose acumulada. Por meio dos experimentos de 
Gedanken pode-se observar algumas desvantagens da câmara lápis, tais como o fato dela não poder ser usada para calcular a dose absoluta e sim permitir apenas a avaliação de dose relativa, além de que ela não pode monitorar os raios X de "saída" (raios X que atravessam e saem do paciente) e nem a dose de profundidade (DIXON, 2006).

Para Boone foi necessário avaliar a eficiência do Índice de Dose em Tomografia Computadorizada (CTDI), para que fosse possível caracterizar as propriedades da dose de radiação de um equipamento de tomografia. Este índice foi medido usando uma câmara de ionização cilíndrica tipo lápis de $10 \mathrm{~cm}$ de comprimento juntamente com um objeto simulador de polimetilmetacrilato (PMMA). A eficiência está relacionada com o comprimento da câmara utilizada; sendo assim, uma medição de eficiência seria avaliar a dose que é determinada com o uso de uma câmara de $10 \mathrm{~cm}$ e compará-la com uma infinitamente longa (BOONE, 2007).

O Índice de Dose em Tomografia Computadorizada $100\left(\right.$ CTDI $\left._{100}\right)$ vem sendo o padrão internacional para a avaliação da dose nestes tipos de feixes de radiação. Ele se refere aos $10 \mathrm{~cm}$ de comprimento integral do perfil de dose ao longo de uma linha perpendicular no sentido do eixo $(x)$, dividido pelo produto fornecido pelo valor nominal da espessura do corte e do número de secções contínuas produzidas por uma varredura axial (NAKONECHNY et al, 2005; GELEIJNS et al, 2010).

Perisinakis e colaboradores avaliaram a subestimativa dos valores do índice de dose no ar $\left(C T D I_{\text {air }}\right)$ e do índice de dose ponderada $\left(C T D I_{w}\right)$ com a câmara de ionização padrão de $10 \mathrm{~cm}\left(\mathrm{CTDl}_{100}\right)$, para diversas combinações de colimação dos feixes de radiação, estimando o comprimento ideal da câmara lápis e objetos simuladores para se obter medições precisas de CTDI e para fornecer valores de $C T D I_{w}$ normalizados para $C T D I_{\text {air }}$ para diferentes tensões do tubo, colimação e filtração dos feixes. O comprimento ideal para a câmara lápis foi estimado como o comprimento de câmara mínimo para um aumento no comprimento que não alterasse 0 valor da relação de $\mathrm{CTDI}_{\mathrm{w}} / \mathrm{CTDI}_{\text {air }}$ (PERISINAKIS et al, 2007). 
No estudo de Mori e colaboradores, utilizando equipamentos de CT com um grande número de fileiras de detectores, a grandeza de CTDI (obtida em $10 \mathrm{~cm}$ da câmara de ionização), não abrange uma área adequada de integração, pois para um intervalo de integração de $30 \mathrm{~cm}$ é necessário se medir com precisão a dose sobre uma largura de feixe nominal de $12,8 \mathrm{~cm}$. No entanto, um objeto simulador grande torna-se inconveniente para a realização das medições rotineiramente na verificação da dose no paciente. Com o intuito de obter esse valor com precisão, eles incorporaram um fator de conversão (CF) que pode ser calculado por meio do perfil de dose integral ponderada $\left(\mathrm{DPI}_{\mathrm{w}}\right)$ para um intervalo de integração de $30 \mathrm{~cm}$ com uma câmara de ionização de comprimento igual a $30 \mathrm{~cm}$ dividido por um intervalo de integração de $10 \mathrm{~cm}$ com uma câmara de ionização de mesmo tamanho. Com isso, eles conseguiram concluir que os valores de CF aumentam com o aumento da largura nominal do feixe. Os valores de CF também podem ser adaptados para outros equipamentos de CT (MORI et al, 2006).

Dixon e Ballard fizeram uma demonstração experimental na qual eles usaram um novo método de dosimetria em tomografia, com uma câmara de ionização menor que a câmara lápis convencional e realizando uma aquisição helicoidal a fim de coletar a mesma integral para qualquer varredura de um dado comprimento (sem limitação dos $10 \mathrm{~cm}$ ). Eles conseguiram provar sua eficácia e versatilidade, pois esta câmara de ionização foi capaz de medir a dose acumulada (DIXON e BALLARD, 2006).

A motivação deste trabalho deve-se às doses elevadas a que os pacientes que se submetem durante um exame de tomografia, além de que, com o avanço da tecnologia e o surgimento de novos tomógrafos que são capazes de irradiar uma área maior do paciente, a câmara de ionização com comprimento de volume sensível de $10 \mathrm{~cm}$ acaba subestimando as doses e consequentemente poderá acarretar em um controle de qualidade ineficiente dos equipamentos.

Uma desvantagem das câmaras de ionização é que elas são importadas e por isso apresentam um alto custo de aquisição para principalmente clínicas de pequeno e médio porte em países como o Brasil. 
Assim, centros de pesquisa como o Laboratório de Calibração de Instrumentos do IPEN ( $\mathrm{LCl}$ ) apresentam um histórico de pesquisas e projetos que se referem a metodologias dosimétricas e desenvolvimento de câmaras de ionização e de sistemas dosimétricos a partir de materiais nacionais de baixo custo, com várias aplicações, a fim de se obter medições de radiações e para calibração de instrumentos cada vez mais exatos e próximos dos níveis de qualidade internacional (MAIA \& CALDAS, 2005; OLIVEIRA \& CALDAS, 2005; COSTA \& CALDAS, 2008; NEVES et al, 2013). O desenvolvimento destes equipamentos dosimétricos leva a uma maior autonomia dos laboratórios de calibração.

Recentemente, foram desenvolvidas no LCl três câmaras de ionização tipo lápis com comprimentos do volume sensível de $1 \mathrm{~cm}, 3 \mathrm{~cm}$ e $10 \mathrm{~cm}$ para serem utilizadas em programas de controle de qualidade. No Laboratório de Calibração de Instrumentos do IPEN são rotineiramente calibrados detectores e dosímetros, com radiações alfa, beta, $\mathrm{X}$ e gama. Para isto, o laboratório conta com arranjos experimentais exclusivos e sistemas padrões secundários para cada tipo de radiação. 


\section{Objetivos}

O objetivo geral desse trabalho é o de melhorar a acurácia da dosimetria de feixes de tomografia computadorizada, fazendo uso de uma câmara de ionização do tipo lápis com comprimento de volume sensível especial nas qualidades padronizadas estabelecidas no Laboratório de Calibração de Instrumentos do IPEN/CNEN. Este trabalho tem como objetivos específicos:

- Desenvolvimento de duas câmaras de ionização do tipo lápis com comprimento de volume sensível de $10 \mathrm{~cm}$ e $30 \mathrm{~cm}$ para aplicação em feixes de CT;

- Caracterização experimental das câmaras desenvolvidas e comparação com as demais câmaras de ionização do mesmo tipo no LCl;

- Aplicação das câmaras desenvolvidas juntamente com uma câmara comercial em feixes clínicos. 


\section{Fundamentos Teóricos}

Este capítulo irá apresentar os conhecimentos básicos necessários para o desenvolvimento deste trabalho.

\subsection{Interação da Radiação com a Matéria}

A interação da radiação com a matéria pode acontecer no intervalo de energia que envolve os raios $\mathrm{X}$ e gama e de diversas formas. A probabilidade de ocorrência depende basicamente da energia da radiação. As principais formas de interação da radiação com a matéria são: Efeito Fotoelétrico, Efeito Compton, Espalhamento Compton Coerente e produção de pares, descritos de forma sucinta a seguir.

\subsubsection{Efeito Fotoelétrico}

O efeito fotoelétrico é o resultado de uma interação entre um fóton e o átomo; o fóton é absorvido pelo meio e toda ou quase toda sua energia é depositada nesse meio. Sendo assim, esse efeito caracteriza-se pela absorção total da radiação $X$ ou gama.

A probabilidade de ocorrência deste efeito é inversamente proporcional ao cubo da energia, e diretamente proporcional ao cubo do número atômico do material absorvedor (BUSHONG, 2010; OKUNO, 2010).

\subsubsection{Efeito Compton}

No efeito Compton, a radiação incidente interage com um elétron da última camada ejetando-o, ou seja, deixando o átomo ionizado. Essa radiação incidente, que segue em outra direção e com uma energia menor, recebe o nome de radiação espalhada.

A energia da radiação espalhada é menor, pois ela é fruto da radiação incidente menos a energia que foi gasta para a ejeção do elétron. A probabilidade de ocorrência do efeito Compton é independente do número atômico do átomo e inversamente proporcional à energia da radiação (BUSHONG, 2010). 


\subsubsection{Espalhamento Compton Coerente ou Efeito Rayleigh}

O espalhamento coerente dá-se pela interação de um fóton com um átomo, em que não há a transferência de energia para o meio, exceto por uma pequena quantidade necessária para o recuo do átomo. É um processo entendido como a absorção de um fóton pelo átomo e sua remissão em outra direção. Sendo assim tem-se a conservação do momento.

Neste espalhamento, a direção do fóton, que é espalhado, é bem próxima à direção do fóton incidente. A frequência para ocorrência desse efeito depende do número atômico (z) do átomo e da energia do fóton. Ele é um fenômeno mais frequente para alto número atômico e baixa energia (OKUNO, 2010).

\subsubsection{Produção de Pares}

Este processo de interação da radiação com a matéria caracteriza-se pela alta energia da radiação incidente; sendo assim, ela consegue escapar das interações com os elétrons e se aproximar mais do núcleo do átomo de forma que é influenciada pela força do campo nuclear.

Essa interação da energia incidente com o campo nuclear faz com que o fóton desapareça e dê espaço para dois elétrons, um carregado positivamente (pósitron) e um negativamente (elétron) (BUSHONG, 2010; OKUNO, 2010).

\subsection{Grandezas Dosimétricas}

A seguir serão apresentas as grandezas que foram relevantes para 0 desenvolvimento deste trabalho.

\subsubsection{Exposição}

A grandeza exposição $(X)$ é o quociente de dQ por $d m$, onde $d Q$ é valor absoluto de todas as cargas elétricas dos íons produzidos no ar por um mesmo sinal, quando todos os elétrons que foram liberados pelos fótons num elemento de volume de ar, cuja massa é $\mathrm{dm}$, são freados completamente no ar. A Equação 3.1 apresenta a fórmula para o cálculo da exposição (ICRU, 1998).

$$
X=\frac{d Q}{d m}
$$


A unidade de exposição no sistema internacional (SI) é dada por coulomb por quilograma $\left[\mathrm{C}^{\mathrm{kg}}{ }^{-1}\right]$. Essa grandeza é definida para medir radiação eletromagnética no meio ar.

\subsubsection{Dose Absorvida}

Dose absorvida $(D)$ é o quociente de $\mathrm{d} \bar{\varepsilon}$ por $d m$, onde $\mathrm{d} \bar{\varepsilon}$ é a energia média cedida pela radiação ionizante à matéria de massa $d m$. A Equação 3.2 apresenta a fórmula para o cálculo da dose absorvida (ICRU, 1998).

$$
D=\frac{\mathrm{d} \bar{\varepsilon}}{d m}
$$

A unidade de dose absorvida no sistema internacional (SI) é dada em joule por quilograma $\left[\mathrm{J}_{\mathrm{kg}}{ }^{-1}\right]$, porém esta grandeza apresenta uma unidade especial conhecida como gray (Gy) [1 $\mathrm{J}_{\mathrm{kg}}{ }^{-1}=1 \mathrm{~Gy}$.

A grandeza dose absorvida pode ser utilizada para qualquer tipo de radiação (nêutrons, alfa, beta, gama, prótons entre outras) e em qualquer material.

\subsubsection{Kerma}

A grandeza kerma $(K)$ é dada pelo quociente de $\mathrm{dE}_{\mathrm{tr}}$ por $d m$, onde $\mathrm{dE}_{\mathrm{tr}}$ é a soma de todas as energias cinéticas iniciais de todas as partículas ionizantes carregadas eletricamente, liberadas pelas partículas ionizantes sem carga em um material de massa $d m$. A Equação 3.3 apresenta a fórmula para o cálculo do kerma (ICRU, 1998).

$$
K=\frac{d E_{t r}}{d m}
$$

A unidade de kerma no sistema internacional (SI) é dada em joule por quilograma $\left[\mathrm{J} . \mathrm{kg}^{-1}\right]$; esta grandeza também apresenta uma unidade especial conhecida como gray (Gy) [1 J.kg $\left.{ }^{-1}=1 \mathrm{~Gy}\right]$.

O kerma pode ser utilizado para qualquer radiação que não seja diretamente ionizante e para todos os meios. Apresenta a vantagem de ser 
independente da complexidade do transporte da energia pelas partículas carregadas secundárias.

\subsection{Fundamentos de Tomografia Computadorizada}

A tomografia computadorizada é um exame que faz uso de radiação ionizante para obtenção de imagens radiográficas de objetos bi- ou tridimensionais. As imagens são formadas por múltiplas projeções de uma região do corpo, obtidas por meio de diversas irradiações da região em ângulos diferentes. Portanto, a radiação é captada por um conjunto de detectores que transmitem a resposta a um computador que é responsável pela reconstrução da imagem.

\subsubsection{Histórico}

O desenvolvimento dos tomógrafos se deu em várias etapas, conhecidas como gerações. A primeira geração inclui o primeiro tomógrafo criado por Godfrey Hounsfield e Alan Cormack no século XX e que Ihes rendeu o Prêmio Nobel de Medicina. Este sistema funcionava de forma que um tubo de raios $X$ emitindo um feixe colimado era detectado por um par de detectores para cada fatia tomográfica; este sistema necessitava de 180 rotações (movimento de translação), sendo que cada uma delas era separada por um grau (movimento de rotação) e levava em média um tempo de exposição de 4,5 min para cada fatia. Esse tomógrafo só conseguia realizar exames de cabeça.

Na segunda geração, os tomógrafos apresentavam também o movimento de translação e rotação; a diferença é que eles apresentavam um feixe em forma de leque, além de um conjunto de múltiplos detectores (5-30 detectores). A vantagem deste sistema era a velocidade devido ao aumento no número de detectores (10 - $90 \mathrm{~s}$ cada corte tomográfico). Sendo assim, a quantidade de movimentos lineares foram reduzidos e consequentemente os movimentos rotacionais puderam ser mais largos. Em contraposição, aumentou-se a influência da radiação espalhada na imagem.

A terceira geração de tomógrafos surgiu com o intuito de diminuir mais ainda o tempo de varredura. Estes passaram a executar somente movimento de rotação, levando à redução do tempo de varredura para $1 \mathrm{~s}$. Os detectores 
desses tomógrafos encontravam-se distribuídos de forma curvilínea, de forma que a distância fonte-detector sempre fosse constante, facilitando a reconstrução da imagem. O feixe continuava sendo em forma de leque, porém era possível realizar uma colimação, diminuindo assim a influência da radiação espalhada. A desvantagem dos tomógrafos dessa geração era o aparecimento de artefatos do tipo anel, que podem ser minimizados durante o processo de reconstrução da imagem.

A quarta geração alterou sua configuração para rotatória/estacionária; sendo assim, a fonte de raios $X$ (mais utilizado: feixe contínuo) realiza 0 movimento circular enquanto que os detectores passaram a ser fixos. Isso acarretou em um aumento significativo na quantidade de detectores presentes em um equipamento. Esses tomógrafos são capazes de produzir imagens em uma fração de segundos, além de proporcionarem diferentes espessuras de corte através de colimação automática. Devido a essa nova configuração, as imagens não apresentam mais artefatos de anel; houve uma melhoria significativa na qualidade da imagem e o tempo de exposição ficou menor.

Como se pode notar desde a primeira geração, a tecnologia dos tomógrafos sofreram mudanças significativas, de forma que a primeira e a segunda geração não são mais usadas comercialmente, mas os de terceira e quarta gerações ainda são utilizados nos hospitais.

As melhorias e o desenvolvimento nos equipamentos não cessaram, de forma que se continua buscando melhorias na qualidade da imagem e redução na dose recebida pelos pacientes. Então, introduziu-se a técnica de tomografia computadorizada volumétrica (helicoidal), na qual o tubo de raios $X$ faz 0 movimento de rotação enquanto o paciente é deslocado pela mesa no gantry. A vantagem desta técnica é a obtenção da imagem de uma região grande em um intervalo de respiração, reduzindo assim os artefatos causados pelo movimento do paciente; redução no tempo de varredura; e permitiu a reconstrução de imagem multiplanar, ou seja, mais precisa.

A última tecnologia que surgiu foi a dos tomógrafos de cortes múltiplos, ou seja, eles são capazes de formar a imagem de vários cortes realizados simultaneamente para cada rotação feita pelo tubo de raios $X$. Sendo assim, o 
tempo gasto para se realizar um exame é menor. Outra configuração acessível deste equipamento é o fato de se poder ter diferentes espessuras de corte em um mesmo exame.

\subsubsection{Principais Componentes do Tomógrafo}

A seguir será apresentado de forma sucinta o funcionamento de um tomógrafo. A Figura 3.1 mostra os componentes que integram o sistema todo, desde a irradiação até a obtenção da imagem.

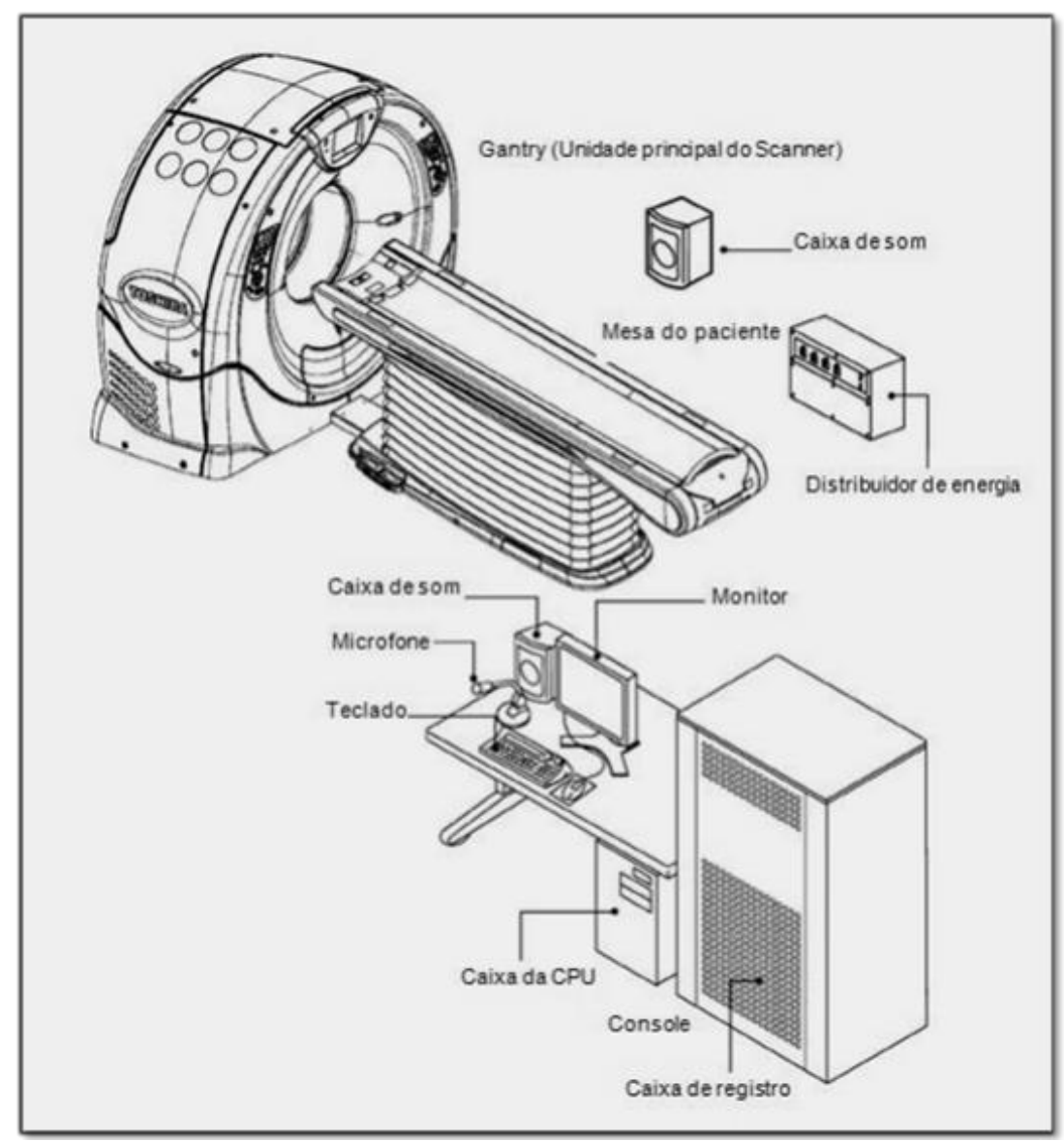

Figura 3.1: Componentes de um tomógrafo. Imagem adaptada (TOSHIBA, 2010)

O tomógrafo pode ser dividido basicamente em dois sistemas; o primeiro é o de irradiação, onde o paciente é posicionado para a realização do exame; o segundo é o sistema de controle, onde acontece a escolha da técnica (parâmetros) e a aquisição das imagens. O primeiro sistema é composto pelo gantry, mesa e distribuidor de energia; sendo assim, o distribuidor de energia fornece a energia para que a mesa e o gantry possam funcionar. A parte mais importante é o gantry onde se encontra o tubo de raios $\mathrm{X}$, os detectores de 
radiação, os colimadores e os filtros. O segundo sistema é composto por um microcomputador e uma caixa de registro.

A realização de um exame de $\mathrm{CT}$ se dá pelo posicionamento do paciente na mesa de exame; em seguida, o técnico fará a escolha da técnica a ser utilizada (a dose é determinada pela tensão, corrente e o tempo de exposição). Após essa escolha, a irradiação é iniciada e as imagens geradas são reconstruídas no computador por meio de um software de tratamento e reconstrução da imagem.

O processo de irradiação de um tomógrafo é composto por um tubo de raios $\mathrm{X}$ e um gerador de alta tensão, e seu funcionamento é semelhante à de um tubo que é utilizado em radiografia convencional. Então, o filamento de tungstênio que se encontra no catodo libera os elétrons que são acelerados até chegarem ao anodo. A interação desses elétrons com o material do anodo libera energia na forma de raios $X$ e calor. Os raios $X$ que foram gerados são detectados pelos detectores que se encontram no sistema de aquisição de dados; estes dados são então transportados para o computador para a geração da imagem que passa por um processo de reconstrução para a retirada de artefatos que foram gerados durante o processo.

\subsubsection{Grandezas Dosimétricas Específicas para Tomografia Computadorizada}

Quando de trata de distribuição de dose para CT sabe-se que ela é bem diferente se comparada à de radiologia convencional, por causa do movimento do tubo de raios $\mathrm{X}$. Portanto, a maneira como a dose era determinada para exames convencionais não poderia ser adotada para CT. Então foram necessários estudos para a determinação de uma grandeza específica para tomografia.

O que impulsionou a determinação desta grandeza foi a utilização da câmara de ionização tipo lápis, pois ela apresenta uma uniformidade em sua resposta para todas as radiações incidentes nos ângulos em torno do seu eixo, tornando possível a realização de medições em cortes tomográficos. 
Como a tomografia computadorizada é composta por vários cortes tomográficos, determinou-se uma grandeza que fosse capaz de informar a dose média no corte central em relação a cortes múltiplos. Esta grandeza ficou conhecida como MSAD (Multi Slice Average Dose) e é definida pela Equação 3.4:

$$
M S A D=\frac{1}{d} \int_{-\frac{d}{2}}^{+\frac{d}{2}} D_{N, d}(z) d z
$$

onde:

d é o incremento da mesa;

$D_{N, d}(z)$ é a dose;

N é o número de cortes em função da posição.

Os estudos não pararam por ai; eles conseguiram então determinar a dose para apenas um corte tomográfico, que ficou conhecida como Índice de Dose em Tomografia Computadorizada - CTDI (Computed Tomography Dose Index) e devido à sua simplicidade de obtenção, ela ficou mais conhecida para a determinação de dose em CT. A Equação 3.5 define o CTDI:

$$
C D T I=\frac{1}{h} \int_{-\infty}^{+\infty} D(z) d z
$$

onde:

$\mathrm{D}(\mathrm{z})$ é a dose absorvida na posição $z$;

h é a espessura do corte tomográfico.

O CTDI pode ser calculado tanto no ar como no simulador de PMMA; no simulador ele apresenta a contribuição da radiação espalhada. Após outros estudos foi proposta a utilização do CTDI ${ }_{100}$ que é a maneira que encontraram para colocar o comprimento do volume sensível da câmara tipo lápis nos limites de integração da integral; portanto, os limites passaram a ser de $-50 \mathrm{~mm}$ a +50 mm (LEITZ et. al, 1995; EUR 16262 EN,1997; FDA, 1997; NAGEL,2000). Em seguida, foi proposto o CTDI ponderado (CTDIw), que significa a dose 
média em um corte tomográfico dentro do simulador quando a câmara de ionização se encontra no centro e na periferia do simulador com diferentes proporções (LEITZ et. al, 1995). Esta contribuição pode ser vista na Equação 3.6:

$$
C T D I_{W}=\frac{1}{3} C T D I_{100, c}+\frac{2}{3} C T D I_{100, p}
$$

onde $\mathrm{c}$ e $\mathrm{p}$ só se referem à posição onde se encontra a câmara de ionização no simulador (centro e periferia).

\subsection{Câmaras de lonização}

Com o surgimento do uso da radiação para fins de diagnóstico e tratamento, tornou-se necessária a elaboração de um equipamento que fosse capaz de determinar a dose absorvida. Esse tipo de equipamento ficou conhecido como dosímetro; um dos mais utilizados tanto em laboratórios que realizam calibrações como em hospitais é a câmara de ionização. Esta determina a dose absorvida no seu volume sensível (BOAG, 1987; KNOLL, 1989; RAJAN, 1992; PODGORSAK, 2005).

\subsubsection{Características Gerais}

As câmaras de ionização são detectores de radiação a gás. Quando se realiza uma medição com este equipamento, obtém-se a coleção dos íons que são gerados pela ionização do gás quando houve a passagem da radiação ionizante (ATTIX, 2004). As câmaras podem apresentar várias formas e tamanhos; o que determina esses fatores é a sua utilização.

A câmara de ionização mais simples apresenta uma parede para a delimitação do gás, no centro do seu interior há um eletrodo coletor responsável pela coleção dos íons que foram gerados. Em geral, as câmaras são não seladas, o que torna necessário um controle das condições ambientais para aplicação das devidas correções na leitura obtida as condições ambientais de referência de temperatura e pressão.

As principais características que essas câmaras devem apresentar são: elas devem possuir uma variação da sua sensibilidade de resposta a um 
intervalo de energia e à direção da radiação incidente pequena; a sua perda por recombinação deve ser a mínima possível; e finalmente devem possuir um volume adequado para a medição no intervalo de interesse, assim como serem calibradas em relação a um sistema padrão de referência deste mesmo intervalo.

\subsubsection{Câmara de Ionização para Tomografia Computadorizada}

A câmara de ionização utilizada para tomografia computadorizada é uma câmara cavitária não selada do tipo lápis, pois esta apresenta uma resposta uniforme ao feixe de radiação incidente em todos os ângulos, o que a torna adequada para esse tipo de equipamento (MAIA, 2005). A câmara convencional mais utilizada apresenta um comprimento de volume sensível de $10 \mathrm{~cm}$, entretanto já existem outras com comprimentos diferentes $(15 \mathrm{~cm}$ e $30 \mathrm{~cm}$ ). A Figura 3.2 apresenta um esquema de uma câmara de ionização.

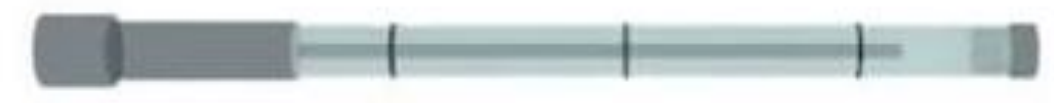

Figura 3.2: Esquema de uma câmara de ionização do tipo lápis.

Normalmente, a leitura realizada por ela é dada em dose ou exposição em relação ao comprimento. Além disso, elas foram desenvolvidas para serem utilizadas em simuladores dosimétricos, para que as condições clínicas fossem melhores representadas. Assim, há simuladores para a cabeça e o abdômen de adultos.

\subsection{Testes de Caracterização e Controle de Qualidade}

Os testes de caracterização são realizados com as câmaras de ionização nos equipamentos com o intuito de observar se este está funcionando de maneira correta (ou seja, fazendo o controle de qualidade) e quais são as possíveis variações e os desvios medidos pela câmara quando há diferentes condições ambientais. Esses testes devem obedecer às recomendações da norma IEC 61674 (IEC, 1997). 


\subsubsection{Teste de Estabilidade}

O teste de estabilidade pode ser dividido em: estabilidade a curto prazo (teste de repetitividade) e a longo prazo (teste de reprodutibilidade). Ambos devem avaliar a constância da resposta da câmara de ionização. A diferença é que a repetitividade deve apresentar uma concordância nos resultados das medições sucessivas de um mesmo mensurando quando as condições de medição são iguais. A reprodutibilidade deve apresentar uma concordância nos resultados das medições de um mesmo mensurando quando as condições de medição são diferentes.

\subsubsection{Teste de Tempo de Estabilização}

O teste de tempo de estabilização tem a função de mostrar o tempo necessário para que a resposta da câmara apresente um desempenho que permaneça dentro de um especificado desvio do seu valor final estável, após a aplicação da tensão de operação na câmara de ionização.

\subsubsection{Teste de Corrente de Fuga}

O teste de corrente de fuga é realizado com a finalidade de avaliar a contribuição na medição de algum sinal que possa ter surgido da montagem da câmara de ionização (detector, cabos e conexões) ou até mesmo no eletrômetro que não é produzido pela ionização no comprimento do volume sensível da câmara.

\subsubsection{Teste de Saturação}

Este teste é realizado com o objetivo de se determinar a tensão na qual a câmara de ionização deve ser operada, pois essa tensão deve ser capaz de coletar todos os íons primários que são gerados pela ionização do ar no volume sensível da câmara de ionização.

\subsubsection{Teste de Linearidade da Resposta}

O teste de linearidade da resposta tem como objetivo avaliar se a relação entre a taxa de kerma no ar em função da variação da tensão do tubo de raios $X$ é linear para a câmara de ionização. 


\subsubsection{Teste de Dependência Angular}

Esse teste tem a finalidade de avaliar a resposta da câmara de ionização nos diferentes ângulos de incidência da radiação. Esta preocupação em relação à dependência angular deve-se à geometria ou à própria construção da câmara de ionização.

\subsubsection{Teste de Dependência Energética}

O teste de dependência energética consiste em se avaliar a resposta da câmara de ionização quando submetida a feixes de radiação com diferentes energias. Portanto, faz-se necessária a calibração da câmara no feixe padrão de radiação. Sendo assim, a dependência energética de cada câmara é determinada observando-se os coeficientes de calibração obtidos para as diferentes energias.

\subsection{Determinação do Fator de Correção das Medições para as Condições Ambientais de Referência}

Como as câmaras de ionização são equipamentos usados para a realização das medições em condições ambientes, e as câmaras são não seladas, ou seja, estão em contato direto com as condições do ambiente, torna-se necessário corrigir as leituras obtidas.

Considerando-se este fato, é preciso corrigir os valores das medições para as condições ambientais de referência de temperatura e pressão. Esta correção é obtida pela Equação 3.7 (IAEA, 2007):

$$
\mathrm{k}_{\mathrm{T}, \mathrm{P}}=\frac{273,2+\mathrm{T}}{273,2+\mathrm{T}_{0}}\left(\frac{\mathrm{P}_{0}}{\mathrm{P}}\right)
$$

onde $T_{0} \quad$ e $\quad P_{0}$ se referem à temperatura e à pressão de referência $\left(P_{0}=101,3 \mathrm{kPa}\right.$ e $\left.T_{0}=20^{\circ} \mathrm{C}\right)$.

\subsection{Conversão de Carga e Corrente em Taxa de Kerma no Ar}

Neste trabalho, as medições obtidas para os testes de caracterização das câmaras de ionização e para os testes realizados nos feixes clínicos foram em carga ou corrente elétrica. Porém, quando se trata de um estudo realizado em 
equipamentos próprios para CT é necessário que a grandeza obtida seja dose ou kerma no ar. Portanto, a seguir serão apresentadas as equações necessárias para a conversão de carga e/ou corrente elétrica em dose.

Primeiramente, deve-se encontrar a energia média gasta em um gás por par de íons formados $\left(\frac{\bar{W}}{e}\right)$; normalmente ela é expressa em elétron volts (eV) por par de íons. Essa energia média é dada pela corrente, no caso de raios $\mathrm{X}$ e/ou radiação gama, para o ar seco $(33,97 \mathrm{eV})$, dividido pela carga do elétron em coulombs $\left(1,602 \times 10^{-19}\right.$ coulombs/elétron).

O resultado para a energia média será de $\left(\frac{\bar{W}}{e}\right)=33,97 \mathrm{~J} / \mathrm{C}$. Em seguida, é necessária a obtenção da densidade do ar, isto é, a obtenção do fator de correção para as condições ambientais de referência, dado pela Equação 3.7.

Após a determinação destes fatores pode-se finalmente obter a Equação 3.8, que converte a carga elétrica em dose absorvida (ATTIX, 2004).

$$
D=\frac{Q}{\rho \times V} \frac{\bar{W}}{e}
$$

onde

Q é a carga elétrica;

$\rho$ é a densidade do ar;

V é o volume da câmara de ionização;

$\frac{\bar{W}}{e}$ é a energia média gasta para a formação de um par de íons em um gás.

Desta forma, será possível a determinação da dose quando a câmara de ionização for utilizada em um tomógrafo.

\subsection{Calibração de Instrumentos}

A calibração de um instrumento é importante principalmente quando se faz uso de radiação ionizante, pois se sabe que esta pode causar consequências a curto e a longo prazos a pessoas que se submetem a 
diagnóstico e tratamento, acompanhantes de pacientes, assim como profissionais da área, e ainda usuários de radiação em seus procedimentos de trabalho. A calibração visa manter o controle de qualidade dos equipamentos utilizados nessas práticas. No caso do presente trabalho, a câmara de ionização é utilizada para que se possa determinar a dose absorvida ou a taxa de kerma no ar do equipamento. Porém, esta câmara deve estar calibrada em relação a um sistema padrão para que a medição obtida seja confiável.

\subsubsection{Objetivos e Técnicas de Calibração}

A calibração de instrumentos tem o objetivo de informar aos usuários dos detectores as suas características e garantir que estes funcionem de modo adequado, para que as suas medições possam ser realizadas com melhores precisões (IAEA, 2000).

Para a calibração dos instrumentos podem ser utilizadas duas técnicas: campos conhecidos ou técnica da substituição. Quando se faz uso da técnica da substituição as propriedades do campo de radiação são menos conhecidas quando comparadas com a técnica de campos conhecidos (IAEA, 1994).

Na técnica de substituição, primeiramente é colocado um instrumento de referência no campo de radiação e são realizadas medições; em seguida, este instrumento é substituído pelo equipamento que se deseja calibrar e também são realizadas medições nas mesmas condições de geometria e irradiação. Finalmente são comparadas as respostas obtidas por ambos os instrumentos e os fatores de calibração e correção podem ser determinados.

Para campos conhecidos não é necessário o uso de um sistema de referência para a realização da calibração, pois o campo de radiação é conhecido por apresentar parâmetros de uma fonte padrão ou por apresentar a medição com um sistema padrão secundário. Sendo assim, o instrumento a ser calibrado é posicionado no campo de radiação e o valor da medição obtida é comparado com o valor que foi previamente determinado na intensidade do feixe de radiação em termos da grandeza desejada. 


\subsubsection{Comparação Interlaboratorial e Rastreabilidade}

Comparação interlaboratorial é a comparação entre o desempenho de equipamentos que apresentem a mesma classificação ou qualidade metrológica. O objetivo da comparação interlaboratorial é garantir a qualidade das medições dos laboratórios de calibração, sendo que pode ser realizada entre laboratórios nacionais ou até mesmo internacionais. Uma das vantagens de se realizar intercomparações é que além de ser possível a determinação dos coeficientes de calibração, acontece uma troca de conhecimento entre os pesquisadores de diferentes laboratórios, e ainda é mantida a mesma qualidade metrológica dos dosímetros.

A rastreabilidade é a maneira pela qual a resposta de uma medição de um instrumento está relacionada a um sistema de referência; sendo assim, é possível observar a contribuição das incertezas no resultado da medição. $\mathrm{Na}$ rastreabilidade deve haver uma cadeia de forma que todas as comparações que asseguram o resultado da medição obtida levem ao sistema padrão mais elevado de referência, que no caso é a um laboratório padrão primário. 


\section{Materiais e Métodos}

Neste capítulo, serão descritos todos os equipamentos e os materiais utilizados para a realização deste trabalho. A caracterização experimental realizada nos feixes padronizados de pesquisa $(\mathrm{LCl})$ e a utilização das câmaras nos feixes clínicos do Hospital Veterinário da Universidade de São Paulo (FMVZ/USP) também serão descritos.

\subsection{Sistemas de Radiação}

Os sistemas de radiação utilizados para a caracterização das câmaras de ionização foram:

- Equipamento de raios X, marca Pantak/Seifert, modelo ISOVOLT 160HS, que opera entre $5 \mathrm{kV}$ e $160 \mathrm{kV}$, utilizado para calibração de detectores de radiação;

$>$ Fonte de controle de ${ }^{90} \mathrm{Sr}+{ }^{90} \mathrm{Y}$, Physikalisch-Technische Werkstätten (PTW), com atividade nominal de $33 \mathrm{MBq}$ (1994), utilizada para os testes de estabilidade de resposta e outros testes das câmaras de ionização desenvolvidas nesse projeto;

> Fonte de controle de ${ }^{90} \mathrm{Sr}+{ }^{90} \mathrm{Y}$, Physikalisch-Technische Werkstätten (PTW), com atividade nominal de $11,1 \mathrm{MBq}$ (1976), utilizada para os testes de estabilidade de resposta e outros testes das câmaras de ionização.

> Tomógrafo Philips, modelo MX8000 IDT 16, que apresenta 16 canais, utilizado para os testes clínicos que foram realizados no Hospital Veterinário da Faculdade de Medicina Veterinária e Zootecnia da Universidade de São Paulo (FMVZ/USP).

> Tomógrafo Toshiba Aquilion 64, que apresenta 64 canais, utilizado para os testes clínicos que foram realizados no Hospital Israelita Albert Einstein (HIAE). 
> Tomógrafo Toshiba Aquilion One Vision, que apresenta 320 canais, utilizado para os testes clínicos que foram realizados no Hospital Israelita Albert Einstein (HIAE).

A Figura 4.1 mostra os dois principais sistemas de radiação que foram utilizados, para a caracterização das câmaras de ionização e para os testes em feixes clínicos.

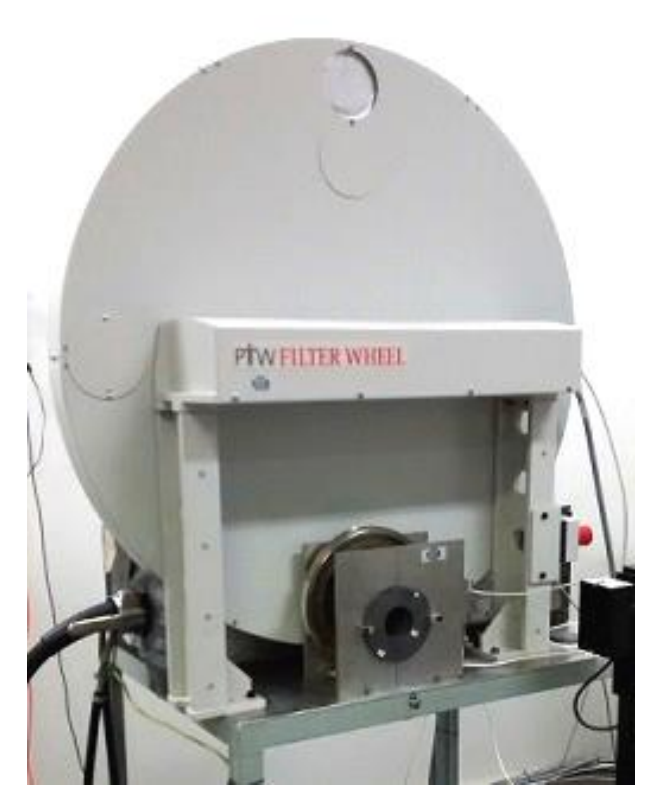

(a)

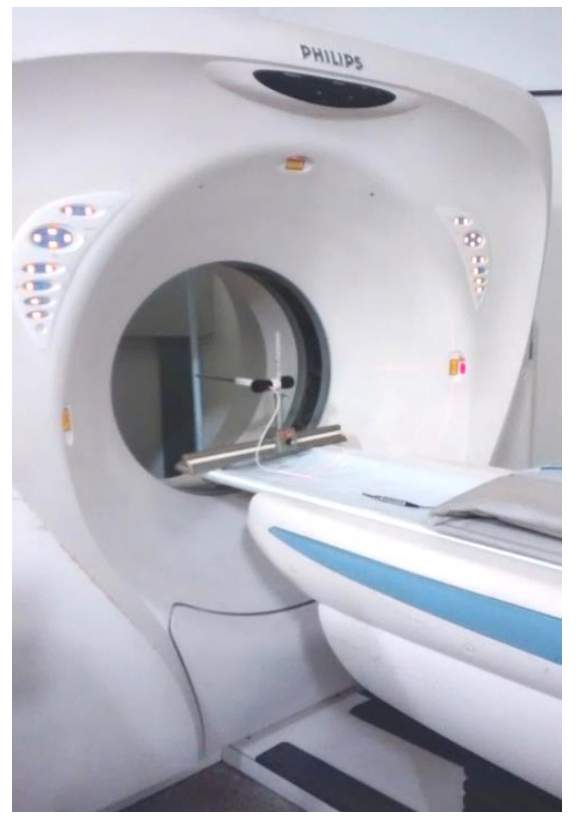

(b)

Figura 4.1: Foto dos sistemas de radiação utilizados na execução deste trabalho: (a) Equipamento de raios X, marca Pantak/Seifert e (b) Tomógrafo Philips.

O sistema de radiação Pantak/Seifert apresenta qualidades de radiação padronizadas e estabelecidas em: radioterapia, radiodiagnóstico convencional, mamografia, tomografia computadorizada e radioproteção, de acordo com as recomendações nacionais e internacionais.

Neste trabalho, foram utilizadas as qualidades de radiação $X$ para tomografia computadorizada, estabelecidas no LCl (IEC, 2005). Suas características são apresentadas na Tabela 4.1. 
Tabela 4.1: Características dos feixes padronizados de radiação $X$ para tomografia computadorizada no LCI (IEC, 2005).

\begin{tabular}{|c|c|c|c|}
\hline $\begin{array}{c}\text { Qualidade } \\
\text { da } \\
\text { Radiação }\end{array}$ & $\begin{array}{c}\text { Tensão } \\
\text { do Tubo } \\
\text { (kV) }\end{array}$ & $\begin{array}{c}\text { Camada } \\
\text { Semirredutora } \\
(\mathrm{mmAl})\end{array}$ & $\begin{array}{c}\text { Taxa de } \\
\text { Kerma no Ar } \\
\text { (mGy/min) }\end{array}$ \\
\hline RQT 8 & 100 & 6,9 & $22,0 \pm 0,3$ \\
\hline $\mathrm{RQT} 9 \dagger$ & 120 & 8,4 & $34,0 \pm 0,5$ \\
\hline RQT 10 & 150 & 10,1 & $57,0 \pm 0,9$ \\
\hline
\end{tabular}

† Qualidade de referência do LCI

Para o estabelecimento destas qualidades fez-se uso de uma câmara de ionização padrão secundário, com rastreabilidade ao Laboratório Padrão Primário Alemão Physikalisch-Technische Bundesanstalt (PTB).

\subsection{Sistemas de Medição}

Os seguintes sistemas de medição foram utilizados nesse trabalho:

> Eletrômetros PTW, modelo UNIDOS E;

> Câmara de lonização padrão tipo lápis, Radcal, modelo RC3CT, com comprimento de volume sensível de $10 \mathrm{~cm}$ e volume de $3 \mathrm{~cm}^{3}$;

Câmara de ionização tipo lápis Victoreen, modelo 660-6, com comprimento de volume sensível de $10 \mathrm{~cm}$ e volume de $3,2 \mathrm{~cm}^{3}$; denominada C1.

A Figura 4.2 mostra os sistemas de medição que foram utilizados ao longo deste trabalho.

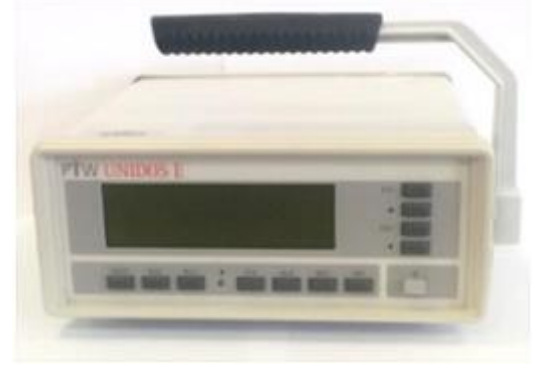

(a)

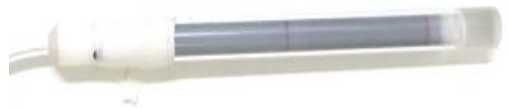

(b)

Figura 4.2: Foto dos sistemas de medição, (a) Eletrômetro PTW (modelo UNIDOS E) e (b) Câmara de ionização Radcal (modelo RC3CT). 
* Câmaras de ionização tipo lápis desenvolvidas anteriormente no LCI:

> Câmara de ionização tipo lápis com comprimento de volume sensível de $1 \mathrm{~cm}$ e volume de $0,34 \mathrm{~cm}^{3}$; denominada $\mathrm{C} 2$.

> Câmara de ionização tipo lápis com comprimento de volume sensível de $3 \mathrm{~cm}$ e volume de $1,02 \mathrm{~cm}^{3}$; denominada $\mathrm{C} 3$.

Câmara de ionização tipo lápis com comprimento de volume sensível de $10 \mathrm{~cm}$ e volume de $3,40 \mathrm{~cm}^{3}$; denominada $\mathrm{C} 4$.

A Tabela 4.2 apresenta as características e as dimensões das câmaras de ionização que foram desenvolvidas no $\mathrm{LCl}$ por Maia (MAIA, 2005). Na Figura 4.3 é possível visualizar as câmaras e a diferença no volume sensível delas.

Tabela 4.2: Características das câmaras de ionização C2, C3 e C4.

\begin{tabular}{cccc}
\hline Características & \multicolumn{3}{c}{ Especificações } \\
\cline { 2 - 4 } & C2 & C3 & C4 \\
\hline Material do eletrodo coletor & Alumínio \\
Material da Parede & PVC com uma camada de grafite \\
Diâmetro do eletrodo coletor central (mm) & \multicolumn{3}{c}{1,22} \\
Diâmetro do interior da câmara de & & 6,72 & \\
$\quad$ ionização $(\mathrm{mm})$ & & 0,26 & 10 \\
$\quad$ Espessura da Parede (mm) & 1 & 3 & 3,40 \\
Comprimento do volume sensível $(\mathrm{cm})$ & 0,34 & 1,02 & \\
Volume sensível (cm $\left.{ }^{3}\right)$ & & &
\end{tabular}




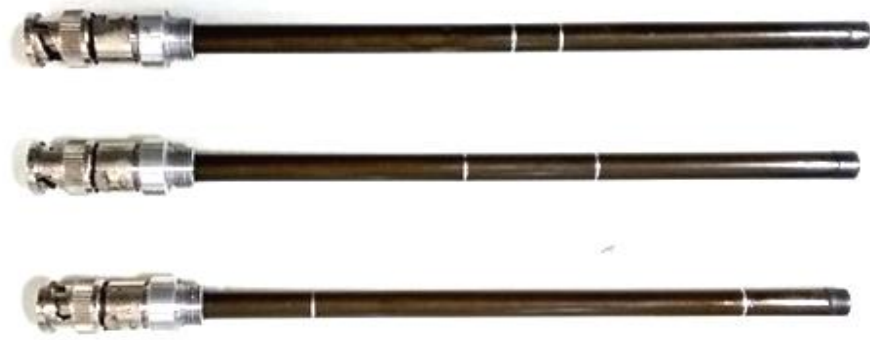

Figura 4.3: Foto das câmaras de ionização C2, C3 e C4 desenvolvidas no LCl.

* Câmaras de ionização tipo lápis desenvolvidas no presente trabalho:

> Câmara de ionização tipo lápis com comprimento de volume sensível de $10 \mathrm{~cm}$ e volume de $3,50 \mathrm{~cm}^{3}$; denominada $\mathrm{C} 5$.

> Câmara de ionização tipo lápis com comprimento de volume sensível de $30 \mathrm{~cm}$ e volume de $10,5 \mathrm{~cm}^{3}$; denominada 66 .

> Câmara de ionização tipo lápis com comprimento de volume sensível de $30 \mathrm{~cm}$ e volume de $10,5 \mathrm{~cm}^{3}$; denominada $\mathrm{C} 7$.

Como pode ser observado foram desenvolvidas duas câmaras de ionização com comprimento de volume sensível de $30 \mathrm{~cm}$. Isso se deve a um imprevisto que ocorreu no decorrer do trabalho, quando a primeira câmara construída (C6) quebrou; sendo assim, uma nova câmara foi construída (C7). No entanto, este imprevisto proporcionou a obtenção de mais resultados e, consequentemente, uma oportunidade de avaliar a reprodutibilidade da metodologia de desenvolvimento das câmaras e de suas respostas.

\subsection{Sistemas Auxiliares}

Os sistemas auxiliares que foram utilizados para a caracterização das câmaras de ionização foram:

Termômetros, higrômetros e barômetros, para o monitoramento das condições ambientais (temperatura, umidade e pressão atmosférica) dos 
laboratórios onde foram realizadas as medições com as câmaras de ionização;

Sistemas de ar condicionado e desumidificadores de ambiente;

> Diversos materiais para confecção das câmaras de ionização que foram desenvolvidas;

> Suporte de PMMA, para auxiliar em alguns testes de caracterização das câmaras de ionização;

Simulador de PMMA de cabeça e abdômen, para auxiliar nos testes realizados no Hospital Veterinário;

> Capa para as câmaras de ionização utilizadas nos feixes clínicos, para as medições realizadas no interior do simulador;

Varetas de PMMA para tampar os orifícios que não são utilizados durante a irradiação da câmara de ionização no simulador.

\subsection{Estimativas das Incertezas}

Para este trabalho, foram feitos os cálculos de incertezas, usando as definições de incerteza do tipo $A$ e do tipo $B$, fornecidas pela ABNT (INMETRO, 2008).

Todos os resultados são de contribuições de várias medições para as mesmas condições experimentais, portanto foi tomada a média das medições obtidas e consequentemente os desvios-padrões foram calculados. A Equação 4.1 apresenta a fórmula para o cálculo da média aritmética.

$$
\overline{\mathrm{x}}=\frac{1}{\mathrm{~N}} \sum_{\mathrm{i}=1}^{\mathrm{N}} \mathrm{x}_{\mathrm{i}}
$$

onde

$X_{i}$ são os valores obtidos; 
$\mathrm{N}$ é o número de medições que foram realizadas para cada experimento.

Os desvios-padrões foram calculados pela Equação 4.2:

$$
\delta_{\overline{\mathrm{x}}}=\sqrt{\frac{1}{\mathrm{~N}(\mathrm{~N}-1)} \sum_{\mathrm{i}=1}^{\mathrm{N}}\left(\mathrm{x}_{\mathrm{i}}-\overline{\mathrm{x}}\right)^{2}}
$$

Para alguns resultados experimentais foi necessária a determinação da incerteza combinada, porque alguns resultados dependem de cálculos anteriores. A incerteza combinada foi obtida segundo a norma INMETRO, a lei de propagação das incertezas, e pode ser observada na Equação 4.3:

$$
\sigma_{k}=\sqrt{\sum_{i}\left(\frac{\partial k}{\partial x_{i}} \sigma_{x_{i}}\right)^{2}}
$$

onde $\partial k / \partial x_{i}$ é a derivada parcial da função $k$ em relação $x_{i}$, e $\sigma_{x_{i}}$ é a incerteza de $x_{i}$.

Para os resultados obtidos nesse projeto foram utilizadas as incertezas combinadas expandidas, considerando-se as incertezas do tipo $A$ e do tipo $B$, e o fator de abrangência $k$ igual a 2. 


\section{Resultados: Projeto, Construção Caracterização Experimental das Câmaras de lonização}

O projeto de desenvolvimento das câmaras de ionização ao longo deste trabalho será apresentado a seguir, além dos resultados da caracterização experimental de todas as câmaras tipo lápis utilizadas nesse trabalho para as qualidades de raios $\mathrm{X}$ de tomografia computadorizada, estabelecidas no $\mathrm{LCl}$. Esses resultados foram analisados e comparados com os limites estabelecidos e recomendados pela norma IEC 61674 (IEC, 2005).

\subsection{Construção das Câmaras de lonização}

Ao longo desse trabalho foram desenvolvidas duas câmaras de ionização do tipo lápis com comprimentos de volume sensível de $10 \mathrm{~cm}$ e $30 \mathrm{~cm}$. Essas câmaras foram construídas baseadas nas especificações das câmaras de ionização da PTW; sendo assim, suas dimensões são bastante similares.

A seguir, será apresentado o projeto das duas câmaras desenvolvidas e uma tabela mostrando as suas configurações.

\subsubsection{Conectores}

Para o acoplamento das câmaras de ionização ao eletrômetro PTW modelo UNIDOS E, foi necessário o uso de conectores do tipo BNC (British Naval Connector).

\subsubsection{Corpo das Câmaras de lonização}

O corpo de cada câmara de ionização foi construído com um material acrílico, polimetilmetacrilato (PMMA), e em seguida foi pintado com spray de grafite, internamente.

O material desta estrutura deve ser condutor, pois quando uma tensão for aplicada será necessário que ela produza um campo elétrico ao redor do eletrodo coletor central. A parede é o limitador de ar na cavidade interna da câmara de ionização, que será ionizado sob o feixe de radiação. 
O corpo da câmara apresenta um comprimento útil de $10 \mathrm{~cm}$ ou $30 \mathrm{~cm}$ com um diâmetro interno de 7,40 $\mathrm{mm}$ e a espessura de sua parede é de 0,26 mm. A Figura 5.1 mostra o corpo da câmara de ionização de $10 \mathrm{~cm}$.

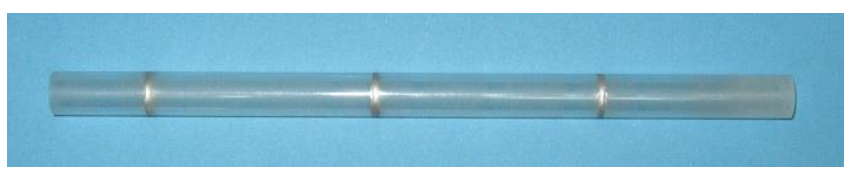

Figura 5.1: Corpo da câmara de ionização de $10 \mathrm{~cm}$, antes da pintura com spray de grafite.

\subsubsection{Eletrodo Coletor}

O eletrodo coletor encontra-se no centro do corpo da câmara de ionização e é responsável por transmitir ao eletrômetro o sinal elétrico, que é obtido pela ionização do ar presente no volume sensível da câmara. Esta peça é um material condutor, que foi feito de alumínio e pintado com uma camada de grafite. O eletrodo apresenta um diâmetro de $3,20 \mathrm{~mm}$ e seu comprimento útil é de $10 \mathrm{~cm}$ para a câmara $\mathrm{C} 5$ e de $30 \mathrm{~cm}$ para a câmara C6, porém o eletrodo é um pouco maior que o comprimento de volume sensível para que possa ser fixado no conector. A Figura 5.2 mostra o eletrodo coletor antes de ser pintado com spray de grafite.

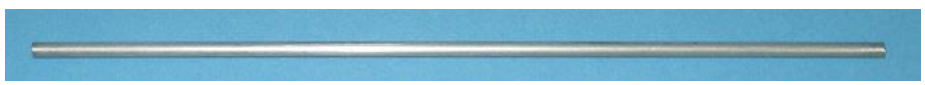

Figura 5.2: Eletrodo coletor antes da pintura com spray de grafite.

\subsubsection{Capa da Câmara de Ionização}

A capa da câmara de ionização foi feita com Teflon; este material foi escolhido para que não ocorresse nenhuma interferência ou variação na captação das cargas, operando assim como um isolante.

\subsubsection{Montagem das Câmaras de ionização}

A montagem das câmaras de ionização tipo lápis foi realizada utilizando cada componente especificado. Inicialmente, o eletrodo coletor e o corpo da câmara foram pintados com grafite. Em seguida, o eletrodo foi soldado ao conector BNC de forma que ficasse com o comprimento de volume útil desejado. Em sequência, foi realizada a mesma coisa com o corpo da câmara, 
de forma que o eletrodo ficasse situado no eixo central, e finalmente as capas das câmaras de ionização foram instaladas na extremidade.

A Tabela 5.1 apresenta as características e as dimensões das câmaras de ionização que foram desenvolvidas no $\mathrm{LCl}$ neste trabalho. A Figura 5.3 mostra as câmaras de ionização prontas.

Tabela 5.1: Características das câmaras de ionização C5, C6 e C7.

\begin{tabular}{|c|c|c|c|}
\hline \multirow{2}{*}{ Características } & \multicolumn{3}{|c|}{ Especificações } \\
\hline & C5 & C6 & C7 \\
\hline Material do eletrodo coletor & \multicolumn{3}{|c|}{$\begin{array}{l}\text { Alumínio com uma } \\
\text { camada de grafite }\end{array}$} \\
\hline Material da parede & \multicolumn{3}{|c|}{$\begin{array}{l}\text { PMMA com uma } \\
\text { camada de grafite }\end{array}$} \\
\hline Diâmetro do eletrodo coletor central $(\mathrm{mm})$ & \multicolumn{3}{|c|}{3,20} \\
\hline $\begin{array}{l}\text { Diâmetro do interior da câmara de } \\
\text { ionização }(\mathrm{mm})\end{array}$ & \multicolumn{3}{|c|}{7,40} \\
\hline Espessura da Parede (mm) & \multicolumn{3}{|c|}{0,26} \\
\hline Comprimento do volume sensível (cm) & 10 & 30 & 30 \\
\hline Volume sensível $\left(\mathrm{cm}^{3}\right)$ & 3,50 & 10,5 & 10,5 \\
\hline
\end{tabular}

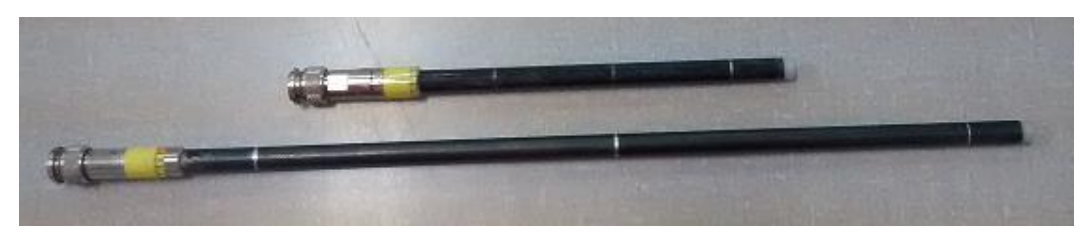

Figura 5.3: Câmaras de ionização prontas, com comprimentos de volume sensível de $10 \mathrm{~cm}$ e $30 \mathrm{~cm}$.

\subsection{Caracterização Experimental das Câmaras de lonização}

Para a caracterização das câmaras de ionização desenvolvidas, foram realizados vários tipos de testes; para alguns fez-se uso das qualidades dos feixes de raios $X$ padronizados para CT e para os outros foi utilizada a fonte de controle de ${ }^{90} \mathrm{Sr}+{ }^{90} \mathrm{Y}$. Os testes de estabilidade em curto e longo prazos, o tempo de estabilização e a corrente de fuga foram realizados utilizando a fonte 
de controle de ${ }^{90} \mathrm{Sr}+{ }^{90} \mathrm{Y}$ e com o auxilio de um suporte de PMMA. O arranjo experimental utilizado para a realização destes testes pode ser visualizado na Figura 5.4.

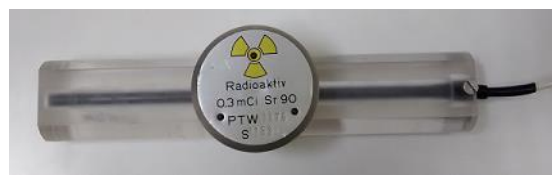

Figura 5.4: Arranjo experimental para realização dos testes de estabilidade a curto e longo prazos, tempo de estabilização e corrente de fuga.

Foram determinados no feixe de raios X: a curva de saturação, o efeito de polaridade, a eficiência de coleção de íons, a linearidade da resposta e as dependências energética e angular; para estes testes também foi utilizado um arranjo experimental específico, no qual a câmara de ionização se encontra posicionada a $1 \mathrm{~m}$ de distância do foco do feixe de raios $\mathrm{X}$. Entre a câmara e o equipamento de raios $X$ encontra-se um colimador. Para o colimador foram usadas diferentes aberturas, com a finalidade de se ampliar o estudo em relação à resposta da câmara para a abertura do campo de radiação. $O$ arranjo para a realização destes testes pode ser visto na Figura 5.5.

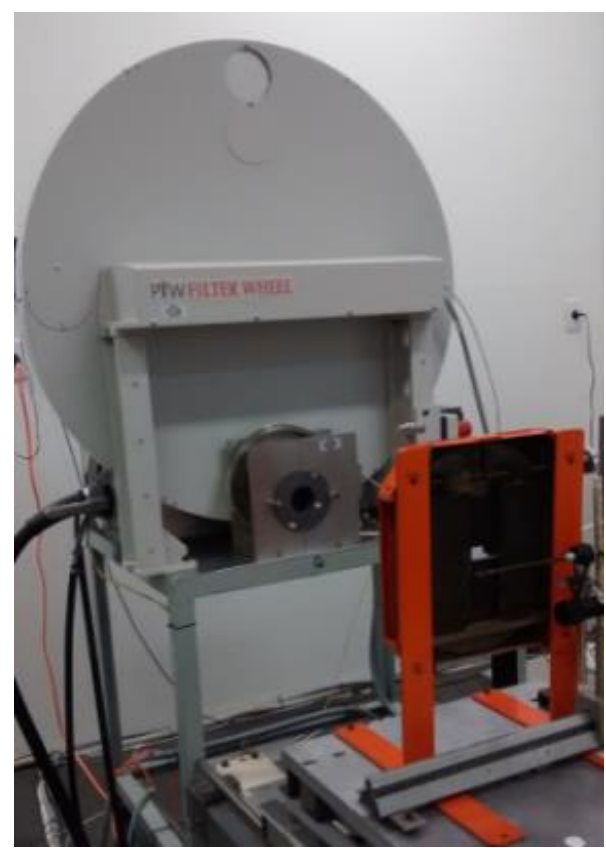

(a)

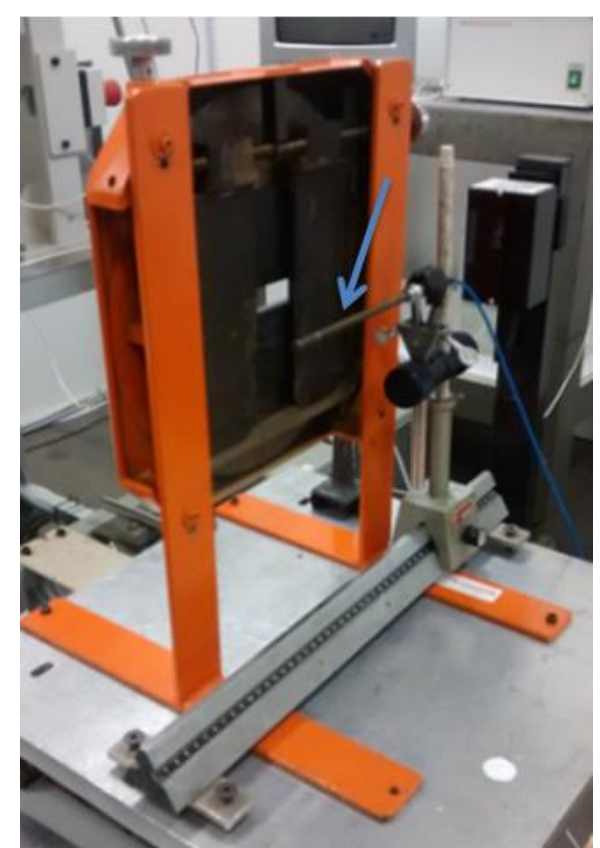

(b)

Figura 5.5: Arranjo experimental (a) completo; (b) evidenciando a posição da câmara de ionização. 


\subsubsection{Corrente de Fuga}

Para o teste de corrente de fuga, o seguinte procedimento foi adotado: espera-se estabilizar as câmaras de ionização pelo período de uma hora para em seguida dar-se início às medições. Foram realizadas seis medições ao longo de vinte minutos durante três momentos diferentes, sendo estes: antes, durante e após a irradiação da câmara de ionização, utilizando o arranjo experimental já apresentado.

Neste teste de caracterização, a corrente de fuga antes e após a irradiação não deve ultrapassar o limite de $5 \%$, quando comparada à corrente de ionização durante o período de irradiação da câmara de ionização (IEC, 2005). A Tabela 5.2 mostra os maiores valores obtidos de corrente de fuga para cada câmara de ionização, nos casos de pré-irradiação e pósirradiação.

Tabela 5.2: Teste de corrente de fuga para as câmaras de ionização.

\begin{tabular}{ccc}
\hline \multicolumn{3}{c}{ Corrente de Fuga (\%) } \\
\hline $\begin{array}{c}\text { Câmara de } \\
\text { lonização }\end{array}$ & $\begin{array}{c}\text { Pré- } \\
\text { irradiação }\end{array}$ & $\begin{array}{c}\text { Pós- } \\
\text { irradiação }\end{array}$ \\
\hline C1 & 0,75 & 0,85 \\
C2 & 1,3 & 1,5 \\
C3 & 0,76 & 0,72 \\
C4 & 1,1 & 0,73 \\
C5 & $<0,02$ & $<0,02$ \\
C6 & $<0,02$ & $<0,02$ \\
C7 & $<0,02$ & $<0,02$ \\
\hline
\end{tabular}

Como é possível observar na Tabela 5.2, os valores obtidos para o teste de corrente de fuga estão dentro dos limites recomendados internacionalmente.

\subsubsection{Tempo de Estabilização}

O teste do tempo de estabilização foi realizado de forma que as câmaras de ionização foram polarizadas durante o período de uma hora no arranjo montado; em seguida, a fonte de controle foi posicionada no suporte durante 15 min. Então, foram realizadas dez medições consecutivas de carga $(p C)$, 
cada uma em 1 min para cada intervalo de tempo, sendo eles:15 min, $30 \mathrm{~min}$, $45 \mathrm{~min}$ e $60 \mathrm{~min}$.

A análise do resultado deu-se pela comparação entre as correntes de ionização obtidas em $15 \mathrm{~min}$ e $60 \mathrm{~min}$; as diferenças entre os valores de corrente foram determinadas em porcentagem, e devem obedecer ao limite de $\pm 2 \%$ (IEC, 2005). A Tabela 5.3 mostra os valores obtidos para todas as câmaras de ionização.

Tabela 5.3: Teste do tempo de estabilização para as câmaras de ionização.

\begin{tabular}{cc}
\hline $\begin{array}{c}\text { Câmaras de } \\
\text { lonização }\end{array}$ & $\begin{array}{c}\Delta \\
(\%)\end{array}$ \\
\hline C1 & 0,24 \\
C2 & 0,19 \\
C3 & 0,78 \\
C4 & 0,12 \\
C5 & 0,03 \\
C6 & 0,02 \\
C7 & 0,04 \\
\hline
\end{tabular}

$\Delta$ : Diferença entre os valores de corrente de ionização medidas em 15 min e 60 min.

Como pode ser visto na Tabela 5.3, os resultados obtidos encontram-se dentro dos limites recomendados pela norma IEC 61674 (2005).

\subsubsection{Teste de Estabilidade em Curto e Longo Prazos}

Os testes de estabilidade a curto e médio prazos foram realizados em todas as câmaras com 0 arranjo já apresentado. As câmaras foram estabilizadas durante o período de uma hora inicialmente. Em seguida a fonte foi posicionada sobre a câmara e após 15 min de estabilização, iniciou-se uma sequência de dez medições consecutivas, cada uma delas realizada em 1 min. Essas medições foram obtidas em carga $(\mathrm{pC})$ e as condições ambientais controladas (temperatura, umidade e pressão atmosférica) foram utilizadas para o cálculo do fator de correção para as condições ambientais de referência. 
Para o teste de estabilidade a curto prazo para câmaras de ionização de radiodiagnóstico, o desvio padrão não deve ultrapassar $1 \%$, enquanto que para a estabilidade a médio prazo o limite recomendável é de $2 \%$ (IEC, 2005). A Tabela 5.4 mostra os resultados obtidos para a estabilidade a curto prazo.

Tabela 5.4: Teste de estabilidade a curto prazo para as câmaras de ionização.

\begin{tabular}{cc}
\hline $\begin{array}{c}\text { Câmara de } \\
\text { lonização }\end{array}$ & $\begin{array}{c}\text { Maior Variação } \\
(\%)\end{array}$ \\
\hline C1 & 0,06 \\
C2 & 0,13 \\
C3 & 0,06 \\
C4 & 0,28 \\
C5 & 0,15 \\
C6 & 0,16 \\
C7 & 0,01 \\
\hline
\end{tabular}

O maior valor obtido para a estabilidade a curto prazo para todas as câmaras de ionização estudadas foi de $0,28 \%$, e este encontra-se dentro do limite recomendado.

Os resultados obtidos para os testes de estabilidade a longo prazo estão apresentados nas Figuras 5.6 a 5.12 para todas as câmaras de ionização estudadas. A resposta obtida foi normalizada para o valor médio das 10 primeiras medições obtidas para cada uma delas. 


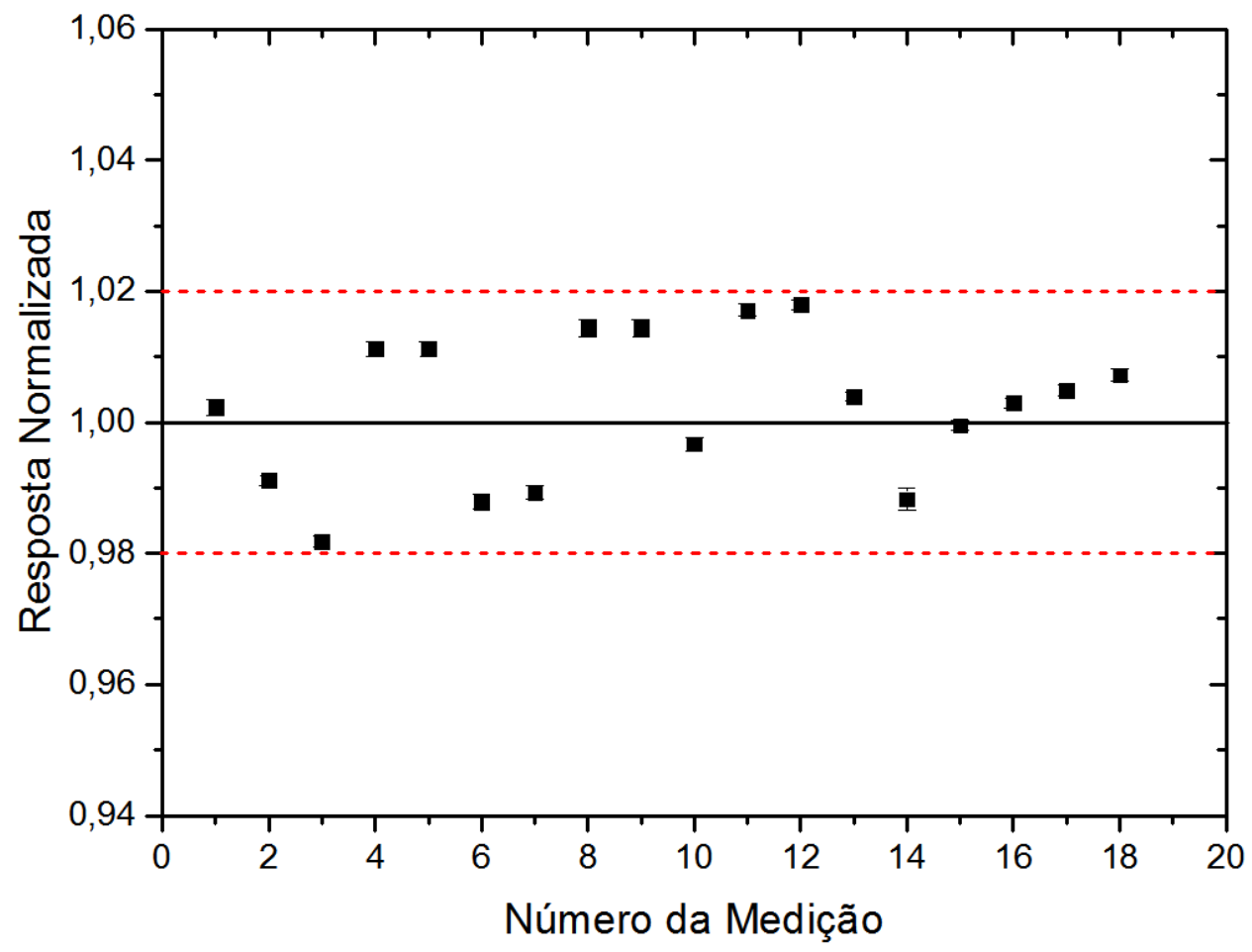

Figura 5.6: Teste de estabilidade para a câmara de ionização $C 1$.

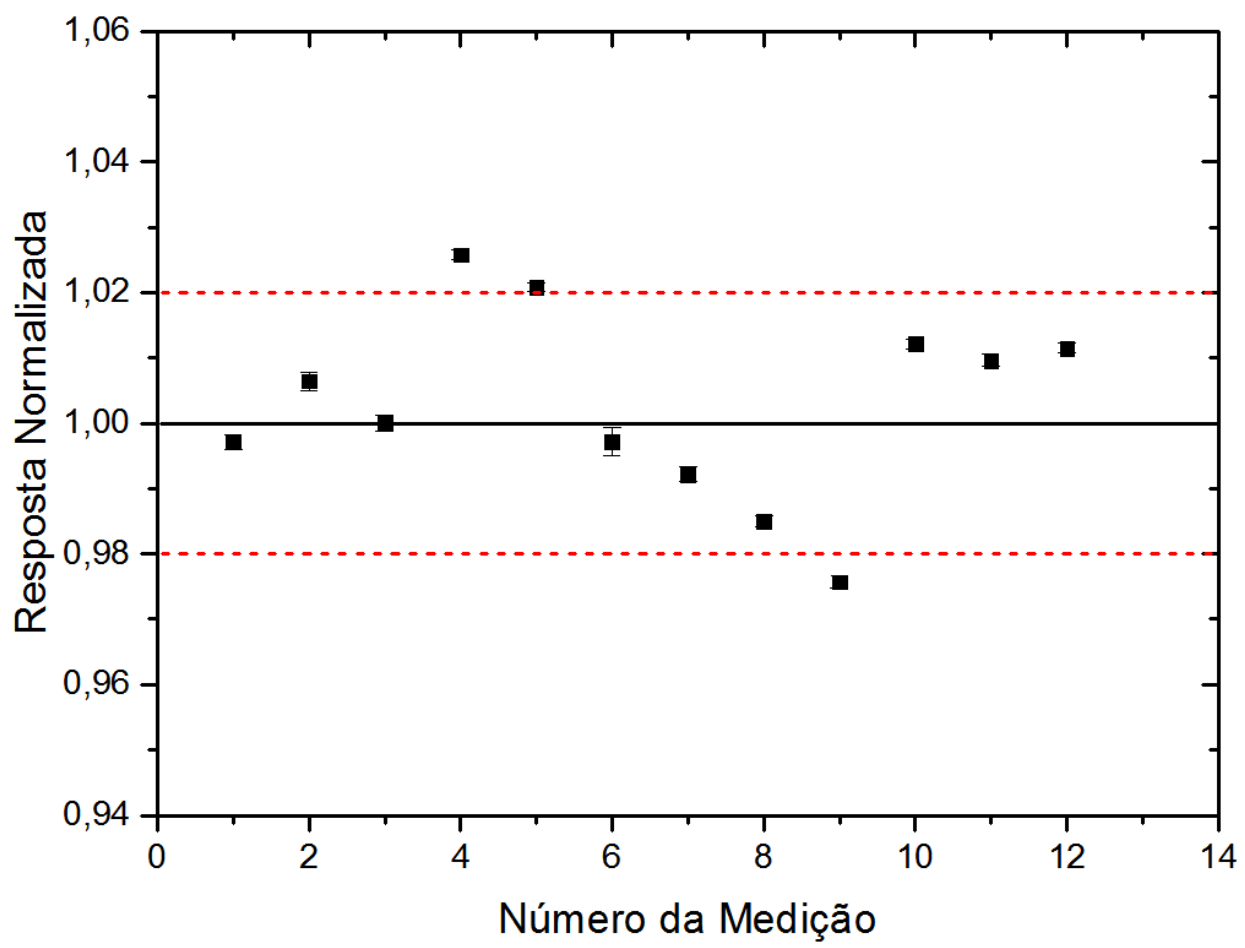

Figura 5.7: Teste de estabilidade para a câmara de ionização C2. 


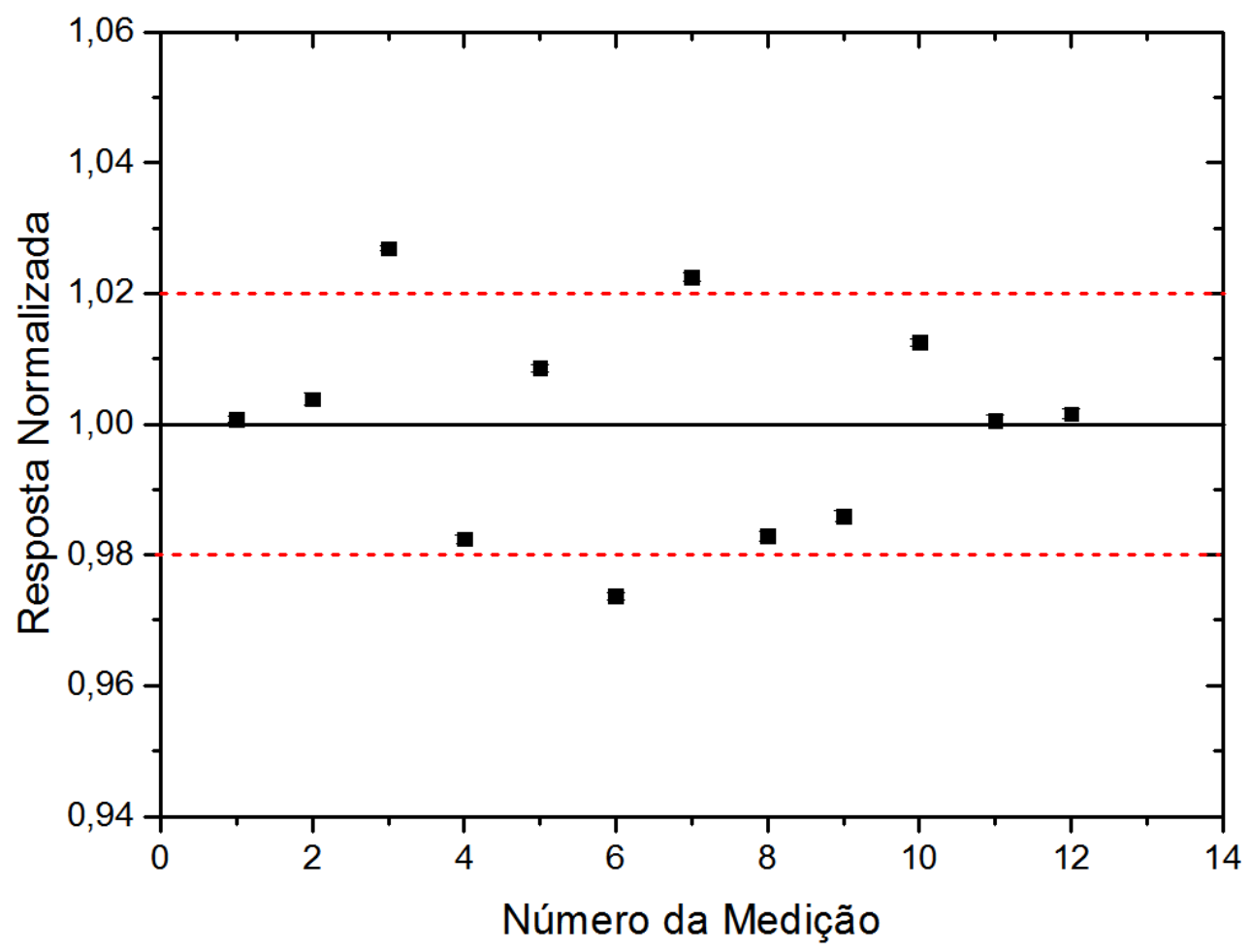

Figura 5.8:Teste de estabilidade para a câmara de ionização C3.

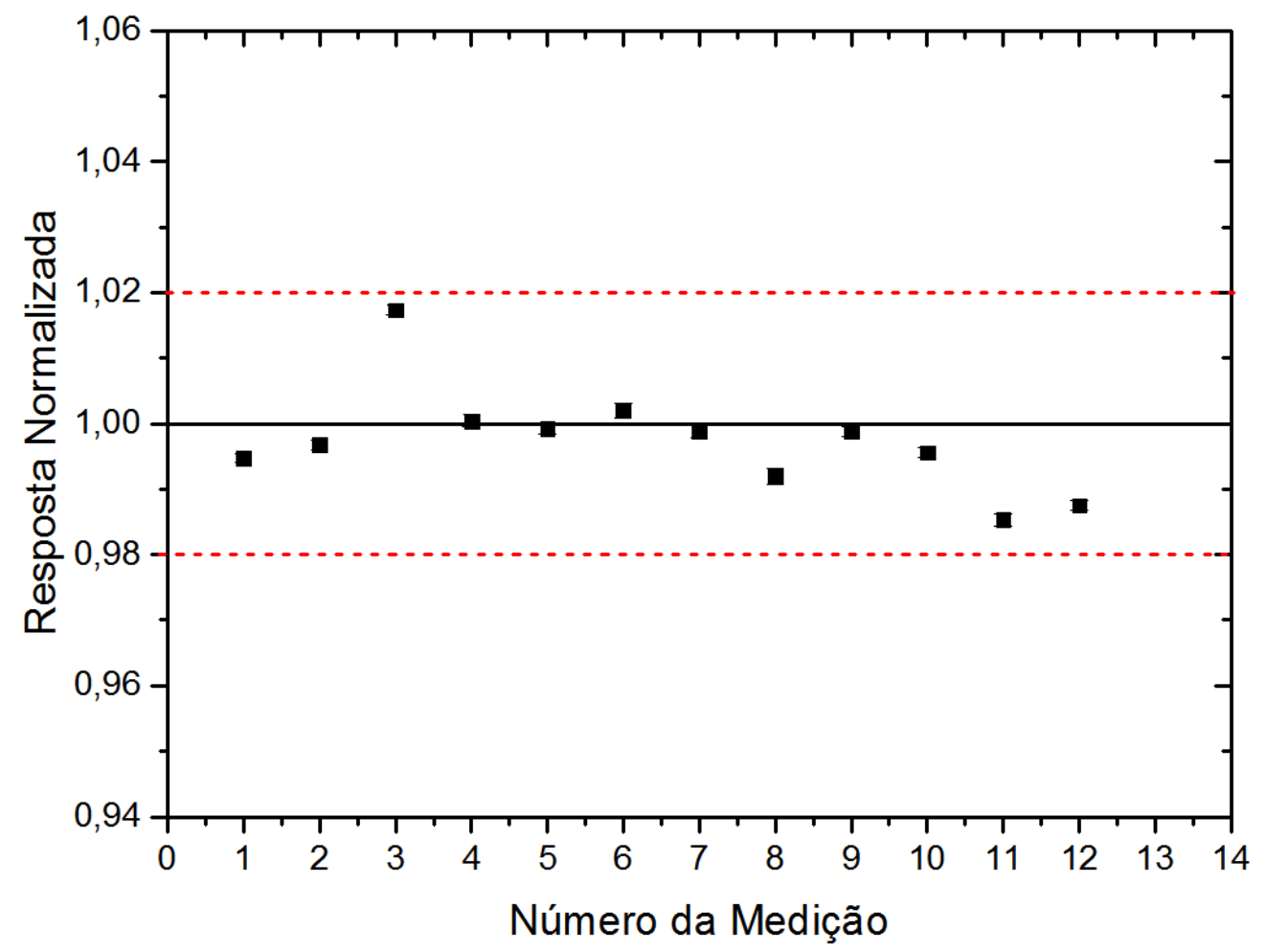

Figura 5.9: Teste de estabilidade para a câmara de ionização C4. 


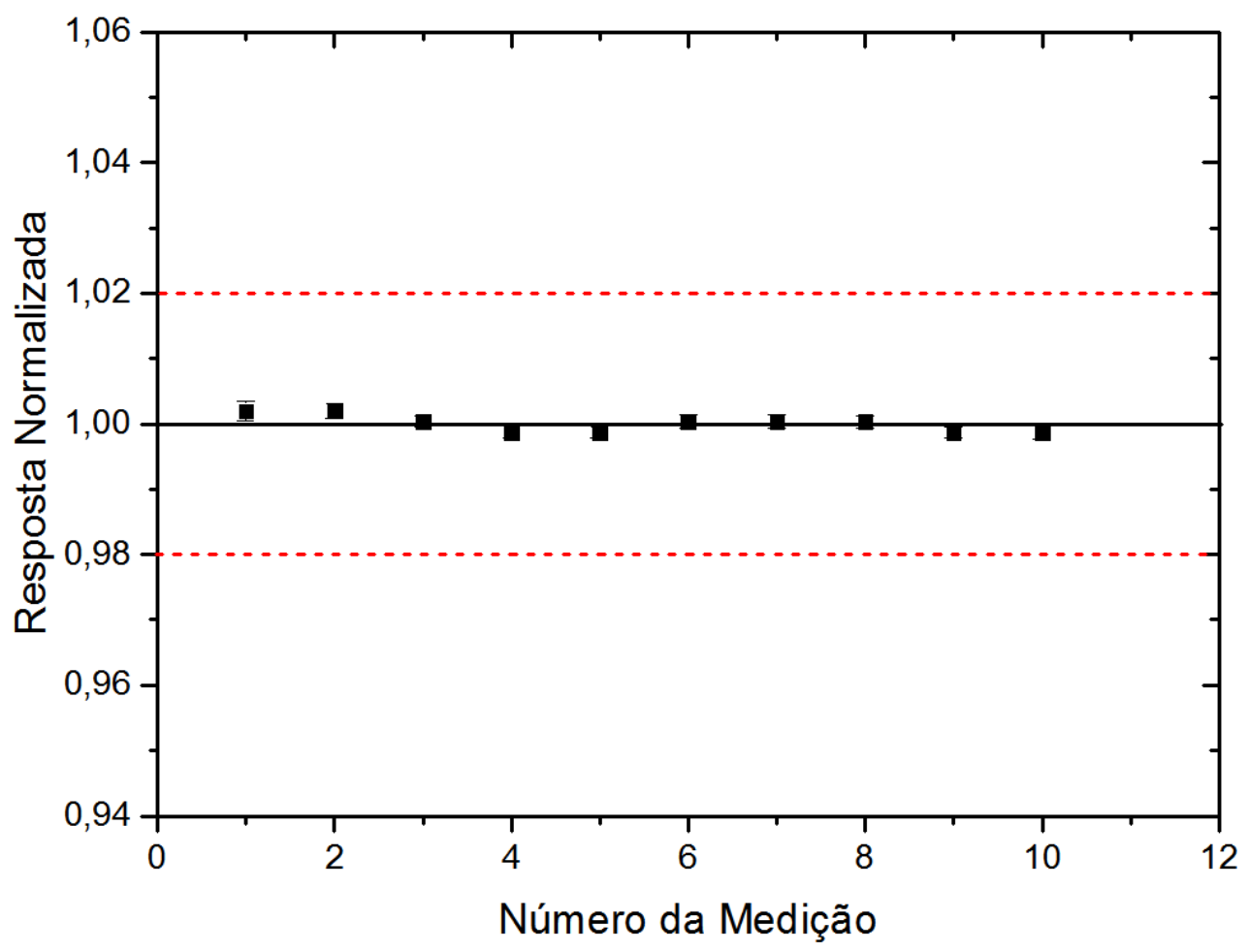

Figura 5.10: Teste de estabilidade para a câmara de ionização C5.

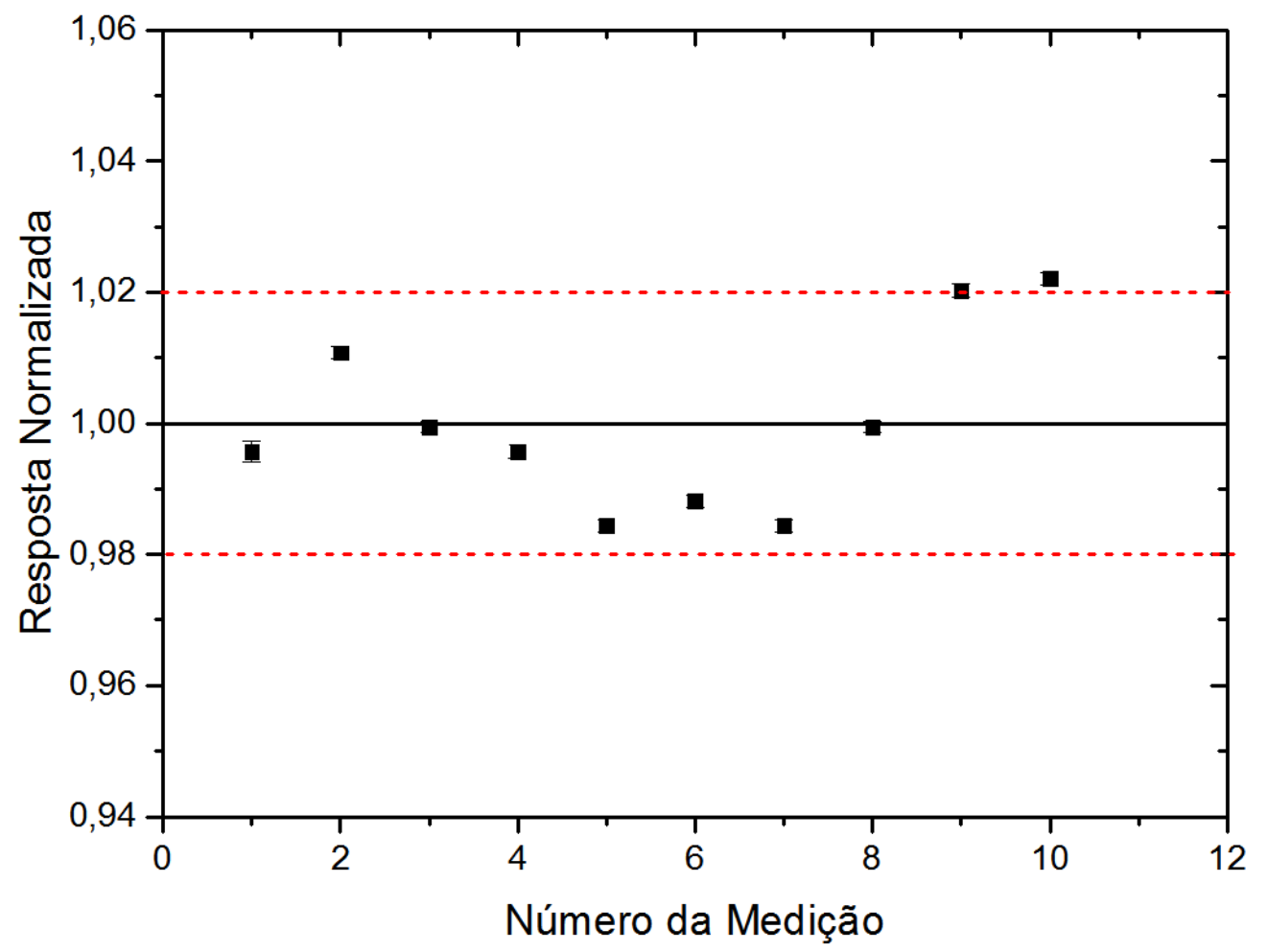

Figura 5.11: Teste de estabilidade para a câmara de ionização C6. 


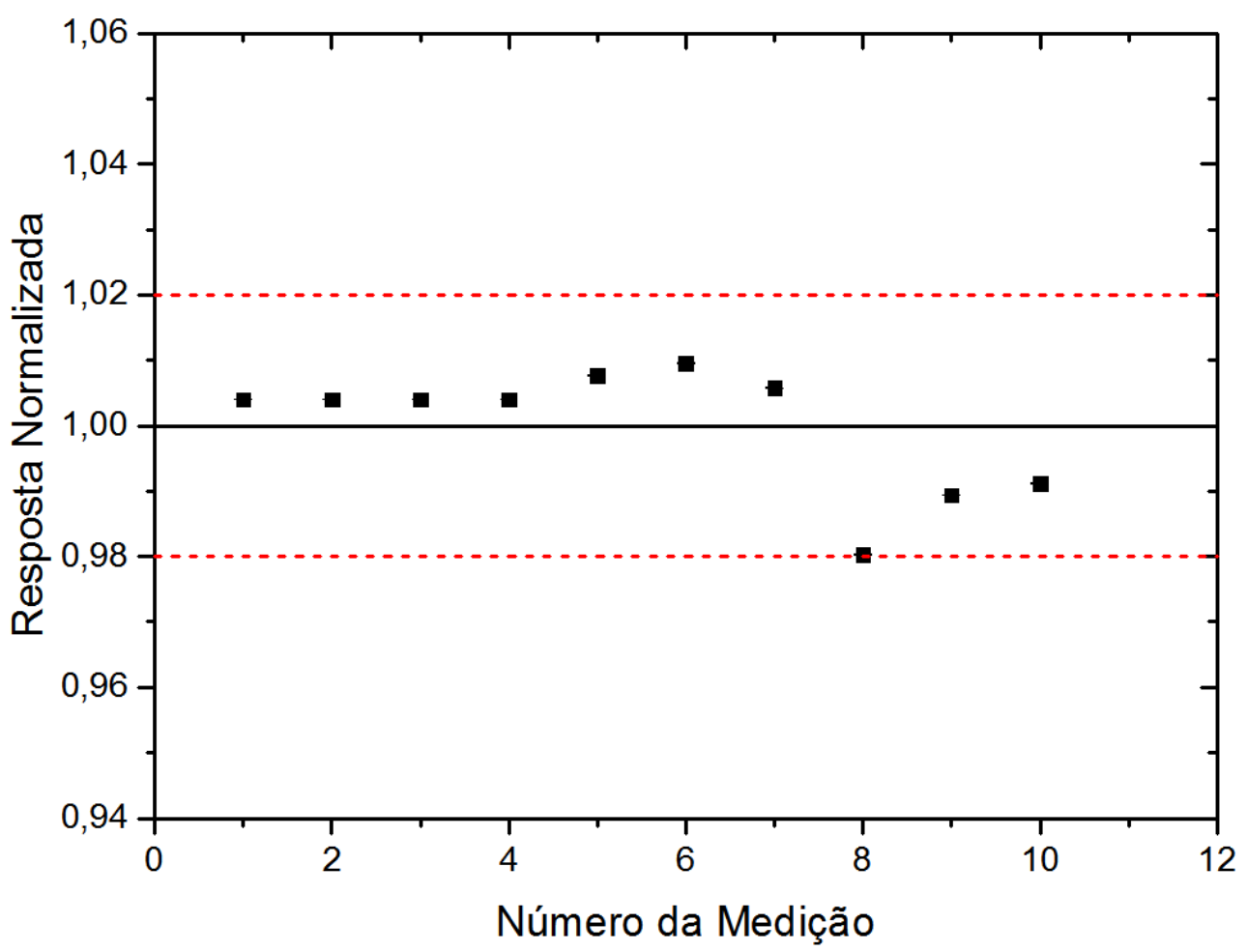

Figura 5.12: Teste de estabilidade para a câmara de ionização C7.

No caso do teste de estabilidade a longo prazo, os resultados obtidos encontram-se dentro dos limites aceitáveis internacionalmente (exceto em alguns poucos casos), comprovando assim que as câmaras encontram-se estáveis e que podem ser utilizadas nos demais testes de caracterização.

\subsubsection{Curva de Saturação, Efeito de Polaridade e Eficiência de Coleção de Î́ons}

Os testes de curva de saturação, efeito de polaridade e eficiência de coleção de íons foram realizados para todas as câmaras de ionização nas três qualidades dos feixes padronizados de radiação $X$ para CT estabelecidas no $\mathrm{LCl}$ e para diferentes aberturas do colimador. Os testes de efeito de polaridade e de eficiência de coleção de íons foram obtidos através dos dados utilizados para a construção das curvas de saturação.

Cada curva de saturação foi obtida por meio da tomada de dez medições consecutivas a cada $30 \mathrm{~s}$ para cada tensão aplicada; ela variou de $-400 \mathrm{~V}$ a +400 V, em passo de $50 \mathrm{~V}$. 
A curva de saturação, o efeito de polaridade e a eficiência e coleção de íons foram obtidos para diferentes aberturas do colimador; esta abertura corresponde ao campo de irradiação em que as câmaras de ionização foram irradiadas. Inicialmente essa abertura foi determinada como metade do comprimento do volume sensível (eixo x) pelo dobro do diâmetro da câmara de ionização (eixo y). Em seguida, foi realizado um estudo mais apurado da norma TRS 457 (IAEA, 2007), e observou-se que o correto era utilizar uma abertura de $5 \mathrm{~cm} \times 2 \mathrm{~cm}$ para câmaras que apresentam um comprimento de volume sensível igual ou superior à câmara comercial disponível mais utilizada $(10 \mathrm{~cm})$; para câmaras de ionização que apresentam um pequeno comprimento de volume sensível, deve-se utilizar o colimador em $(2 \mathrm{~cm} \times 2 \mathrm{~cm})$.

Os dados que foram obtidos anteriormente também serão apresentados, de forma que se possa comparar os comportamento das câmaras de ionização quando estas são irradiadas em campos diferentes. Para as câmaras que apresentam comprimentos de volume sensível de $10 \mathrm{~cm}$ e $30 \mathrm{~cm}$, optou-se por utilizar o colimador também na abertura de $(2 \mathrm{~cm} \times 2 \mathrm{~cm})$, pois quando elas são irradiadas em feixes clínicos, o campo é bem menor, se comparado a quando elas são irradiadas em laboratórios de calibração. Portanto, essa configuração permite a obtenção de resultados mais fieis àquilo que essas câmaras são realmente destinadas. A Tabela 5.5 mostra as aberturas do colimador utilizadas para cada câmara de ionização.

Tabela 5.5: Abertura do colimador utilizada para cada câmara de ionização, nos testes de curva de saturação, efeito de polaridade e eficiência de coleção de íons.

\begin{tabular}{ccc}
\hline Câmara de lonização & \multicolumn{2}{c}{ Abertura do colimador } \\
\hline C1 & $2 \mathrm{~cm} \times 2 \mathrm{~cm}$ & $5 \mathrm{~cm} \times 2 \mathrm{~cm}$ \\
C2 & $0,5 \mathrm{~cm} \times 2 \mathrm{~cm}$ & $2 \mathrm{~cm} \times 2 \mathrm{~cm}$ \\
C3 & $1,5 \mathrm{~cm} \times 2 \mathrm{~cm}$ & $2 \mathrm{~cm} \times 2 \mathrm{~cm}$ \\
C4 & $2 \mathrm{~cm} \times 2 \mathrm{~cm}$ & $5 \mathrm{~cm} \times 2 \mathrm{~cm}$ \\
C5 & $2 \mathrm{~cm} \times 2 \mathrm{~cm}$ & $5 \mathrm{~cm} \times 2 \mathrm{~cm}$ \\
C7 & $2 \mathrm{~cm} \times 2 \mathrm{~cm}$ & $5 \mathrm{~cm} \times 2 \mathrm{~cm}$ \\
\hline
\end{tabular}


As curvas de saturação para as câmaras de ionização para cada qualidade de radiação e para as diferentes aberturas de colimador podem ser visualizadas nas Figuras 5.13 a 5.18 , para todas as qualidades de radiação $X$ estabelecidas no LCl.

Em seguida, será apresentada uma comparação para a resposta das câmaras de ionização $\mathrm{C} 6$ e $\mathrm{C} 7$, para todas as qualidades de radiação $X$ estabelecidas para CT no LCl. O campo em que as duas câmaras foram irradiadas foi de $30 \mathrm{~cm}^{2}$; sendo assim, a abertura correspondente é de $15 \mathrm{~cm}$ (eixo $\mathrm{x}$ ) por $2 \mathrm{~cm}$ (eixo y). O resultado obtido pode ser visto na Figura 5.19. 

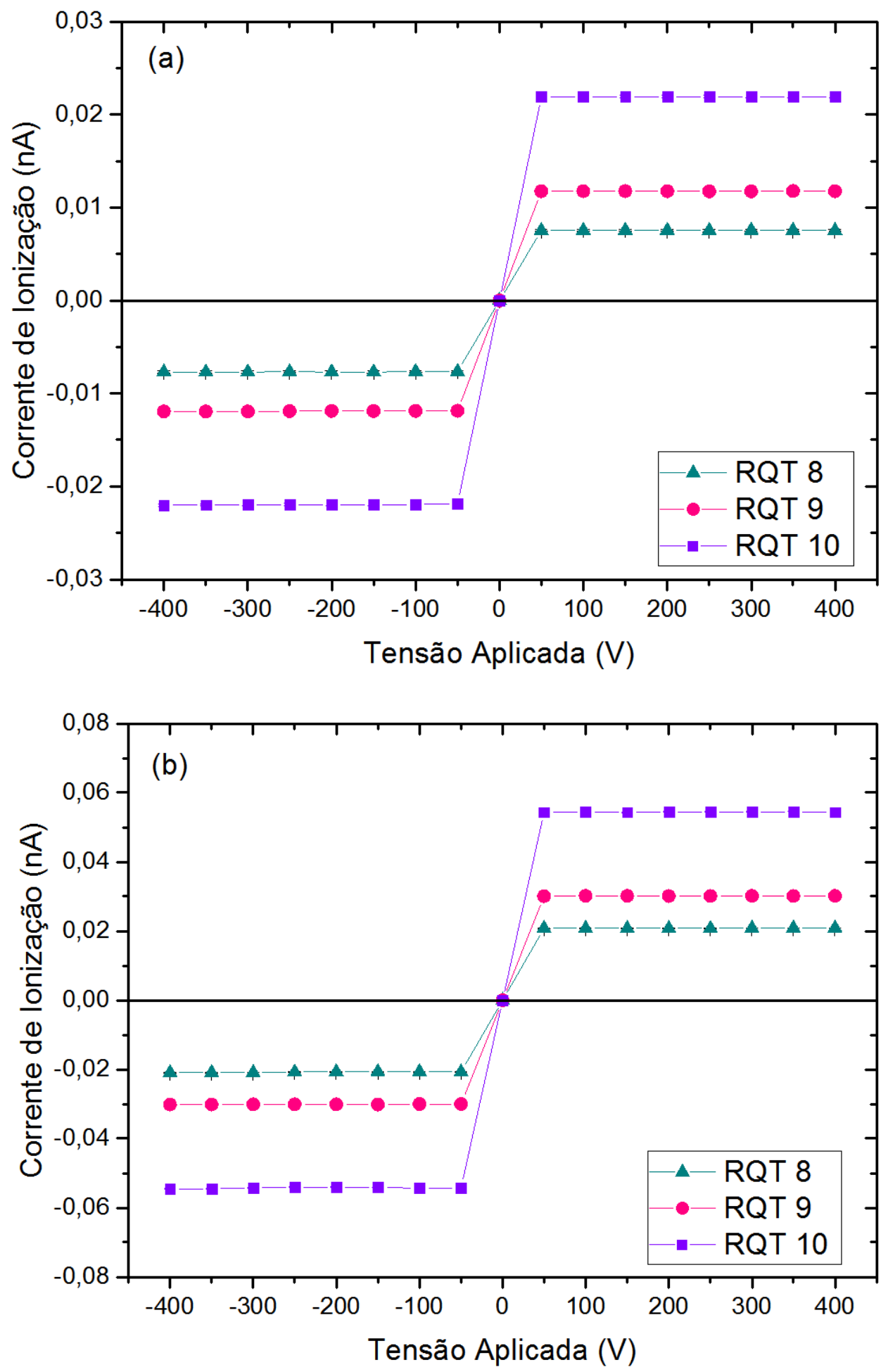

Figura 5.13: Curvas de saturação da câmara de ionização $C 1$ para as qualidades dos feixes padronizados de radiação X para CT no LCl. A incerteza máxima das medições de todas as figuras foi de $0,01 \%$, não visível nos gráficos. Aberturas do colimador: (a) $2 \mathrm{~cm} \times 2 \mathrm{~cm} \mathrm{e} \mathrm{(b)} 5 \mathrm{~cm} \times 2 \mathrm{~cm}$. 

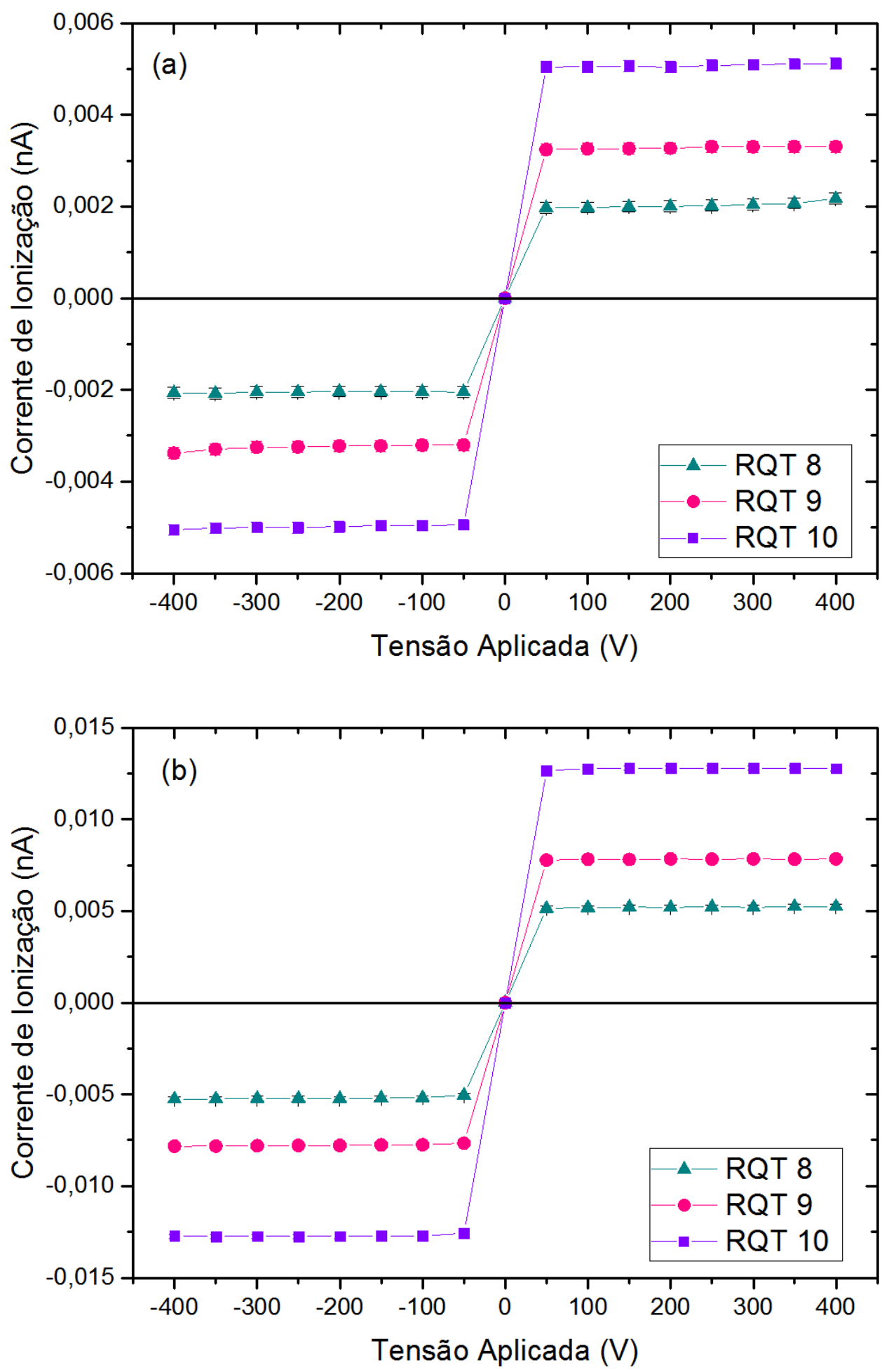

Figura 5.14: Curvas de saturação da câmara de ionização $C 2$ para as qualidades dos feixes padronizados de radiação X para CT no LCl. A incerteza máxima das medições de todas as figuras foi de $0,01 \%$, não visível nos gráficos. Aberturas do colimador: (a) $0,5 \mathrm{~cm} \times 2 \mathrm{~cm}$ e (b) $2 \mathrm{~cm} \times 2 \mathrm{~cm}$. 

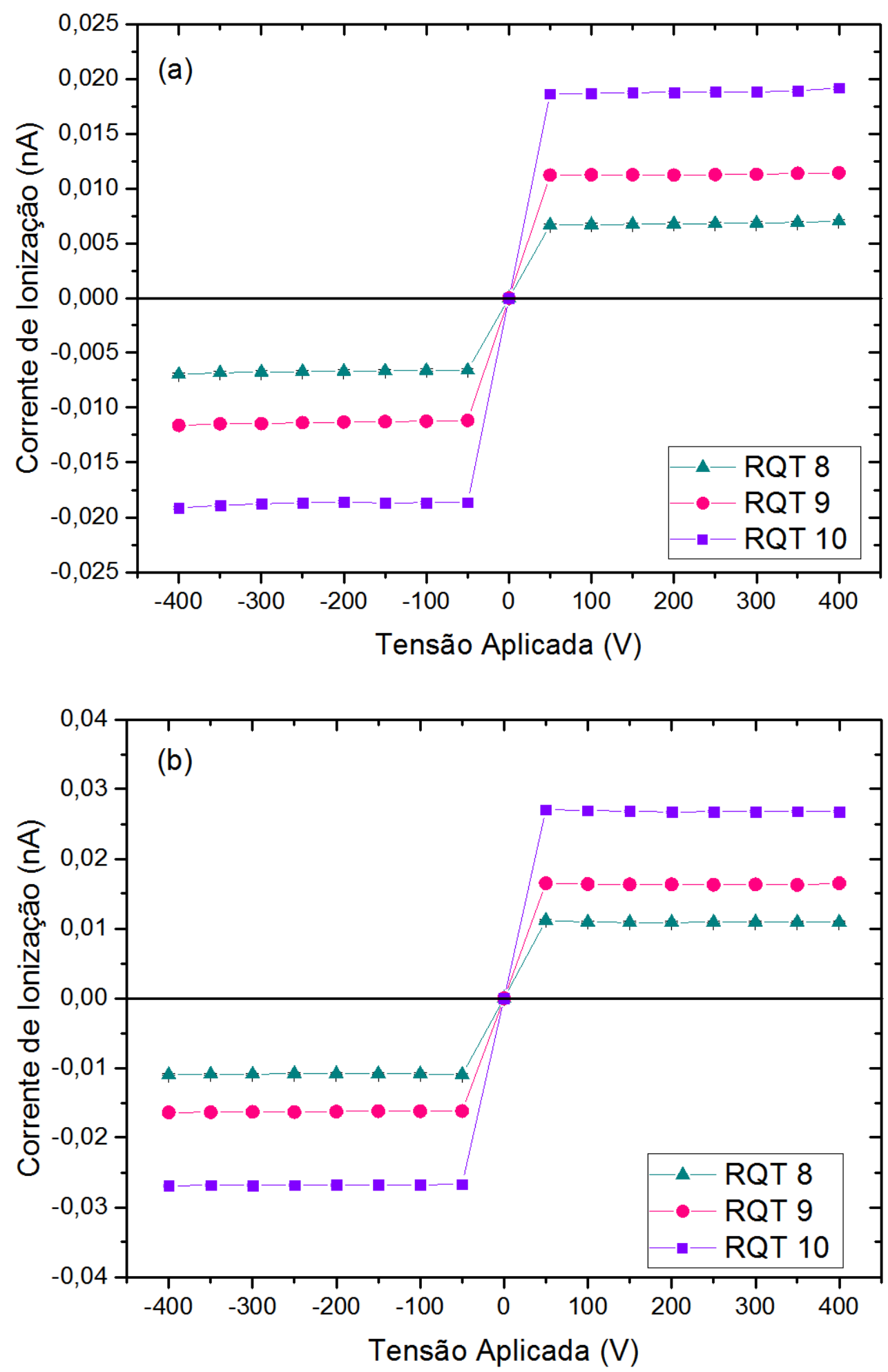

Figura 5.15: Curvas de saturação da câmara de ionização C3 para as qualidades dos feixes padronizados de radiação X para CT no LCl. A incerteza máxima das medições de todas as figuras foi de $0,01 \%$, não visível nos gráficos. Aberturas do colimador: (a) $1,5 \mathrm{~cm} \times 2 \mathrm{~cm}$ e (b) $2 \mathrm{~cm} \times 2 \mathrm{~cm}$. 

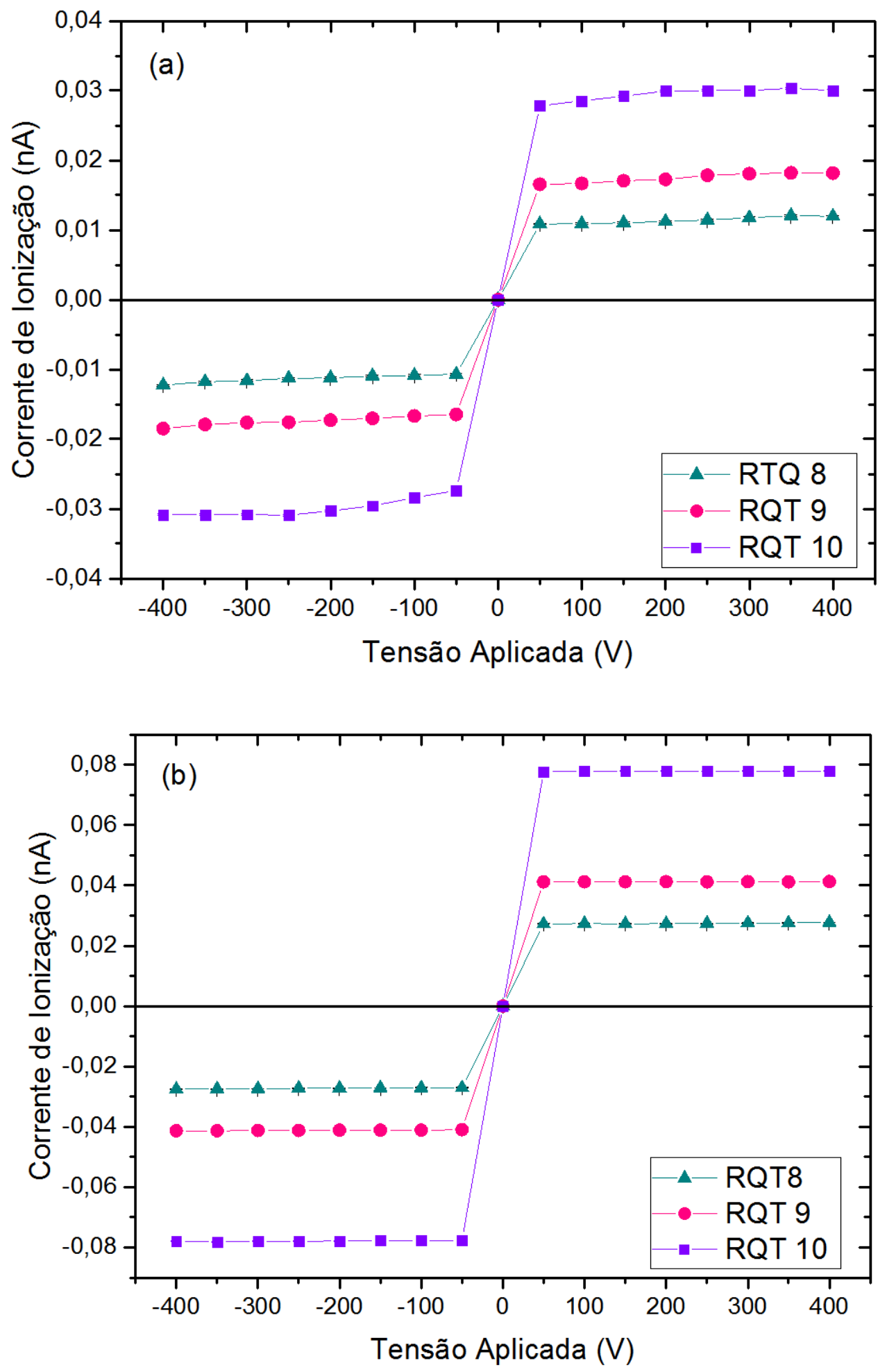

Figura 5.16: Curvas de saturação da câmara de ionização C4 para as qualidades dos feixes padronizados de radiação X para CT no LCl. A incerteza máxima das medições de todas as figuras foi de $0,01 \%$, não visível nos gráficos. Aberturas do colimador: (a) $2 \mathrm{~cm} \times 2 \mathrm{~cm} \mathrm{e} \mathrm{(b)} 5 \mathrm{~cm} \times 2 \mathrm{~cm}$. 

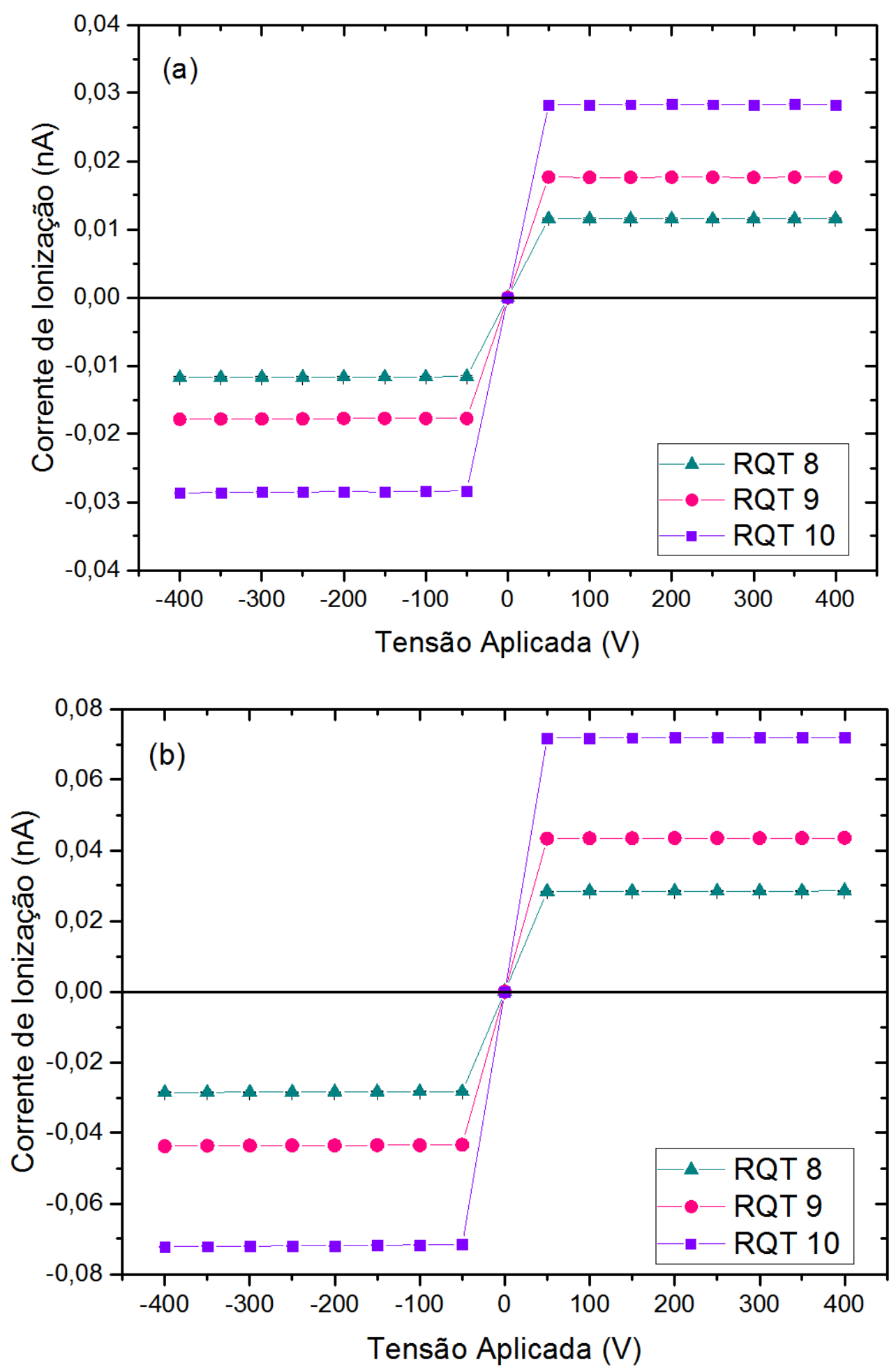

Figura 5.17: Curvas de saturação da câmara de ionização C5 para as qualidades dos feixes padronizados de radiação X para CT no LCl. A incerteza máxima das medições de todas as figuras foi de 0,01\%, não visível nos gráficos. Aberturas do colimador: (a) $2 \mathrm{~cm} \times 2 \mathrm{~cm}$ e (b) $5 \mathrm{~cm} \times 2 \mathrm{~cm}$. 

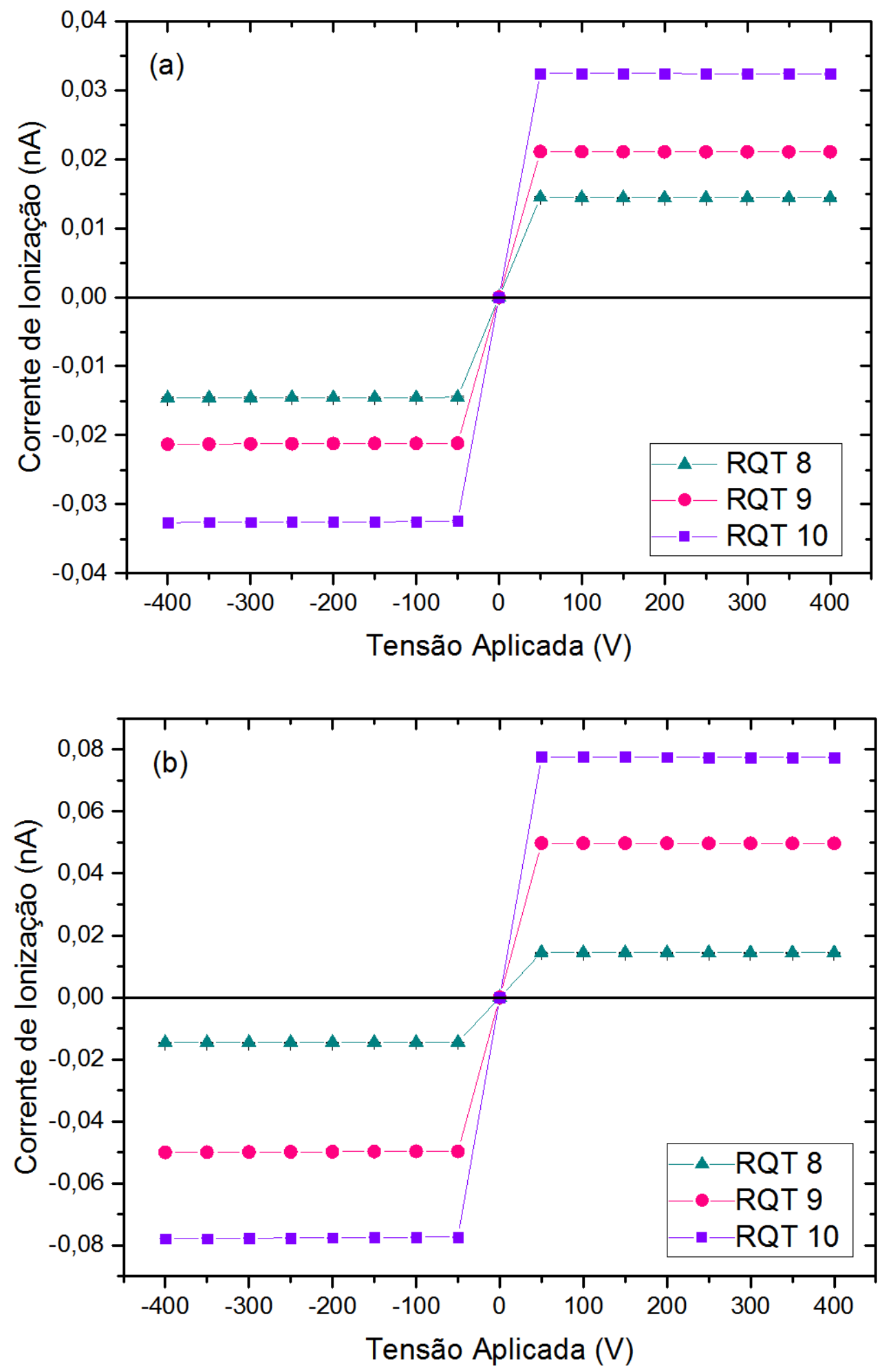

Figura 5.18: Curvas de saturação da câmara de ionização $C 7$ para as qualidades dos feixes padronizados de radiação X para CT no LCl. A incerteza máxima das medições de todas as figuras foi de $0,01 \%$, não visível nos gráficos. Aberturas do colimador: (a) $2 \mathrm{~cm} \times 2 \mathrm{~cm} \mathrm{e} \mathrm{(b)} 5 \mathrm{~cm} \times 2 \mathrm{~cm}$. 

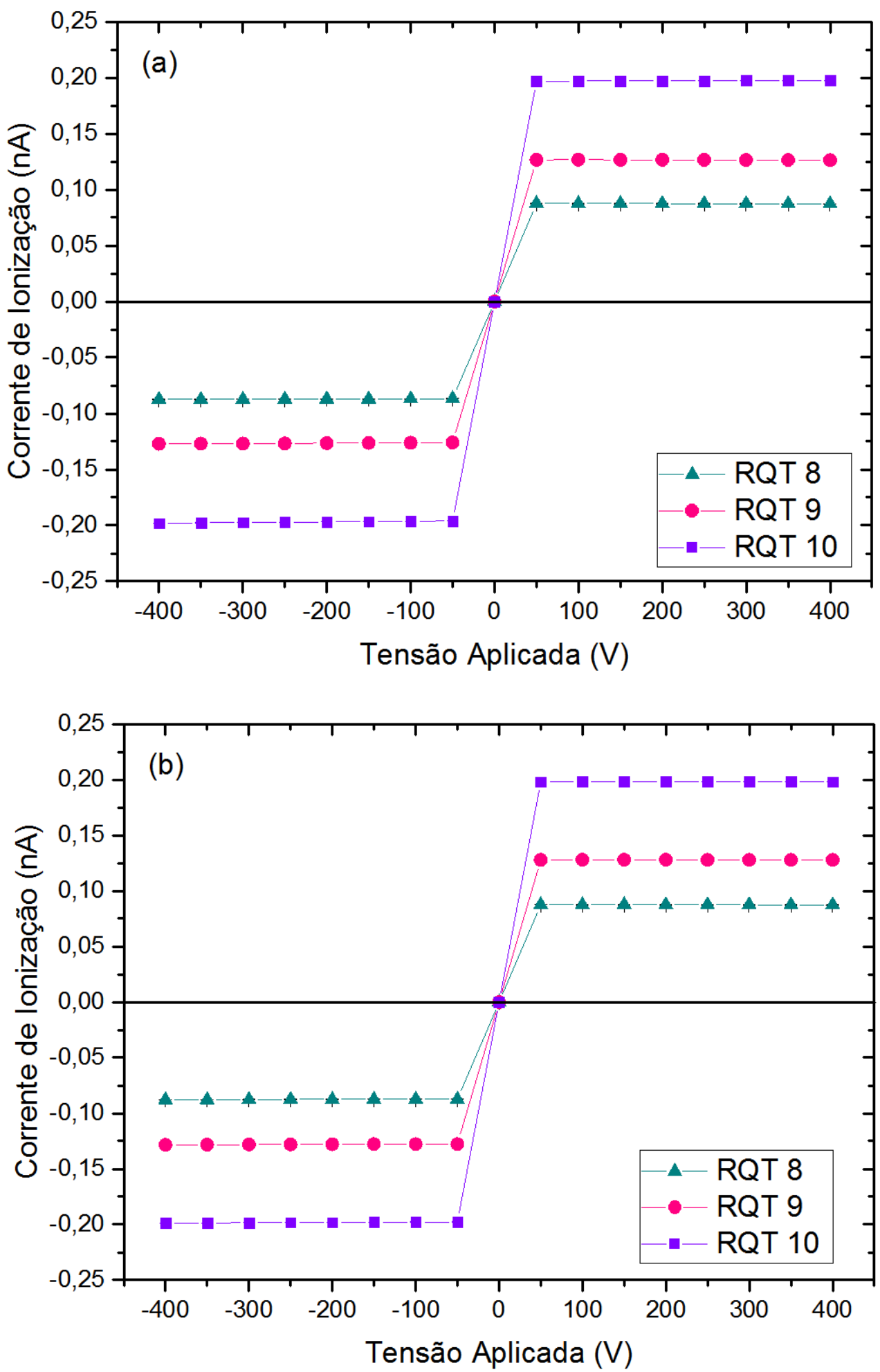

Figura 5.19: Curvas de saturação para as qualidades dos feixes padronizados de radiação $\mathrm{X}$ para $\mathrm{CT}$ no $\mathrm{LCl}$. A incerteza máxima das medições de todas as figuras foi de $0,01 \%$, não visível nos gráficos. Abertura do colimador de $(15 \mathrm{~cm} \times 2 \mathrm{~cm}$ ) para as câmaras de ionização: (a) C6 e (b) C7. 
Observa-se, pelas Figuras 5.13 a 5.18 , que as curvas de saturação obtidas, independente do campo de radiação, apresentam respostas semelhantes, variando-se somente a corrente de ionização; isso se deve ao tamanho do campo sob irradiação. Somente para a câmara C4, para a abertura de $(2 \mathrm{~cm} \times 2 \mathrm{~cm})$, a resposta obtida não se encontra no patamar esperado; isto pode ter ocorrido devido ao fato da câmara de ionização já ser muito antiga.

A Figura 5.19 permite observar que as respostas fornecidas pelas câmaras $\mathrm{C} 6$ e C7, para o campo de irradiação de $30 \mathrm{~cm}^{2}$, têm comportamentos similares, mostrando que a construção das câmaras ocorreu de maneira reprodutiva.

O efeito de polaridade foi determinado pela razão entre os valores de corrente de ionização obtidos para as polaridades positiva e negativa, para cada tensão utilizada; os resultados obtidos para todas as câmaras de ionização devem se encontrar dentro dos limites recomendados internacionalmente $(1 \%)$, ou seja, os valores devem estar presentes no intervalo de 0,99 e 1,01 (IEC, 2005). Os resultados máximos obtidos para cada qualidade de radiação podem ser visualizados nas Tabelas 5.6 a 5.11. A Tabela 5.12 apresenta os resultados de comparação para as respostas das câmaras de ionização C6 e C7.

Tabela 5.6: Efeito de polaridade (\%) para a câmara de ionização $C 1$ em todas as qualidades dos feixes padronizados de radiação $X$ para $\mathrm{CT}$ no $\mathrm{LCl}$, para as aberturas do colimador de $(2 \mathrm{~cm} \times 2 \mathrm{~cm})$ e $(5 \mathrm{~cm} \times 2 \mathrm{~cm})$.

\begin{tabular}{ccccccc}
\hline Tensão & \multicolumn{3}{c}{$\mathbf{2 ~ c m ~ \times ~ 2 ~ c m ~}$} & \multicolumn{3}{c}{$\mathbf{5} \mathbf{~ c m ~ \times ~ 2 ~ c m ~}$} \\
\cline { 2 - 7 } Aplicada & RQT 8 & RQT 9 & RQT 10 & RQT 8 & RQT 9 & RQT 10 \\
\hline $\mathbf{5 0}$ & 0,986 & 0,989 & 1,000 & 1,003 & 1,002 & 1,002 \\
$\mathbf{1 0 0}$ & 0,984 & 0,988 & 0,999 & 1,004 & 1,003 & 1,002 \\
$\mathbf{1 5 0}$ & 0,980 & 0,987 & 0,999 & 1,003 & 1,001 & 1,005 \\
$\mathbf{2 0 0}$ & 0,981 & 0,988 & 0,998 & 1,002 & 1,000 & 1,017 \\
$\mathbf{2 5 0}$ & 0,981 & 0,986 & 0,998 & 0,999 & 1,001 & 1,017 \\
$\mathbf{3 0 0}$ & 0,981 & 0,982 & 0,998 & 0,998 & 1,001 & 1,004 \\
$\mathbf{3 5 0}$ & 0,977 & 0,984 & 0,996 & 0,998 & 0,999 & 0,998 \\
$\mathbf{4 0 0}$ & 0,977 & 0,984 & 0,995 & 0,996 & 1,001 & 0,996 \\
\hline
\end{tabular}


Tabela 5.7: Efeito de polaridade (\%) para a câmara de ionização C2 em todas as qualidades dos feixes padronizados de radiação $X$ para $\mathrm{CT}$ no $\mathrm{LCl}$, para as aberturas do colimador de $(0,5 \mathrm{~cm} \times 2 \mathrm{~cm})$ e $(2 \mathrm{~cm} \times 2 \mathrm{~cm})$.

\begin{tabular}{ccccccc}
\hline Tensão & \multicolumn{3}{c}{$\mathbf{0 , 5} \mathbf{~ c m ~ \times ~ 2 ~ c m ~}$} & \multicolumn{3}{c}{$\mathbf{2 ~ c m ~ \times ~ 2 ~ c m ~}$} \\
\cline { 2 - 7 } Aplicada & RQT 8 & RQT 9 & RQT 10 & RQT 8 & RQT 9 & RQT 10 \\
\hline $\mathbf{5 0}$ & 0,963 & 1,012 & 1,019 & 1,018 & 1,014 & 1,006 \\
$\mathbf{1 0 0}$ & 0,970 & 1,017 & 1,018 & 0,999 & 1,007 & 1,004 \\
$\mathbf{1 5 0}$ & 0,979 & 1,012 & 1,020 & 1,001 & 1,006 & 1,004 \\
$\mathbf{2 0 0}$ & 0,983 & 1,014 & 1,011 & 0,992 & 1,006 & 1,005 \\
$\mathbf{2 5 0}$ & 0,986 & 1,018 & 1,015 & 1,000 & 1,004 & 1,004 \\
$\mathbf{3 0 0}$ & 0,995 & 1,016 & 1,018 & 0,993 & 1,003 & 1,005 \\
$\mathbf{3 5 0}$ & $\mathbf{0 , 9 9 7}$ & 1,003 & 1,019 & 0,997 & 1,000 & 1,003 \\
$\mathbf{4 0 0}$ & 1,056 & 0,977 & 1,012 & 0,995 & 1,000 & 1,003 \\
\hline
\end{tabular}

Tabela 5.8: Efeito de polaridade (\%) para a câmara de ionização C3 em todas as qualidades dos feixes padronizados de radiação $X$ para $\mathrm{CT}$ no $\mathrm{LCl}$, para as aberturas do colimador de $(1,5 \mathrm{~cm} \times 2 \mathrm{~cm})$ e $(2 \mathrm{~cm} \times 2 \mathrm{~cm})$.

\begin{tabular}{ccccccc}
\hline Tensão & \multicolumn{3}{c}{$\mathbf{1 , 5} \mathbf{~ c m ~ \times ~ 2 ~ c m ~}$} & \multicolumn{3}{c}{$\mathbf{2 ~ c m ~ \times ~ 2 ~ c m ~}$} \\
\cline { 2 - 7 } Aplicada & RQT 8 & RQT 9 & RQT 10 & RQT 8 & RQT 9 & RQT 10 \\
\hline $\mathbf{5 0}$ & 1,011 & 1,004 & 0,999 & 1,020 & 1,016 & 1,013 \\
$\mathbf{1 0 0}$ & 1,013 & 1,000 & 1,001 & 1,004 & 1,008 & 1,005 \\
$\mathbf{1 5 0}$ & 1,011 & 0,997 & 1,003 & 1,002 & 1,008 & 1,003 \\
$\mathbf{2 0 0}$ & 1,012 & 0,991 & 1,009 & 1,002 & 1,003 & 0,998 \\
$\mathbf{2 5 0}$ & 1,011 & 0,990 & 1,008 & 1,006 & 0,996 & 0,998 \\
$\mathbf{3 0 0}$ & 1,011 & 0,985 & 1,001 & 1,000 & 0,999 & 0,998 \\
$\mathbf{3 5 0}$ & 1,011 & 0,990 & 0,999 & 0,999 & 0,994 & 0,999 \\
$\mathbf{4 0 0}$ & 1,006 & 0,982 & 1,002 & 0,992 & 1,007 & 0,996 \\
\hline
\end{tabular}


Tabela 5.9: Efeito de polaridade (\%) para a câmara de ionização C4 em todas as qualidades dos feixes padronizados de radiação $X$ para CT no $\mathrm{LCl}$, para as a aberturas do colimador de $(2 \mathrm{~cm} \times 2 \mathrm{~cm})$ e $(5 \mathrm{~cm} \times 2 \mathrm{~cm})$.

\begin{tabular}{ccccccc}
\hline Tensão & \multicolumn{3}{c}{$\mathbf{2 ~ c m ~ \times ~ 2 ~ c m ~}$} & \multicolumn{3}{c}{$\mathbf{~ c m ~ x ~ 2 ~ c m ~}$} \\
\cline { 2 - 7 } Aplicada & RQT 8 & RQT 9 & RQT 10 & RQT 8 & RQT 9 & RQT 10 \\
\hline $\mathbf{5 0}$ & 1,016 & 1,006 & 1,016 & 1,003 & 1,004 & 1,002 \\
$\mathbf{1 0 0}$ & 1,002 & 0,999 & 1,005 & 1,016 & 1,001 & 1,001 \\
$\mathbf{1 5 0}$ & 1,008 & 1,002 & 0,987 & 1,003 & 0,999 & 1,002 \\
$\mathbf{2 0 0}$ & 1,000 & 0,999 & 0,988 & 1,002 & 1,002 & 1,000 \\
$\mathbf{2 5 0}$ & 1,013 & 1,015 & 0,990 & 1,004 & 0,998 & 0,998 \\
$\mathbf{3 0 0}$ & 1,011 & 1,025 & 0,999 & 1,003 & 0,999 & 0,999 \\
$\mathbf{3 5 0}$ & 1,024 & 1,015 & 0,999 & 1,001 & 0,995 & 0,996 \\
$\mathbf{4 0 0}$ & 0,977 & 0,982 & 1,000 & 1,015 & 0,998 & 0,999 \\
\hline
\end{tabular}

Tabela 5.10: Efeito de polaridade (\%) para a câmara de ionização C5 em todas as qualidades dos feixes padronizados de radiação $X$ para $\mathrm{CT}$ no $\mathrm{LCl}$, para as aberturas do colimador de $(2 \mathrm{~cm} \times 2 \mathrm{~cm})$ e $(5 \mathrm{~cm} \times 2 \mathrm{~cm})$.

\begin{tabular}{ccccccc}
\hline Tensão & \multicolumn{3}{c}{$\mathbf{2 ~ c m ~ \times ~ 2 ~ c m ~}$} & \multicolumn{3}{c}{$\mathbf{5} \mathbf{~ m ~ x ~ 2 ~ c m ~}$} \\
\cline { 2 - 7 } Aplicada & RQT 8 & RQT 9 & RQT 10 & RQT 8 & RQT 9 & RQT 10 \\
\hline $\mathbf{5 0}$ & 0,996 & 0,995 & 0,997 & 0,996 & 0,995 & 0,997 \\
$\mathbf{1 0 0}$ & 0,990 & 0,992 & 0,994 & 0,990 & 0,992 & 0,994 \\
$\mathbf{1 5 0}$ & 0,989 & 0,992 & 0,992 & 0,989 & 0,992 & 0,992 \\
$\mathbf{2 0 0}$ & 0,988 & 0,993 & 0,994 & 0,988 & 0,993 & 0,994 \\
$\mathbf{2 5 0}$ & 0,984 & 0,991 & 0,993 & 0,984 & 0,991 & 0,993 \\
$\mathbf{3 0 0}$ & 0,984 & 0,989 & 0,989 & 0,985 & 0,989 & 0,989 \\
$\mathbf{3 5 0}$ & 0,985 & 0,988 & 0,990 & 0,984 & 0,989 & 0,990 \\
$\mathbf{4 0 0}$ & 0,984 & 0,988 & 0,987 & 0,985 & 0,988 & 0,987 \\
\hline
\end{tabular}


Tabela 5.11: Efeito de polaridade (\%) para a câmara de ionização C7 em todas as qualidades dos feixes padronizados de radiação $X$ para $\mathrm{CT}$ no $\mathrm{LCl}$, para as aberturas do colimador de $(2 \mathrm{~cm} \times 2 \mathrm{~cm})$ e $(5 \mathrm{~cm} \times 2 \mathrm{~cm})$.

\begin{tabular}{ccccccc}
\hline Tensão & \multicolumn{3}{c}{$\mathbf{2 ~ c m ~ \times ~ 2 ~ c m ~}$} & \multicolumn{3}{c}{$\mathbf{5 ~ c m ~ \times ~ 2 ~ c m ~}$} \\
\cline { 2 - 7 } Aplicada & RQT 8 & RQT 9 & RQT 10 & RQT 8 & RQT 9 & RQT 10 \\
\hline $\mathbf{5 0}$ & 0,998 & 0,997 & 0,999 & 0,998 & 1,001 & 1,003 \\
$\mathbf{1 0 0}$ & 0,991 & 0,994 & 0,997 & 0,991 & 1,001 & 1,002 \\
$\mathbf{1 5 0}$ & 0,989 & 0,993 & 0,996 & 0,989 & 1,000 & 1,000 \\
$\mathbf{2 0 0}$ & 0,989 & 0,993 & 0,995 & 0,989 & 0,999 & 0,999 \\
$\mathbf{2 5 0}$ & 0,988 & 0,992 & 0,994 & 0,988 & 0,997 & 0,997 \\
$\mathbf{3 0 0}$ & 0,987 & 0,990 & 0,993 & 0,987 & 0,996 & 0,996 \\
$\mathbf{3 5 0}$ & 0,986 & 0,989 & 0,992 & 0,986 & 0,995 & 0,995 \\
$\mathbf{4 0 0}$ & 0,984 & 0,988 & 0,991 & 0,984 & 0,994 & 0,994 \\
\hline
\end{tabular}

Tabela 5.12:Efeito de polaridade (\%) para as câmaras de ionização C6 e C7 em todas as qualidades dos feixes padronizados de radiação $X$ para $C T$ no LCl. Para a abertura do colimador de $(15 \mathrm{~cm} \times 2 \mathrm{~cm})$.

\begin{tabular}{ccccccc}
\hline Tensão & \multicolumn{3}{c}{ C6 } & & \multicolumn{3}{c}{ C7 } \\
\cline { 2 - 7 } Aplicada & RQT 8 & RQT 9 & RQT 10 & RQT 8 & RQT 9 & RQT 10 \\
\hline $\mathbf{5 0}$ & 1,008 & 1,004 & 1,004 & 1,003 & 1,001 & 1,002 \\
$\mathbf{1 0 0}$ & 1,006 & 1,003 & 1,003 & 1,002 & 1,003 & 1,003 \\
$\mathbf{1 5 0}$ & 1,004 & 1,001 & 1,002 & 1,002 & 1,002 & 1,002 \\
$\mathbf{2 0 0}$ & 1,004 & 1,000 & 1,001 & 1,000 & 1,001 & 1,001 \\
$\mathbf{2 5 0}$ & 1,002 & 0,998 & 1,000 & 0,999 & 0,999 & 1,000 \\
$\mathbf{3 0 0}$ & $\mathbf{1 , 0 0 0}$ & 0,996 & 0,999 & 0,998 & 0,998 & 0,999 \\
$\mathbf{3 5 0}$ & 0,997 & 0,995 & 0,999 & 0,996 & 0,996 & 0,998 \\
$\mathbf{4 0 0}$ & 0,997 & 0,993 & 0,997 & 0,994 & 0,995 & 0,996 \\
\hline
\end{tabular}


Os resultados do teste de efeito de polaridade encontram-se em sua maioria dentro dos limites recomendados internacionalmente $(88,4 \%)$; exceto para algumas câmaras de ionização, pode-se observar também que para algumas câmaras, quando o campo de irradiação foi menor, os valores obtidos se encontraram fora do permitido, quando comparado com quando o campo de irradiação delas foi maior; porém, esses resultados não interferem no funcionamento das câmaras nos demais testes, uma vez que elas são utilizadas na mesma polaridade e com a mesma tensão, que é o que ocorre com as câmaras utilizadas em radiodiagnóstico.

A Tabela 5.12 permite observar que as respostas fornecidas pelas câmaras C6 e C7 para o campo de irradiação de $30 \mathrm{~cm}^{2}$ são muito parecidas, e todos os resultados obtidos para esse campo encontram-se dentro do limite recomendado (2\%), comprovando assim que a construção e o funcionamento das câmaras são reprodutivos.

A eficiência de coleção de íons foi obtida usando as tensões $V_{1}=+200 \mathrm{~V}$ e $V_{2}=+100 \mathrm{~V}$ para todas as qualidades de cada câmara de ionização para todos os campos de irradiação sob teste. Os resultados máximos obtidos podem ser visualizados nas Tabelas 5.13 a 5.18, e estes devem apresentar-se dentro do limite recomendado de $95 \%$ (IEC, 2005). A Tabela 5.19 apresenta os resultados obtidos para a comparação entre as respostas das câmaras de ionização C6 e C7 para a abertura do colimador de $(15 \mathrm{~cm} \times 2 \mathrm{~cm})$.

Tabela 5.13: Eficiência de coleção de íons da câmara de ionização $C 1$ (\%) em todas as qualidades dos feixes padronizados de radiação $\mathrm{X}$ para CT no $\mathrm{LCl}$.

Aberturas do colimador: $(2 \mathrm{~cm} \times 2 \mathrm{~cm})$ e $(5 \mathrm{~cm} \times 2 \mathrm{~cm})$.

\begin{tabular}{cccc}
\hline Abertura do & \multicolumn{3}{c}{ Qualidade de Radiação } \\
\cline { 2 - 4 } Colimador & RQT 8 & RQT 9 & RQT 10 \\
\hline $2 \mathrm{~cm} \times 2 \mathrm{~cm}$ & 99,99 & 99,99 & 99,98 \\
$5 \mathrm{~cm} \times 2 \mathrm{~cm}$ & 99,97 & 99,97 & 100,0 \\
\hline
\end{tabular}


Tabela 5.14: Eficiência de coleção de íons da câmara de ionização C2 (\%) em todas as qualidades dos feixes padronizados de radiação $X$ para CT no LCI.

Aberturas do colimador: $(0,5 \mathrm{~cm} \times 2 \mathrm{~cm})$ e $(2 \mathrm{~cm} \times 2 \mathrm{~cm})$.

\begin{tabular}{cccc}
\hline Abertura do & \multicolumn{3}{c}{ Qualidade de Radiação } \\
\cline { 2 - 4 } Colimador & RQT 8 & RQT 9 & RQT 10 \\
\hline $0,5 \mathrm{~cm} \times 2 \mathrm{~cm}$ & 99,58 & 99,91 & 99,92 \\
$2 \mathrm{~cm} \times 2 \mathrm{~cm}$ & 99,92 & 99,90 & 99,92 \\
\hline
\end{tabular}

Tabela 5.15: Eficiência de coleção de íons da câmara de ionização C3 (\%) em todas as qualidades dos feixes padronizados de radiação $X$ para CT no LCI. Aberturas do colimador: $(1,5 \mathrm{~cm} \times 2 \mathrm{~cm})$ e $(2 \mathrm{~cm} \times 2 \mathrm{~cm})$.

\begin{tabular}{cccc}
\hline Abertura do & \multicolumn{3}{c}{ Qualidade de Radiação } \\
\cline { 2 - 4 } Colimador & RQT 8 & RQT 9 & RQT 10 \\
\hline $1,5 \mathrm{~cm} \times 2 \mathrm{~cm}$ & 99,68 & 99,90 & 99,85 \\
$2 \mathrm{~cm} \times 2 \mathrm{~cm}$ & 99,88 & 99,92 & 99,75 \\
\hline
\end{tabular}

Tabela 5.16: Eficiência de coleção de íons da câmara de ionização C4 (\%) em todas as qualidades dos feixes padronizados de radiação $X$ para CT no LCI. Aberturas do colimador: $(2 \mathrm{~cm} \times 2 \mathrm{~cm})$ e $(5 \mathrm{~cm} \times 2 \mathrm{~cm})$.

\begin{tabular}{cccc}
\hline Abertura do & \multicolumn{3}{c}{ Qualidade de Radiação } \\
\cline { 2 - 4 } Colimador & RQT 8 & RQT 9 & RQT 10 \\
\hline $2 \mathrm{~cm} \times 2 \mathrm{~cm}$ & 99,02 & 98,81 & 98,33 \\
$5 \mathrm{~cm} \times 2 \mathrm{~cm}$ & 100,0 & 99,97 & 99,99 \\
\hline
\end{tabular}


Tabela 5.17: Eficiência de coleção de íons da câmara de ionização C5 (\%) em todas as qualidades dos feixes padronizados de radiação $X$ para CT no LCl.

Aberturas do colimador: $(2 \mathrm{~cm} \times 2 \mathrm{~cm})$ e $(5 \mathrm{~cm} \times 2 \mathrm{~cm})$.

\begin{tabular}{cccc}
\hline Abertura do & \multicolumn{3}{c}{ Qualidade de Radiação } \\
\cline { 2 - 4 } Colimador & RQT 8 & RQT 9 & RQT 10 \\
\hline $2 \mathrm{~cm} \times 2 \mathrm{~cm}$ & 100,0 & 99,95 & 99,92 \\
$5 \mathrm{~cm} \times 2 \mathrm{~cm}$ & 100,0 & 99,97 & 99,95 \\
\hline
\end{tabular}

Tabela 5.18: Eficiência de coleção de íons da câmara de ionização C7 (\%) em todas as qualidades dos feixes padronizados de radiação $X$ para CT no LCI. Aberturas do colimador: $(2 \mathrm{~cm} \times 2 \mathrm{~cm})$ e $(5 \mathrm{~cm} \times 2 \mathrm{~cm})$.

\begin{tabular}{cccc}
\hline Abertura do & \multicolumn{3}{c}{ Qualidade de Radiação } \\
\cline { 2 - 4 } Colimador & RQT 8 & RQT 9 & RQT 10 \\
\hline $2 \mathrm{~cm} \times 2 \mathrm{~cm}$ & 99,96 & 99,99 & 99,99 \\
$5 \mathrm{~cm} \times 2 \mathrm{~cm}$ & 99,96 & 100,00 & 99,97 \\
\hline
\end{tabular}

Tabela 5.19: Eficiência de coleção de íons (\%) das câmaras de ionização C6 e $\mathrm{C} 7$ em todas as qualidades dos feixes padronizados de radiação $X$ para CT no LCI. Abertura do colimador: $(15 \mathrm{~cm} \times 2 \mathrm{~cm})$.

\begin{tabular}{cccc}
\hline Câmara de & \multicolumn{3}{c}{ Qualidade de Radiação } \\
\cline { 2 - 4 } lonização & RQT 8 & RQT 9 & RQT 10 \\
\hline C6 & 100,0 & 99,98 & 99,99 \\
C7 & 100,0 & 99,98 & 99,99 \\
\hline
\end{tabular}


Como pode ser visto nas Tabelas 5.13 a 5.18, os resultados obtidos para o teste de eficiência de coleção de íons encontram-se dentro dos limites recomendados pela norma IEC 61674 (IEC, 2005). A Tabela 5.19 mostra a resposta idêntica das câmaras para a coleção de íons em cada qualidade de radiação.

\subsubsection{Linearidade da Resposta}

O teste de linearidade da resposta foi realizado para todas as câmaras de ionização deste trabalho e para a qualidade de referência do LCI (RQT 9) para tomografia computadorizada. $O$ procedimento adotado para a realização desse teste foi obter dez medições da corrente de ionização, quando a corrente do tubo de raios $\mathrm{X}$ variou de $2 \mathrm{~mA}$ a $18 \mathrm{~mA}$.

A linearidade da resposta foi obtida para diferentes aberturas do colimador; como já informado, esta abertura corresponde ao campo de irradiação em que as câmaras de ionização foram irradiadas. A Tabela 5.20 mostra as aberturas do colimador que foram utilizadas para cada câmara de ionização. A reta obtida para a linearidade das respostas pode ser vista nas Figuras 5.20 a 5.25. O ajuste linear também foi obtido para a resposta de cada câmara de ionização.

Tabela 5.20: Abertura do colimador utilizada para cada câmara de ionização nos testes de linearidade da resposta.

\begin{tabular}{ccc}
\hline Câmara de lonização & \multicolumn{2}{c}{ Abertura do colimador } \\
\hline C1 & $2 \mathrm{~cm} \times 2 \mathrm{~cm}$ & $5 \mathrm{~cm} \times 2 \mathrm{~cm}$ \\
C2 & $0,5 \mathrm{~cm} \times 2 \mathrm{~cm}$ & $2 \mathrm{~cm} \times 2 \mathrm{~cm}$ \\
C3 & $1,5 \mathrm{~cm} \times 2 \mathrm{~cm}$ & $2 \mathrm{~cm} \times 2 \mathrm{~cm}$ \\
C4 & $2 \mathrm{~cm} \times 2 \mathrm{~cm}$ & $5 \mathrm{~cm} \times 2 \mathrm{~cm}$ \\
C5 & $2 \mathrm{~cm} \times 2 \mathrm{~cm}$ & $5 \mathrm{~cm} \times 2 \mathrm{~cm}$ \\
C7 & $2 \mathrm{~cm} \times 2 \mathrm{~cm}$ & $5 \mathrm{~cm} \times 2 \mathrm{~cm}$
\end{tabular}

Em seguida, será apresentada uma comparação para a resposta das câmaras de ionização $\mathrm{C} 6$ e C7, para a qualidade de referência de CT no LCl (RQT 9). O campo em que ambas as câmaras foram irradiadas foi de $30 \mathrm{~cm}^{2} \mathrm{e}$ o resultado obtido pode ser visto na Figura 5.26. 

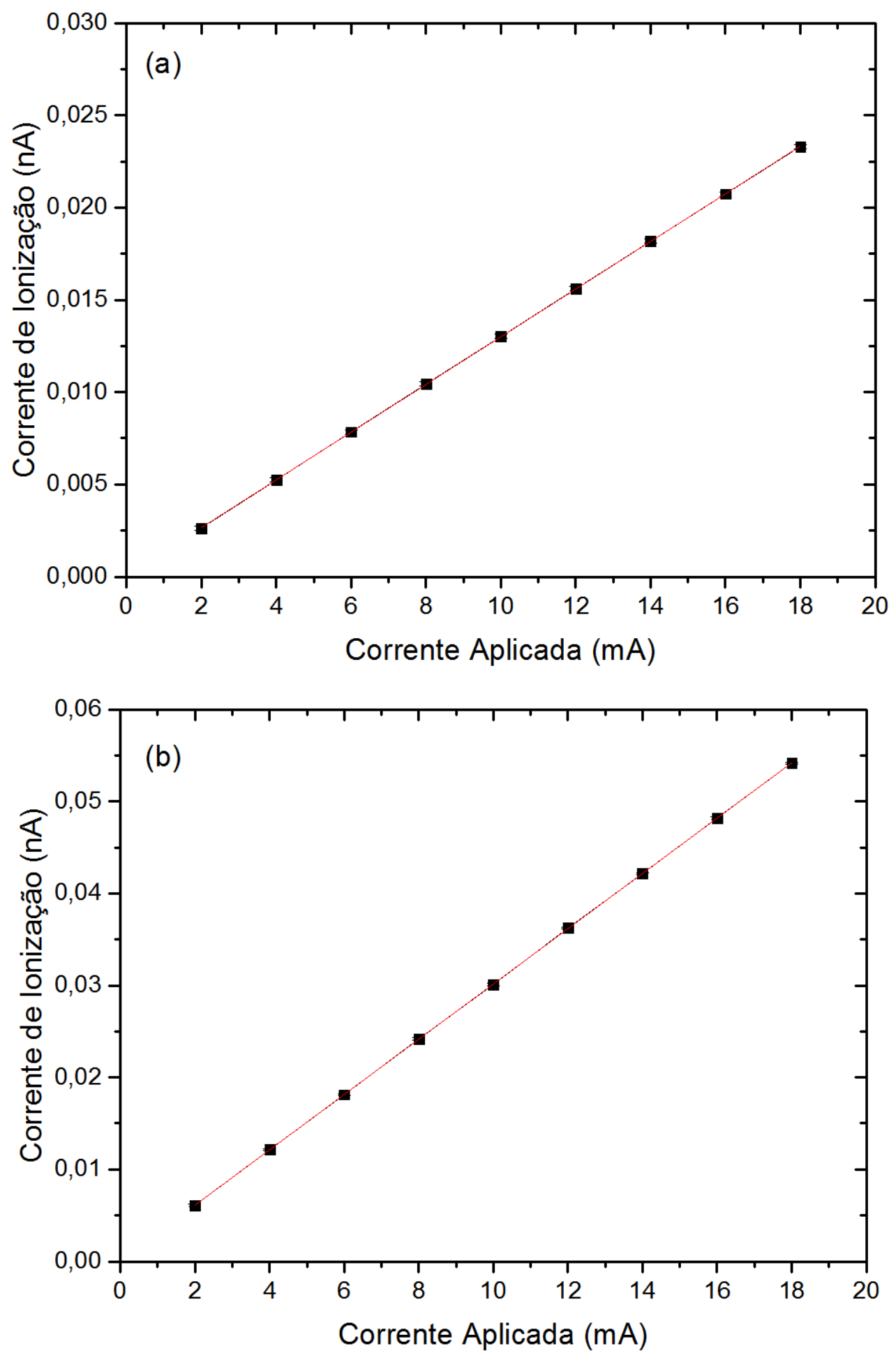

Figura 5.20: Linearidade da resposta da câmara de ionização $C 1$ para a qualidade de referência de CT no LCI (RQT 9). A incerteza máxima das medições das figuras foi de $0,02 \%$, não visível nos gráficos. Aberturas do colimador: (a) $2 \mathrm{~cm} \times 2 \mathrm{~cm} \mathrm{e} \mathrm{(b)} 5 \mathrm{~cm} \times 2 \mathrm{~cm}$. O ajuste de reta obtido foi de

$$
\mathrm{R}^{2}=0,9999 \text {. }
$$



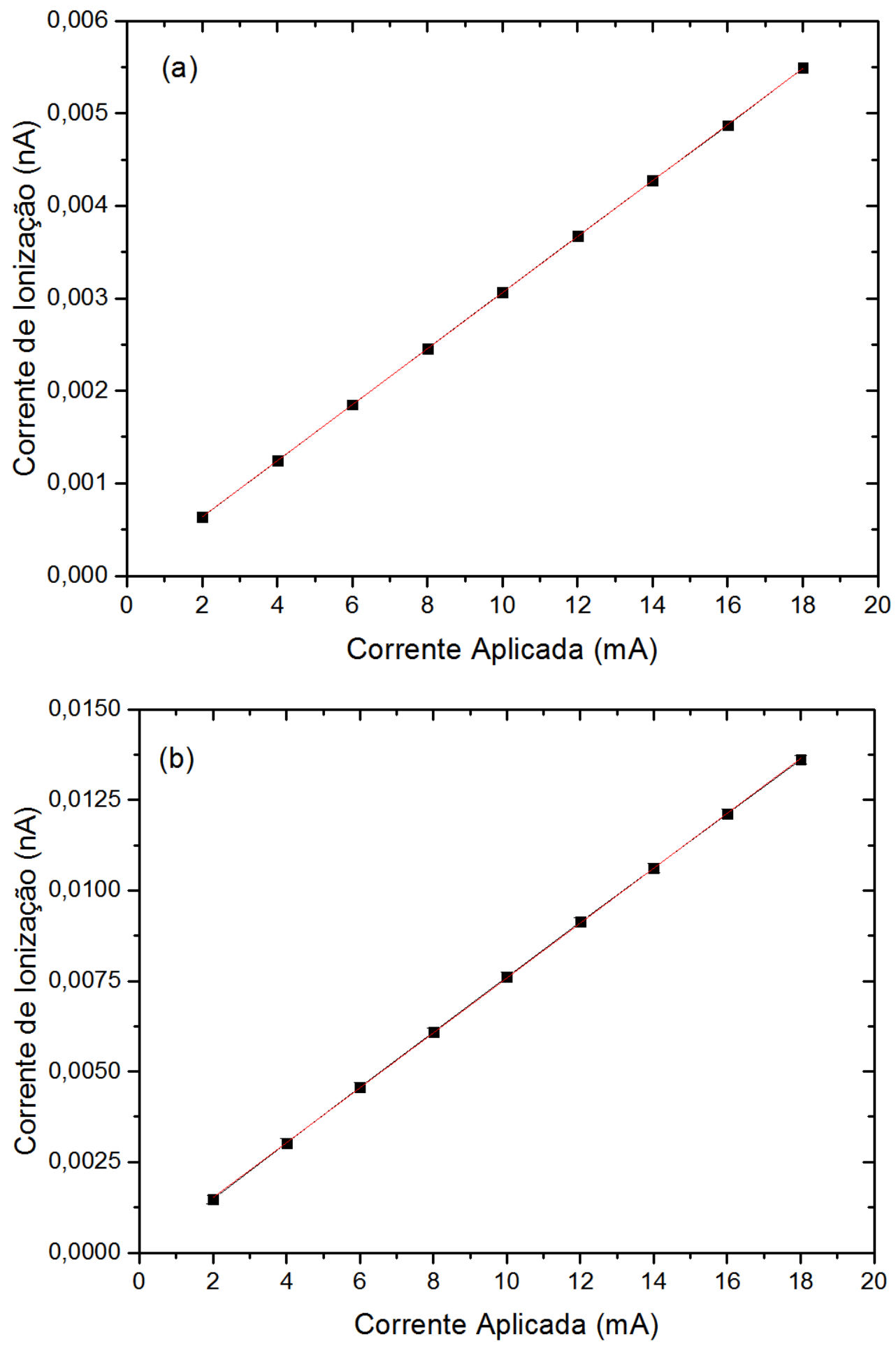

Figura 5.21: Linearidade da resposta da câmara de ionização C2 para a qualidade de referência de CT no LCl (RQT 9). A incerteza máxima das medições das figuras foi de $0,02 \%$, não visível nos gráficos. Aberturas do colimador: (a) $0,5 \mathrm{~cm} \times 2 \mathrm{~cm}$ e (b) $2 \mathrm{~cm} \times 2 \mathrm{~cm}$. O ajuste de reta obtido foi de $R^{2}=0,9999$. 

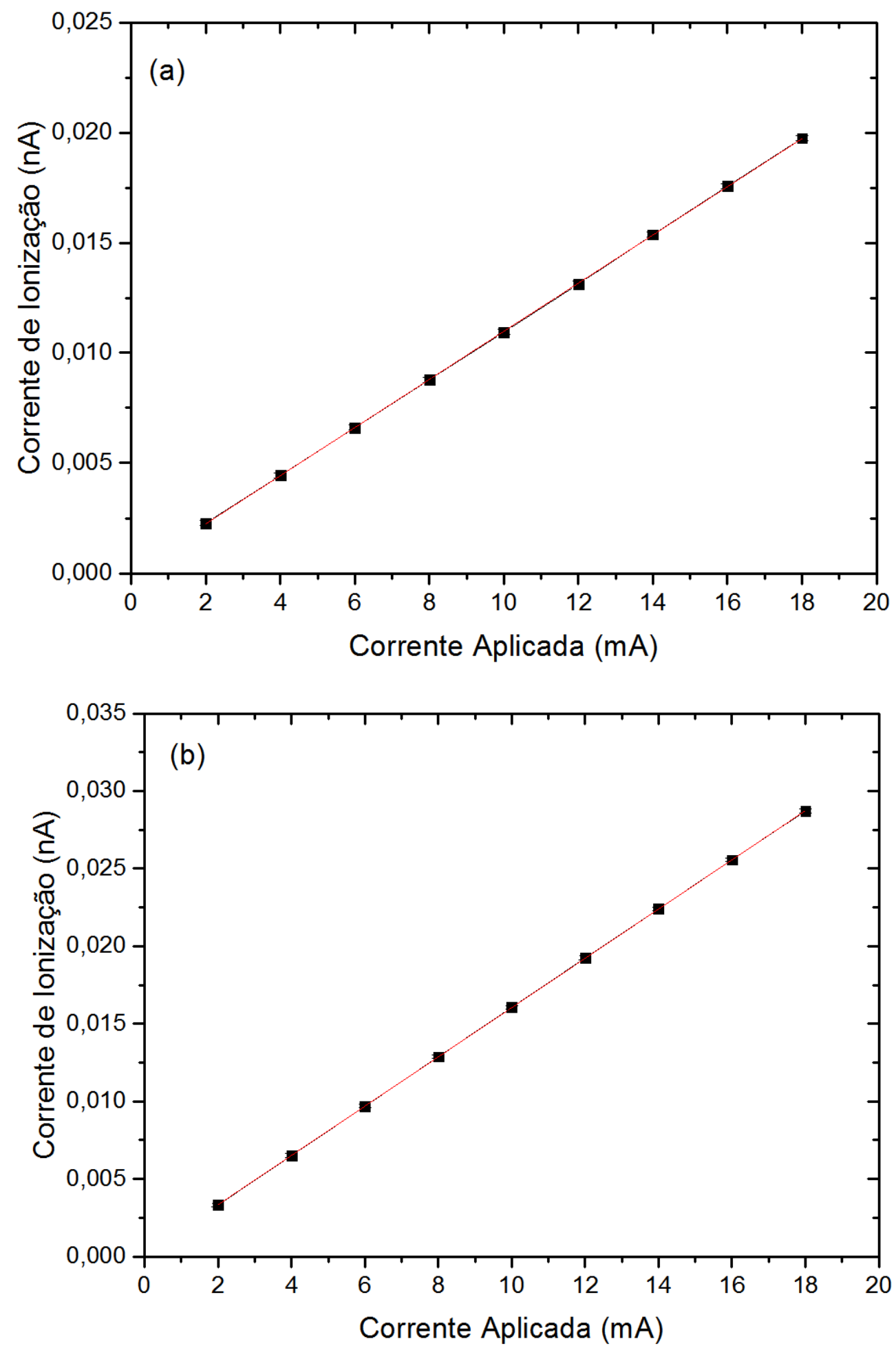

Figura 5.22: Linearidade da resposta da câmara de ionização C3 para a qualidade de referência de CT no LCI (RQT 9). A incerteza máxima das medições das figuras foi de $0,02 \%$, não visível nos gráficos. Aberturas do colimador: (a) $1,5 \mathrm{~cm} \times 2 \mathrm{~cm}$ e (b) $2 \mathrm{~cm} \times 2 \mathrm{~cm}$. Os ajustes de reta obtidos foram de: (a) $R^{2}=0,9999$ e (b) $R^{2}=1,0000$. 

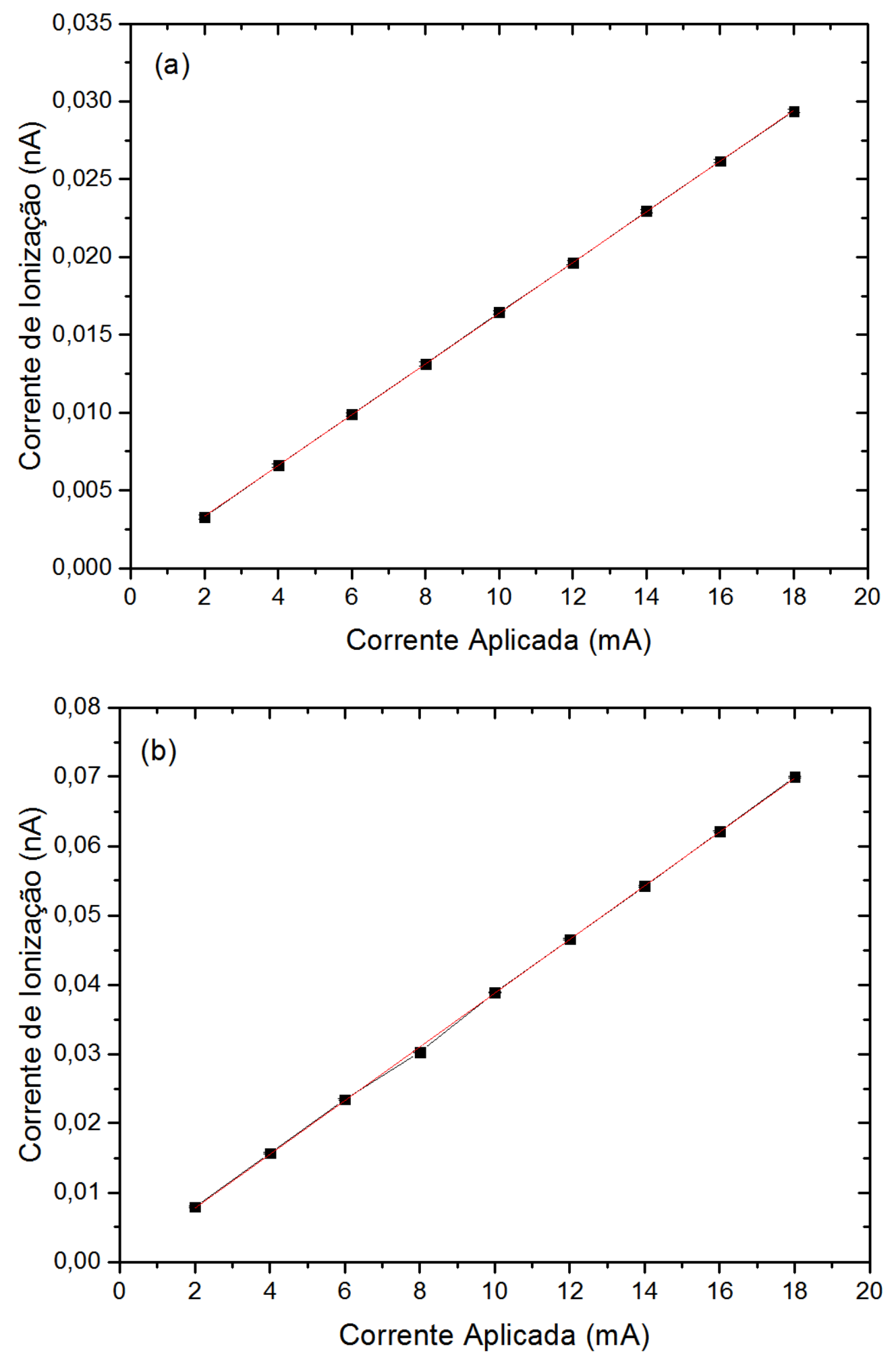

Figura 5.23: Linearidade da resposta da câmara de ionização C4 para a qualidade de referência de CT no LCl (RQT 9). A incerteza máxima das medições das figuras foi de 0,02 \%, não visível nos gráficos. Aberturas do colimador: (a) $2 \mathrm{~cm} \times 2 \mathrm{~cm}$ e (b) $5 \mathrm{~cm} \times 2 \mathrm{~cm}$. Os ajustes de reta obtidos foram de: (a) $R^{2}=0,9999$ e (b) $R^{2}=0,9998$. 

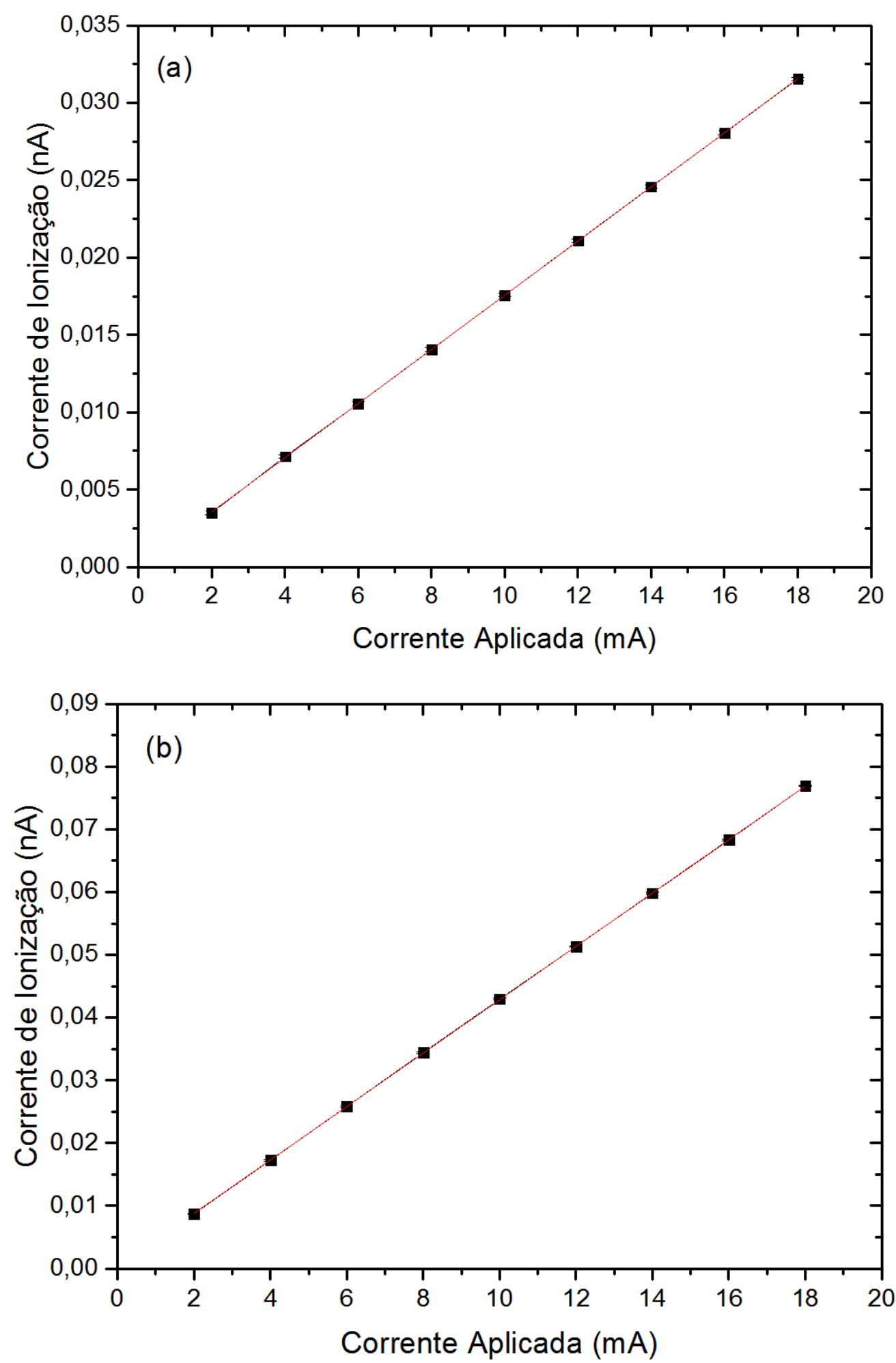

Figura 5.24: Linearidade da resposta da câmara de ionização C5 para a qualidade de referência de CT no LCl (RQT 9). A incerteza máxima das medições das figuras foi de $0,02 \%$, não visível nos gráficos. Aberturas do colimador: (a) $2 \mathrm{~cm} \times 2 \mathrm{~cm}$ e (b) $5 \mathrm{~cm} \times 2 \mathrm{~cm}$. Os ajustes de reta obtidos foram de: (a) $R^{2}=0,9999$ e (b) $R^{2}=0,9999$. 

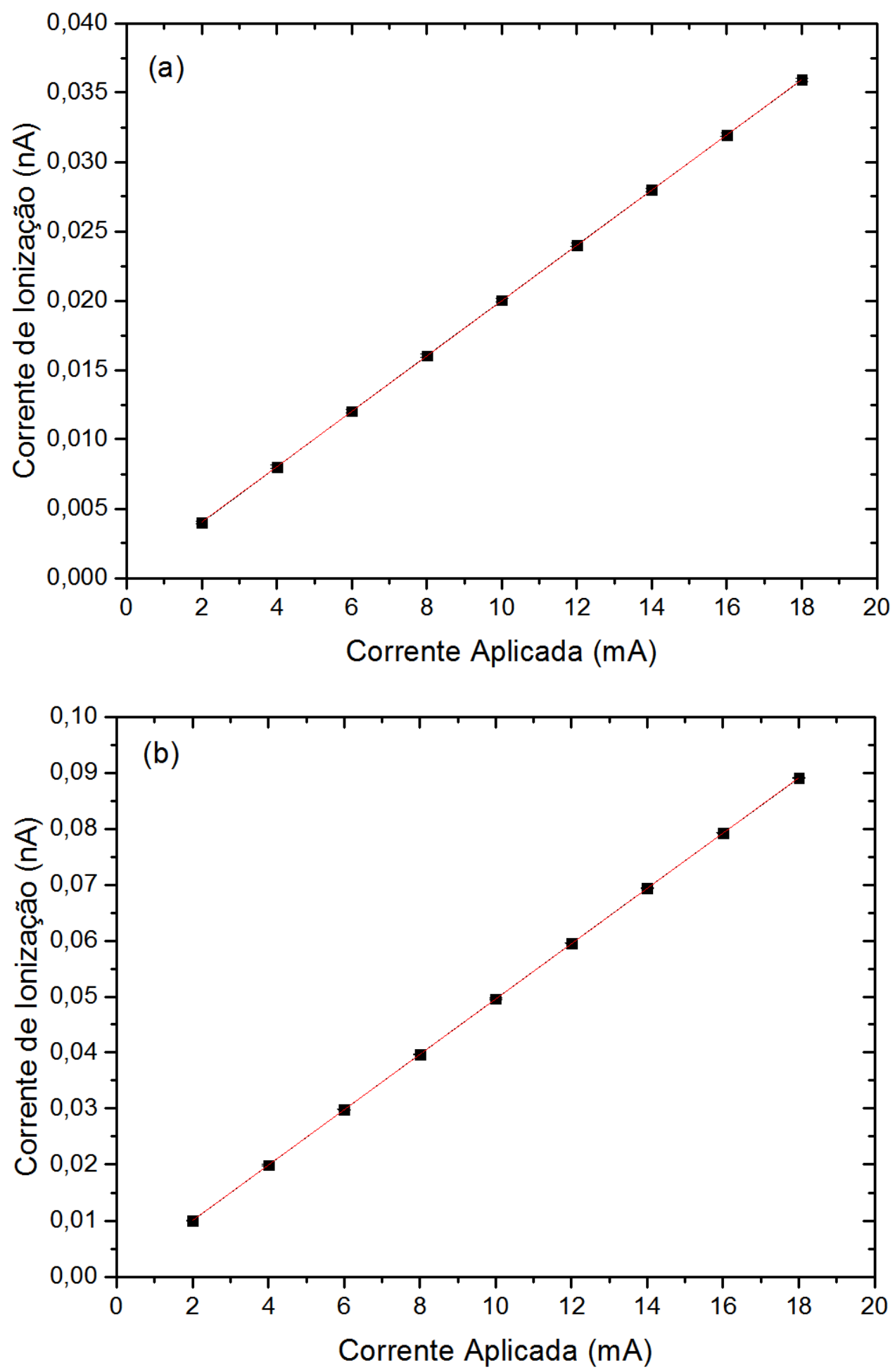

Figura 5.25: Linearidade da resposta da câmara de ionização $C 7$ para a qualidade de referência de CT no LCl (RQT 9). A incerteza máxima das medições das figuras foi de $0,02 \%$, não visível nos gráficos. Aberturas do colimador: (a) $2 \mathrm{~cm} \times 2 \mathrm{~cm}$ e (b) $5 \mathrm{~cm} \times 2 \mathrm{~cm}$. Os ajustes de reta obtidos foram de: (a) $R^{2}=0,9999$ e (b) $R^{2}=1,0000$. 

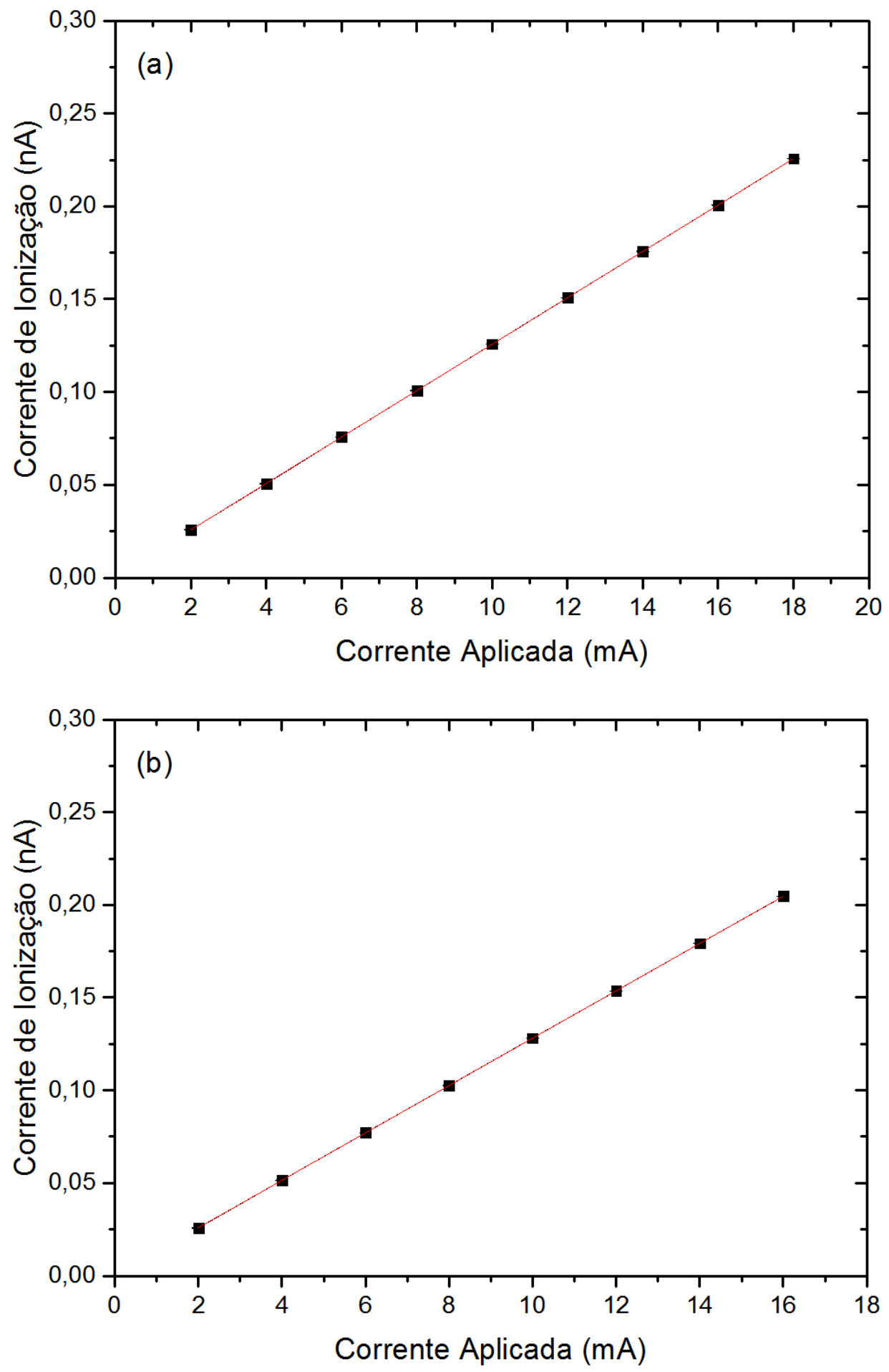

Figura 5.26: Linearidade da resposta para a qualidade RQT 9, com a abertura do colimador de $(15 \mathrm{~cm} \times 2 \mathrm{~cm})$. A incerteza máxima das medições foi de 0,01 \%, não visível nos gráficos, para as câmaras de ionização: (a) C6 e

(b) $C 7$. $O$ ajuste de reta obtido foi de $R^{2}=1,0000$ para os dois casos. 
Pelas curvas de linearidade obtidas, foi possível observar o comportamento individual para cada câmara utilizada neste trabalho em diferentes campos de radiação. Todas as câmaras apresentaram respostas lineares, ou seja, o ajuste de reta para cada curva foi de aproximadamente $R=1,000$, exceto para a câmara $C 4$ com um campo de radiação de $10 \mathrm{~cm}^{2}$, onde é possível observar um maior desvio da linearidade.

A comparação entre as câmaras de ionização C6 e C7, apresentada na Figura 6.26, mostra que estas câmaras de ionização têm respostas semelhantes; isso se deve ao fato das configurações do desenvolvimento e de construção terem sido iguais. Portanto, a metodologia e os materiais que foram utilizados para a construção proporcionaram uma reprodutibilidade.

\subsubsection{Dependência Energética}

O teste de dependência energética analisa a energia efetiva do feixe de raios $X$. Este teste foi realizado para todas as câmaras, para as três qualidades de radiação de tomografia computadorizada e para diferentes aberturas do colimador. A Tabela 5.21 mostra as aberturas do colimador utilizadas para cada câmara de ionização.

Tabela 5.21: Abertura do colimador utilizada para cada câmara de ionização nos testes de dependência energética.

\begin{tabular}{ccc}
\hline Câmara de lonização & \multicolumn{2}{c}{ Abertura do colimador } \\
\hline C1 & $2 \mathrm{~cm} \times 2 \mathrm{~cm}$ & $5 \mathrm{~cm} \times 2 \mathrm{~cm}$ \\
C2 & $0,5 \mathrm{~cm} \times 2 \mathrm{~cm}$ & $2 \mathrm{~cm} \times 2 \mathrm{~cm}$ \\
C3 & $1,5 \mathrm{~cm} \times 2 \mathrm{~cm}$ & $2 \mathrm{~cm} \times 2 \mathrm{~cm}$ \\
C4 & $2 \mathrm{~cm} \times 2 \mathrm{~cm}$ & $5 \mathrm{~cm} \times 2 \mathrm{~cm}$ \\
C5 & $2 \mathrm{~cm} \times 2 \mathrm{~cm}$ & $5 \mathrm{~cm} \times 2 \mathrm{~cm}$ \\
C7 & $2 \mathrm{~cm} \times 2 \mathrm{~cm}$ & $5 \mathrm{~cm} \times 2 \mathrm{~cm}$ \\
\hline
\end{tabular}

Em seguida, será apresentada uma comparação para a resposta das câmaras de ionização $\mathrm{C} 6$ e C7, para todas as qualidades de radiação de CT no LCI. O campo em que as câmaras foram irradiadas foi de $30 \mathrm{~cm}^{2}$. 
O procedimento utilizado para a calibração das câmaras foi o de substituição, fazendo-se uso da câmara de ionização padrão tipo lápis do laboratório (Radcal, RC3CT). Foram tomadas dez medições de carga elétrica para cada câmara, para cada uma das qualidades de radiação, e foram obtidos os valores de taxa de kerma no ar, para se obter finalmente os coeficientes de calibração. Os fatores de correção para cada caso foram obtidos normalizandose os coeficientes de calibração para a qualidade de referência RQT 9, para uma melhor visualização da dependência energética da resposta de cada câmara de ionização. Os resultados são apresentados nas Tabelas 5.22 a 5.27 .

Tabela 5.22: Coeficientes de calibração e fatores de correção para a câmara de ionização $\mathrm{C} 1$ nas qualidades de radiação de $\mathrm{CT}$. Aberturas do colimador:

$(2 \mathrm{~cm} \times 2 \mathrm{~cm})$ e $(5 \mathrm{~cm} \times 2 \mathrm{~cm})$.

\begin{tabular}{ccc}
\hline $\begin{array}{c}\text { Qualidade } \\
\text { de Radiação }\end{array}$ & $\begin{array}{c}\text { Coeficiente de Calibração } \\
\text { (mGy/pC) }\end{array}$ & $\begin{array}{c}\text { Fator de } \\
\text { Correção }\end{array}$ \\
\hline & Abertura do Colimador: $\mathbf{2 ~ c m ~ x ~ 2 ~ c m ~}$ \\
\hline RQT 8 & $0,0456 \pm 0,0001$ & $1,0430 \pm 0,0007$ \\
RQT 9 & $0,0437 \pm 0,0001$ & $1,0000 \pm 0,0001$ \\
RQT 10 & $0,0433 \pm 0,0001$ & $0,9929 \pm 0,0007$ \\
\hline \multicolumn{3}{c}{ Abertura do Colimador: $\mathbf{5 ~ c m ~ \times ~ 2 ~ c m ~}$} \\
\hline RQT8 & $0,0177 \pm 0,0001$ & $0,9757 \pm 0,0009$ \\
RQT 9 & $0,0181 \pm 0,0001$ & $1,0000 \pm 0,0001$ \\
RQT 10 & $0,0175 \pm 0,0001$ & $0,9641 \pm 0,0001$ \\
\hline
\end{tabular}


Tabela 5.23: Coeficientes de calibração e fatores de correção para a câmara de ionização $\mathrm{C} 2$ nas qualidades de radiação de $\mathrm{CT}$. Aberturas do colimador:

$(0,5 \mathrm{~cm} \times 2 \mathrm{~cm})$ e $(2 \mathrm{~cm} \times 2 \mathrm{~cm})$.

\begin{tabular}{ccc}
\hline $\begin{array}{c}\text { Qualidade } \\
\text { de Radiação }\end{array}$ & $\begin{array}{c}\text { Coeficiente de Calibração } \\
\text { (mGy/pC) }\end{array}$ & $\begin{array}{c}\text { Fator de } \\
\text { Correção }\end{array}$ \\
\hline \multicolumn{4}{c}{ Abertura do Colimador: $\mathbf{0 , 5} \mathbf{~ c m ~ \times ~ 2 ~ c m ~}$} \\
\hline RQT 8 & $0,1854 \pm 0,0001$ & $1,0030 \pm 0,0009$ \\
RQT 9 & $0,1849 \pm 0,0001$ & $1,0000 \pm 0,0001$ \\
RQT 10 & $0,1881 \pm 0,0001$ & $1,0170 \pm 0,0006$ \\
\hline \multicolumn{4}{r}{ Abertura do Colimador: $\mathbf{2 ~ c m ~ \times ~ 2 ~ c m ~}$} \\
\hline RQT8 & $0,0708 \pm 0,0001$ & $0,9758 \pm 0,0009$ \\
RQT 9 & $0,0726 \pm 0,0001$ & $1,0000 \pm 0,0001$ \\
RQT 10 & $0,0744 \pm 0,0001$ & $1,0250 \pm 0,0006$ \\
\hline
\end{tabular}

Tabela 5.24: Coeficientes de calibração e fatores de correção para a câmara de ionização C3 nas qualidades de radiação de CT. Aberturas do colimador: $(1,5 \mathrm{~cm} \times 2 \mathrm{~cm})$ e $(2 \mathrm{~cm} \times 2 \mathrm{~cm})$.

\begin{tabular}{ccc}
\hline $\begin{array}{c}\text { Qualidade } \\
\text { de Radiação }\end{array}$ & $\begin{array}{c}\text { Coeficiente de Calibração } \\
(\mathbf{m G y} / \mathbf{p C})\end{array}$ & $\begin{array}{c}\text { Fator de } \\
\text { Correção }\end{array}$ \\
\hline \multicolumn{3}{c}{ Abertura do Colimador: 1,5 cm x 2 cm } \\
\hline RQT 8 & $0,0523 \pm 0,0001$ & $1,0100 \pm 0,0007$ \\
RQT 9 & $0,0518 \pm 0,0001$ & $1,0000 \pm 0,0001$ \\
RQT 10 & $0,0508 \pm 0,0001$ & $0,9821 \pm 0,0007$ \\
\hline \multicolumn{4}{r}{ Abertura do Colimador: $\mathbf{2 ~ c m ~ \times ~ 2 ~ c m ~}$} \\
\hline RQT8 & $0,0336 \pm 0,0001$ & $0,9697 \pm 0,0006$ \\
RQT 9 & $0,0346 \pm 0,0001$ & $1,0000 \pm 0,0001$ \\
RQT 10 & $0,0353 \pm 0,0001$ & $1,0190 \pm 0,0006$ \\
\hline
\end{tabular}


Tabela 5.25: Coeficientes de calibração e fatores de correção para a câmara de ionização $\mathrm{C} 4$ nas qualidades de radiação de $\mathrm{CT}$. Aberturas do colimador:

$(2 \mathrm{~cm} \times 2 \mathrm{~cm})$ e $(5 \mathrm{~cm} \times 2 \mathrm{~cm})$.

\begin{tabular}{ccc}
\hline $\begin{array}{c}\text { Qualidade } \\
\text { de Radiação }\end{array}$ & $\begin{array}{c}\text { Coeficiente de Calibração } \\
\text { (mGy/pC) }\end{array}$ & $\begin{array}{c}\text { Fator de } \\
\text { Correção }\end{array}$ \\
\hline \multicolumn{3}{c}{ Abertura do Colimador: $\mathbf{2} \mathbf{~ c m ~ \times ~ 2 ~ c m ~}$} \\
\hline RQT 8 & $0,0337 \pm 0,0001$ & $0,9908 \pm 0,0007$ \\
RQT 9 & $0,0340 \pm 0,0001$ & $1,0000 \pm 0,0001$ \\
RQT 10 & $0,0333 \pm 0,0001$ & $0,9800 \pm 0,0007$ \\
\hline \multicolumn{4}{r}{ Abertura do Colimador: $\mathbf{5} \mathbf{~ c m ~ \times ~ 2 ~ c m ~}$} \\
\hline RQT8 & $0,0132 \pm 0,0001$ & $0,9662 \pm 0,0007$ \\
RQT 9 & $0,0137 \pm 0,0001$ & $1,0000 \pm 0,0001$ \\
RQT 10 & $0,0131 \pm 0,0001$ & $0,9544 \pm 0,0007$ \\
\hline
\end{tabular}

Tabela 5.26: Coeficientes de calibração e fatores de correção para a câmara de ionização C5 nas qualidades de radiação de CT. Aberturas do colimador:

$(2 \mathrm{~cm} \times 2 \mathrm{~cm})$ e $(5 \mathrm{~cm} \times 2 \mathrm{~cm})$.

\begin{tabular}{ccc}
\hline $\begin{array}{c}\text { Qualidade } \\
\text { de Radiação }\end{array}$ & $\begin{array}{c}\text { Coeficiente de Calibração } \\
\text { (mGy/pC) }\end{array}$ & $\begin{array}{c}\text { Fator de } \\
\text { Correção }\end{array}$ \\
\hline \multicolumn{3}{c}{ Abertura do Colimador: $\mathbf{2 ~ c m ~ x ~ 2 ~ c m ~}$} \\
\hline RQT 8 & $0,0318 \pm 0,0001$ & $0,9882 \pm 0,0006$ \\
RQT 9 & $0,0322 \pm 0,0001$ & $1,0000 \pm 0,0001$ \\
RQT 10 & $0,0336 \pm 0,0001$ & $1,0450 \pm 0,0006$ \\
\hline \multicolumn{4}{r}{ Abertura do Colimador: $\mathbf{5 ~ c m ~ \times ~ 2 ~ c m ~}$} \\
\hline RQT8 & $0,0129 \pm 0,0001$ & $0,9880 \pm 0,0006$ \\
RQT 9 & $0,0131 \pm 0,0001$ & $1,0000 \pm 0,0001$ \\
RQT 10 & $0,0132 \pm 0,0001$ & $1,0130 \pm 0,0006$ \\
\hline
\end{tabular}


Tabela 5.27: Coeficientes de calibração e fatores de correção para a câmara de ionização $\mathrm{C} 7$ nas qualidades de radiação de CT. Aberturas do colimador $(2 \mathrm{~cm} \times 2 \mathrm{~cm})$ e $(5 \mathrm{~cm} \times 2 \mathrm{~cm})$.

\begin{tabular}{ccc}
\hline $\begin{array}{c}\text { Qualidade } \\
\text { de Radiação }\end{array}$ & $\begin{array}{c}\text { Coeficiente de Calibração } \\
(\mathbf{m G y} / \mathbf{p C})\end{array}$ & $\begin{array}{c}\text { Fator de } \\
\text { Correção }\end{array}$ \\
\hline \multicolumn{3}{c}{ Abertura do Colimador: $\mathbf{2 ~ c m ~ \times ~ 2 ~ c m ~}$} \\
\hline RQT 8 & $0,0270 \pm 0,0001$ & $0,9547 \pm 0,0009$ \\
RQT 9 & $0,0283 \pm 0,0001$ & $1,0000 \pm 0,0001$ \\
RQT 10 & $0,0291 \pm 0,0001$ & $1,0280 \pm 0,0006$ \\
\hline \multicolumn{4}{c}{ Abertura do Colimador: $\mathbf{5 ~ c m ~ \times ~ 2 ~ c m ~}$} \\
\hline RQT8 & $0,0109 \pm 0,0001$ & $0,9505 \pm 0,0009$ \\
RQT 9 & $0,0114 \pm 0,0001$ & $1,0000 \pm 0,0001$ \\
RQT 10 & $0,0120 \pm 0,0001$ & $1,0480 \pm 0,0006$
\end{tabular}

Tabela 5.28: Coeficientes de calibração e fatores de correção nas qualidades de radiação de CT. Abertura do colimador: $15 \mathrm{~cm} \times 2 \mathrm{~cm}$. Para as câmaras de ionização: (a) C6 e (b) C7.

\begin{tabular}{ccc}
\hline $\begin{array}{c}\text { Qualidade } \\
\text { de Radiação }\end{array}$ & $\begin{array}{c}\text { Coeficiente de } \\
\text { Calibração }(\mathbf{m G y} / \mathbf{p C})\end{array}$ & $\begin{array}{c}\text { Fator de } \\
\text { Correção }\end{array}$ \\
\hline \multicolumn{3}{c}{ C6 } \\
\hline RQT 8 & $0,0043 \pm 0,0001$ \\
RQT 9 & $0,0045 \pm 0,0001$ & $0,9524 \pm 0,0009$ \\
RQT 10 & $0,0047 \pm 0,0001$ & $1,0000 \pm 0,0001$ \\
\multicolumn{3}{c}{ C7 } \\
RQT8 & $0,0042 \pm 0,0001$ \\
RQT 9 & $0,0044 \pm 0,0001$ & 0,00006 \\
RQT 10 & $0,0046 \pm 0,0001$ & $1,0000 \pm 0,0000010 \pm 0,0006$ \\
\hline
\end{tabular}


A variação da dependência energética não deve exceder $O$ limite estabelecido de $\pm 5 \%$ em relação à qualidade de referência (IEC, 2005). A maior dependência energética para as seis câmaras de ionização utilizadas nesse trabalho foi de $5 \%$ e todas se encontram dentro dos limites estabelecidos pela norma IEC 61674 .

\subsubsection{Dependência Angular}

O teste de dependência angular foi realizado para todas as câmaras de ionização, utilizando a qualidade de radiação RQT 9, aplicando-se um movimento de rotação em torno do próprio eixo de cada câmara de $-180^{\circ}$ a $+180^{\circ}$, com passo de $30^{\circ}$. Foram realizadas dez medições de 30 s para cada ângulo de incidência de radiação. $O$ campo de radiação em que as câmaras de ionização foram expostas é apresentado na Tabela 5.29, para cada câmara de ionização utilizada. Os resultados obtidos para resposta normalizada versus ângulo podem ser vistos nas Figuras 5.27 a 5.32. A resposta de cada câmara de ionização foi normalizada em relação à posição de $0^{\circ}$. Segundo as recomendações internacionais, a dependência angular não deve exceder 0 limite de $3 \%$ (IEC, 2005).

Tabela 5.29: Abertura do colimador utilizado para cada câmara de ionização nos testes de dependência angular.

\begin{tabular}{ccc}
\hline Câmara de lonização & \multicolumn{2}{c}{ Abertura do colimador } \\
\hline C1 & $2 \mathrm{~cm} \times 2 \mathrm{~cm}$ & $5 \mathrm{~cm} \times 2 \mathrm{~cm}$ \\
C2 & $0,5 \mathrm{~cm} \times 2 \mathrm{~cm}$ & $2 \mathrm{~cm} \times 2 \mathrm{~cm}$ \\
C3 & $1,5 \mathrm{~cm} \times 2 \mathrm{~cm}$ & $2 \mathrm{~cm} \times 2 \mathrm{~cm}$ \\
C4 & $2 \mathrm{~cm} \times 2 \mathrm{~cm}$ & $5 \mathrm{~cm} \times 2 \mathrm{~cm}$ \\
C5 & $2 \mathrm{~cm} \times 2 \mathrm{~cm}$ & $5 \mathrm{~cm} \times 2 \mathrm{~cm}$ \\
C7 & $2 \mathrm{~cm} \times 2 \mathrm{~cm}$ & $5 \mathrm{~cm} \times 2 \mathrm{~cm}$ \\
\hline
\end{tabular}

Em seguida, será apresentada uma comparação entre as respostas das câmaras de ionização $\mathrm{C} 6$ e C7, para a qualidade de referência de CT no $\mathrm{LCl}$ (RQT 9). O campo em que as câmaras foram expostas foi de $30 \mathrm{~cm}^{2}$, e o resultado obtido pode ser visto na Figura 5.33. 

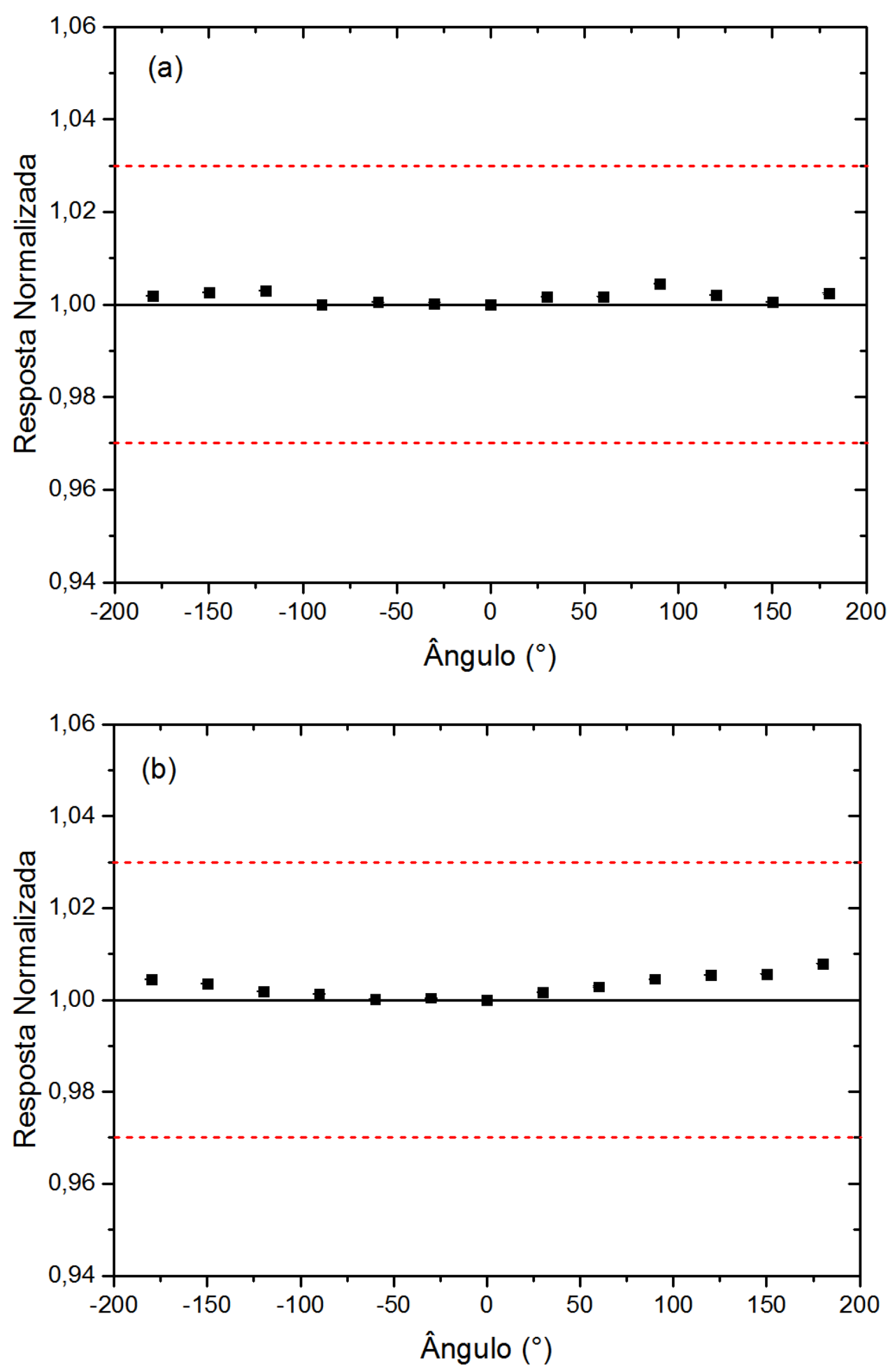

Figura 5.27: Dependência angular, para a qualidade de referência (RQT 9) dos feixes padronizados de radiação X para CT no LCl e para a câmara de ionização $C 1$. A incerteza máxima das medições foi de $0,01 \%$, não visível nos gráficos. Aberturas do colimador: (a) $2 \mathrm{~cm} \times 2 \mathrm{~cm} \mathrm{e} \mathrm{(b)} 5 \mathrm{~cm} \times 2 \mathrm{~cm}$. 

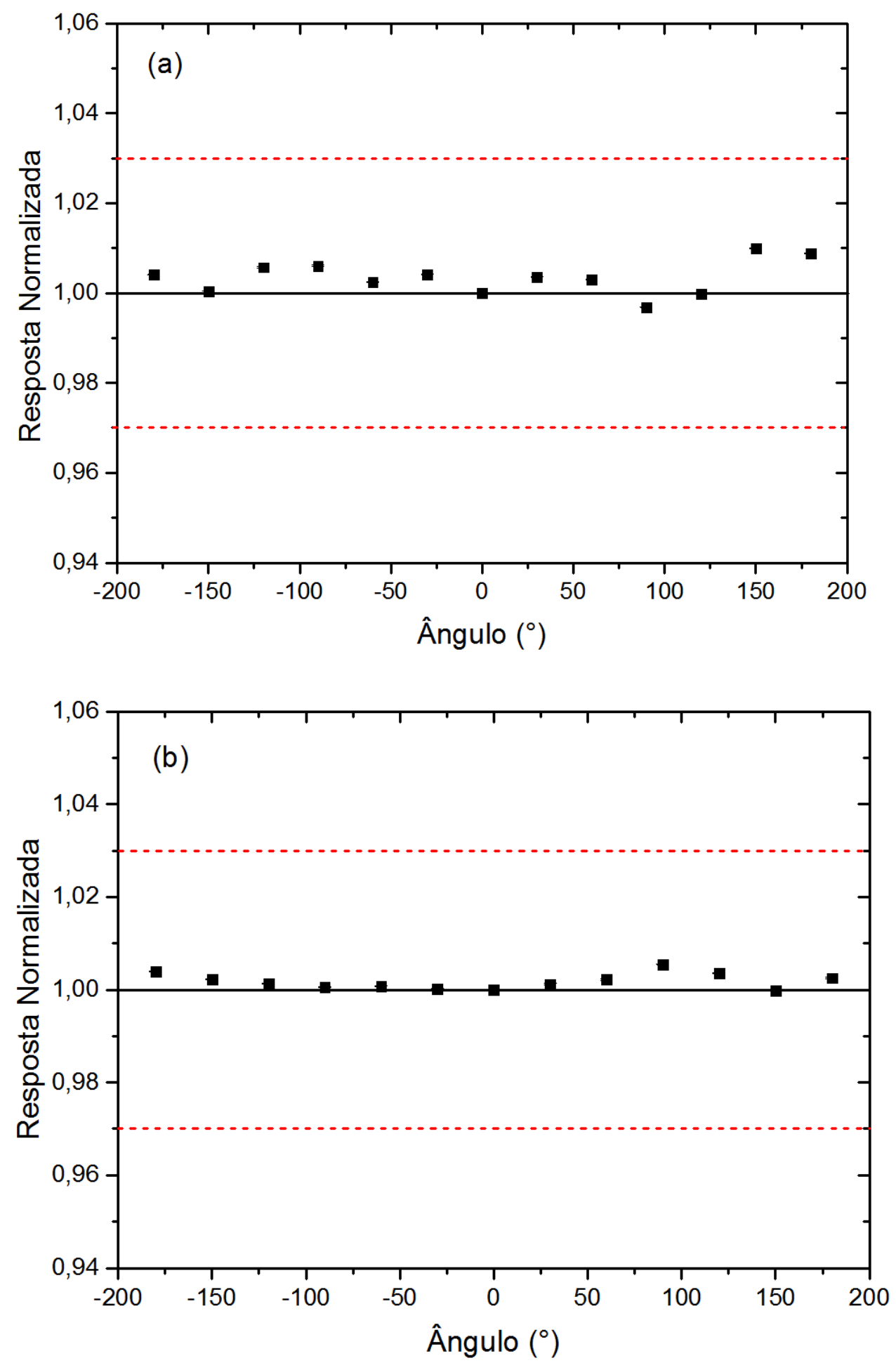

Figura 5.28: Dependência angular, para a qualidade de referência (RQT 9) dos feixes padronizados de radiação X para CT no LCl e para a câmara de ionização C2. A incerteza máxima das medições foi de $0,01 \%$, não visível nos gráficos. Aberturas do colimador: (a) $0,5 \mathrm{~cm} \times 2 \mathrm{~cm}$ e (b) $2 \mathrm{~cm} \times 2 \mathrm{~cm}$. 

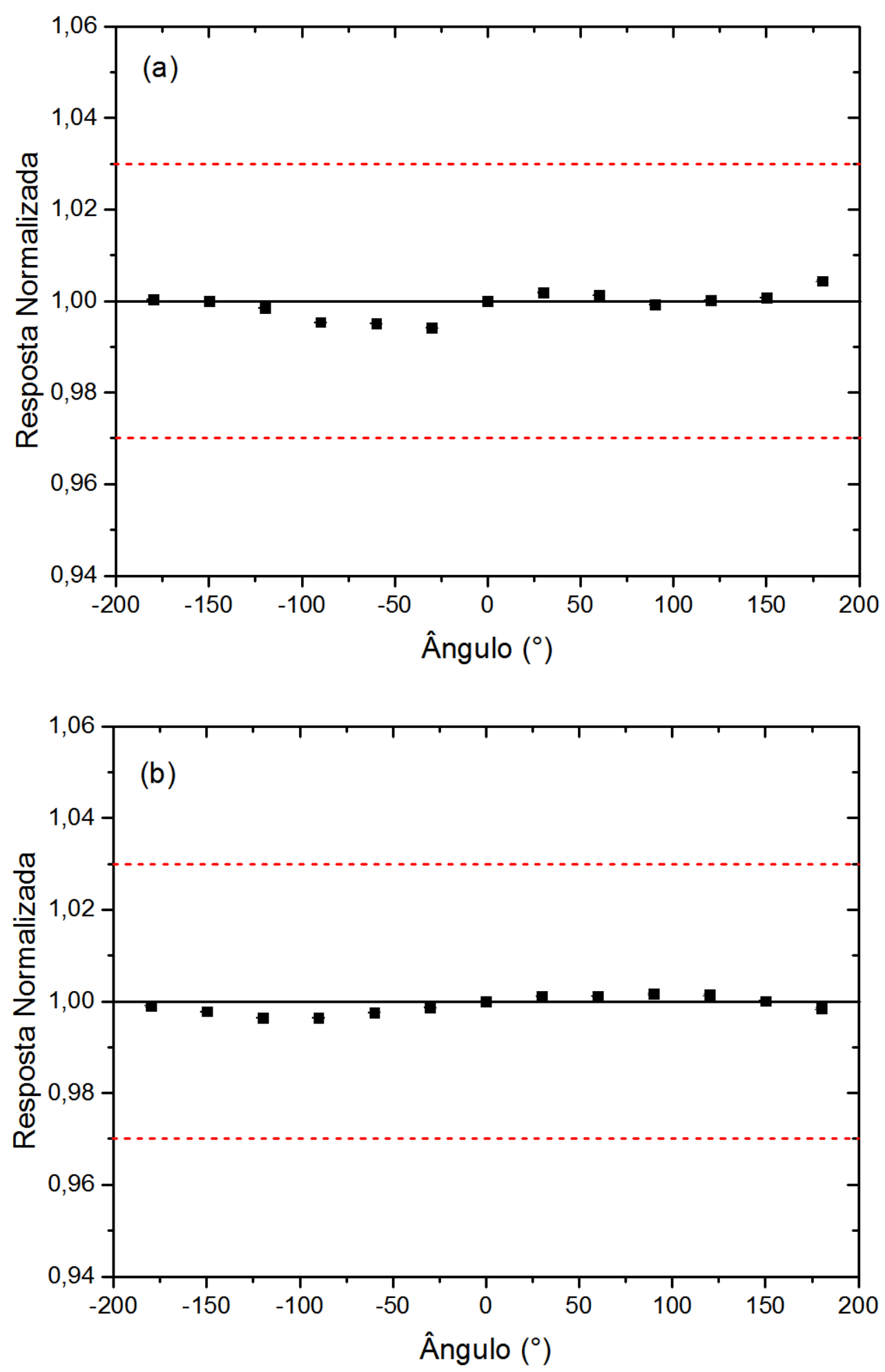

Figura 5.29: Dependência angular, para a qualidade de referência (RQT 9) dos feixes padronizados de radiação X para CT no $\mathrm{LCl}$ e para a câmara de ionização C3. A incerteza máxima das medições foi de $0,01 \%$, não visível nos gráficos. Aberturas do colimador: (a) $1,5 \mathrm{~cm} \times 2 \mathrm{~cm}$ e (b) $2 \mathrm{~cm} \times 2 \mathrm{~cm}$. 

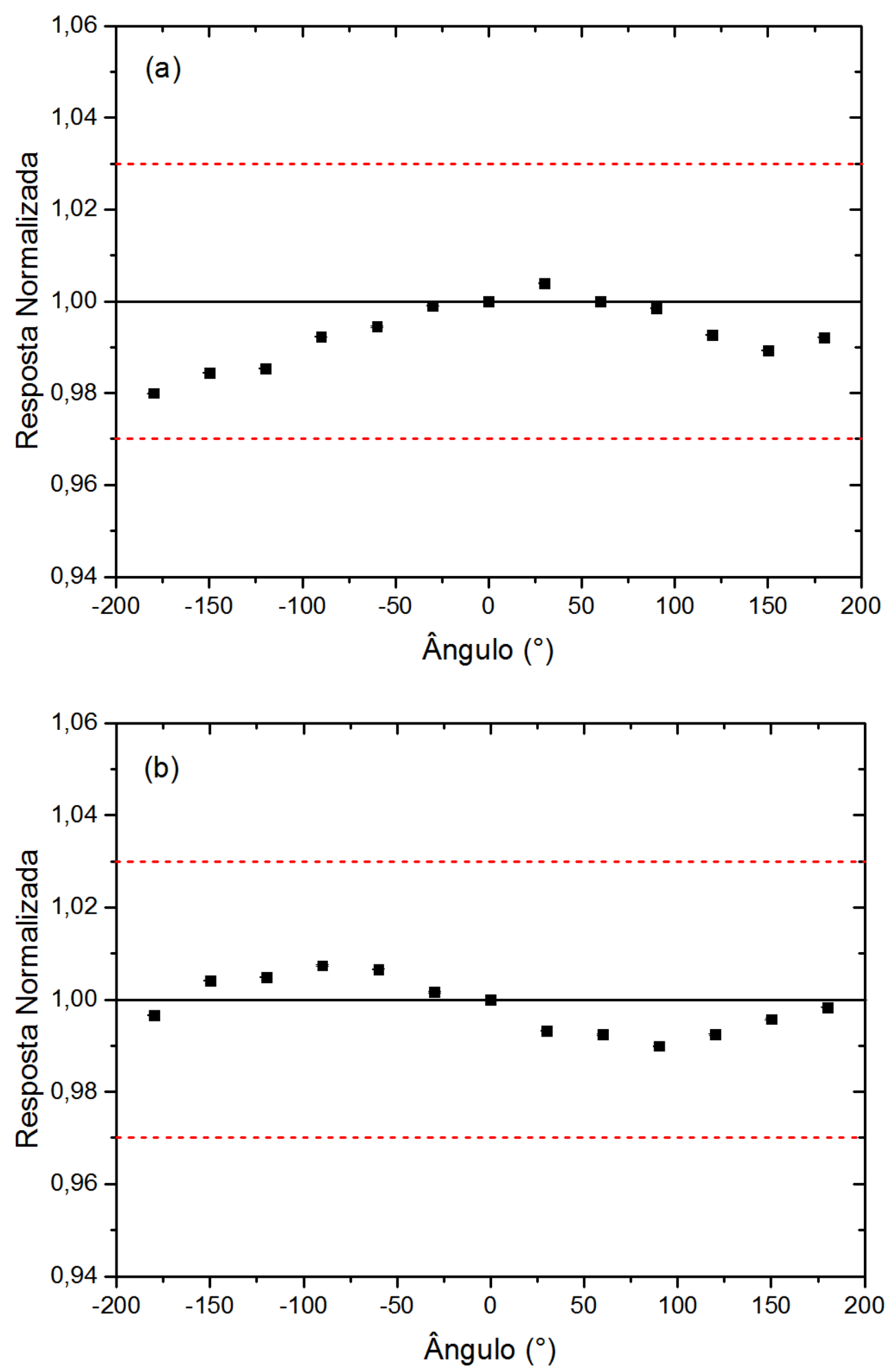

Figura 5.30: Dependência angular, para a qualidade de referência (RQT 9) dos feixes padronizados de radiação $X$ para CT no $\mathrm{LCl}$ e para a câmara de ionização C4. A incerteza máxima das medições foi de 0,01 \%, não visível nos gráficos. Aberturas do colimador: (a) $2 \mathrm{~cm} \times 2 \mathrm{~cm} \mathrm{e} \mathrm{(b)} 5 \mathrm{~cm} \times 2 \mathrm{~cm}$. 

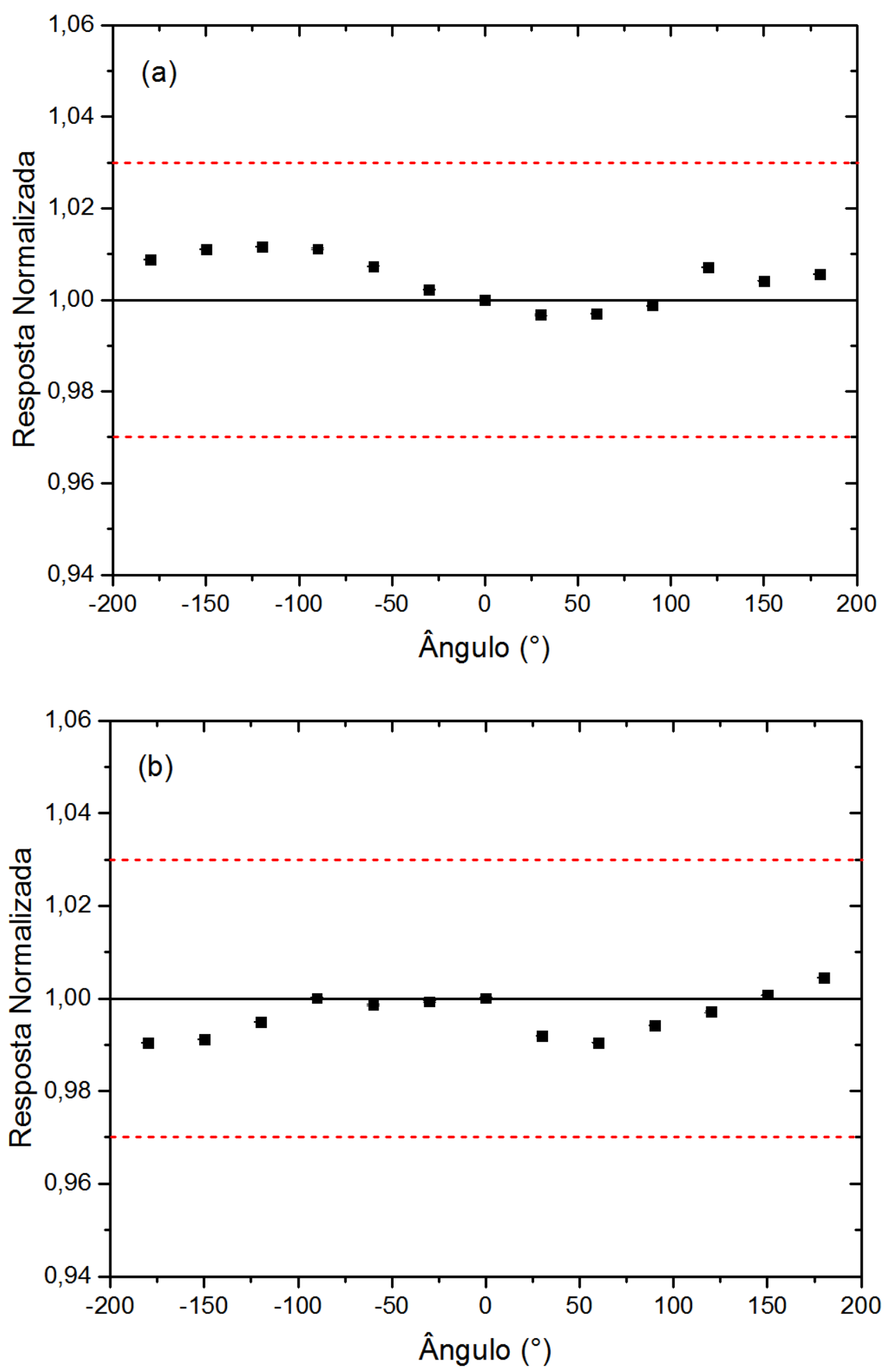

Figura 5.31: Dependência angular, para a qualidade de referência (RQT 9) dos feixes padronizados de radiação $\mathrm{X}$ para $\mathrm{CT}$ no $\mathrm{LCl}$ e para a câmara de ionização C5. A incerteza máxima das medições foi de 0,01 \%, não visível nos gráficos. Aberturas do colimador: (a) $2 \mathrm{~cm} \times 2 \mathrm{~cm}$ e (b) $5 \mathrm{~cm} \times 2 \mathrm{~cm}$. 

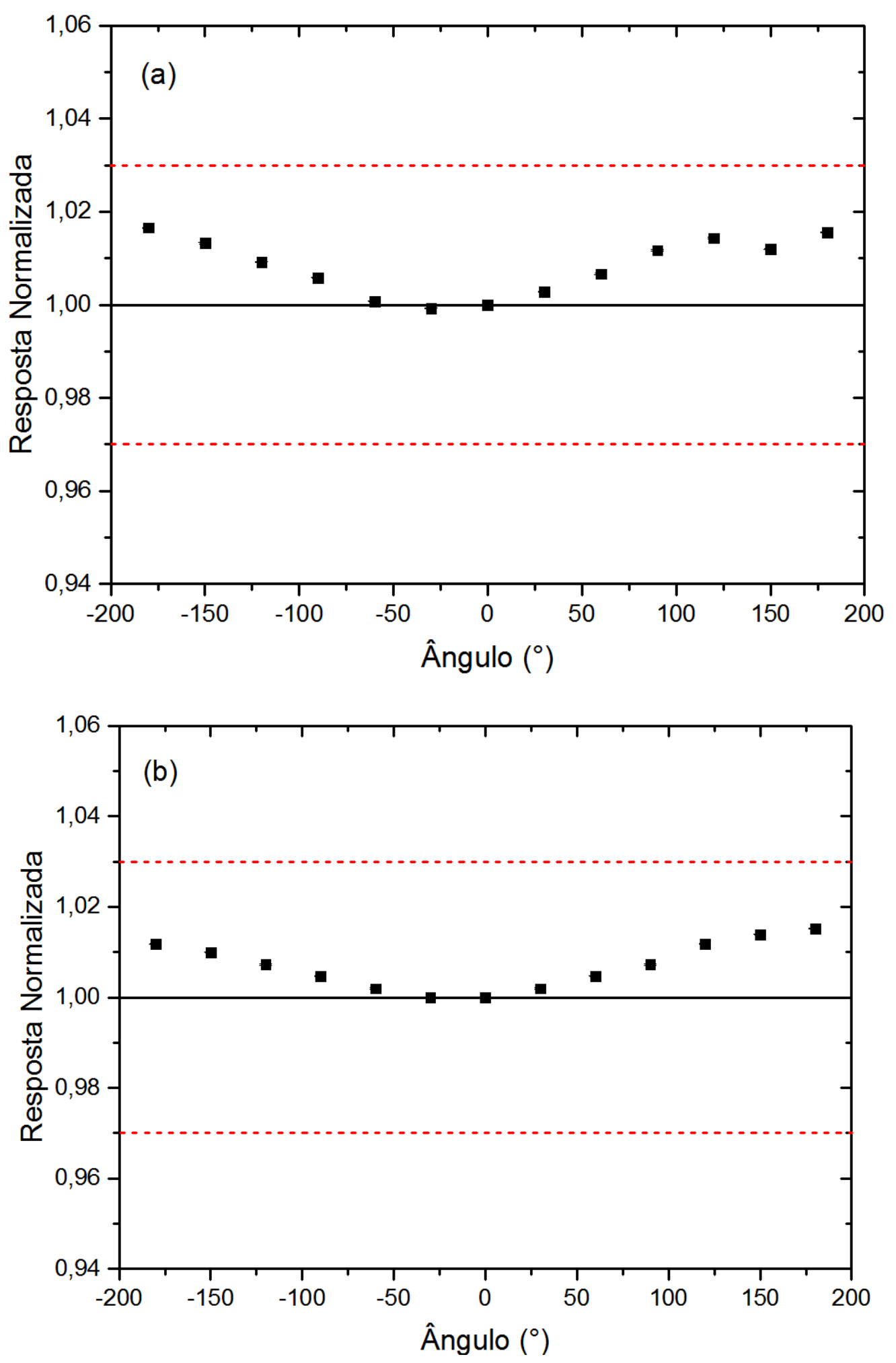

Figura 5.32: Dependência angular, para a qualidade de referência (RQT 9) dos feixes padronizados de radiação X para CT no LCl e para a câmara de ionização $C 7$. A incerteza máxima das medições foi de 0,01\%, não visível nos gráficos. Aberturas do colimador: (a) $2 \mathrm{~cm} \times 2 \mathrm{~cm}$ e (b) $5 \mathrm{~cm} \times 2 \mathrm{~cm}$. 

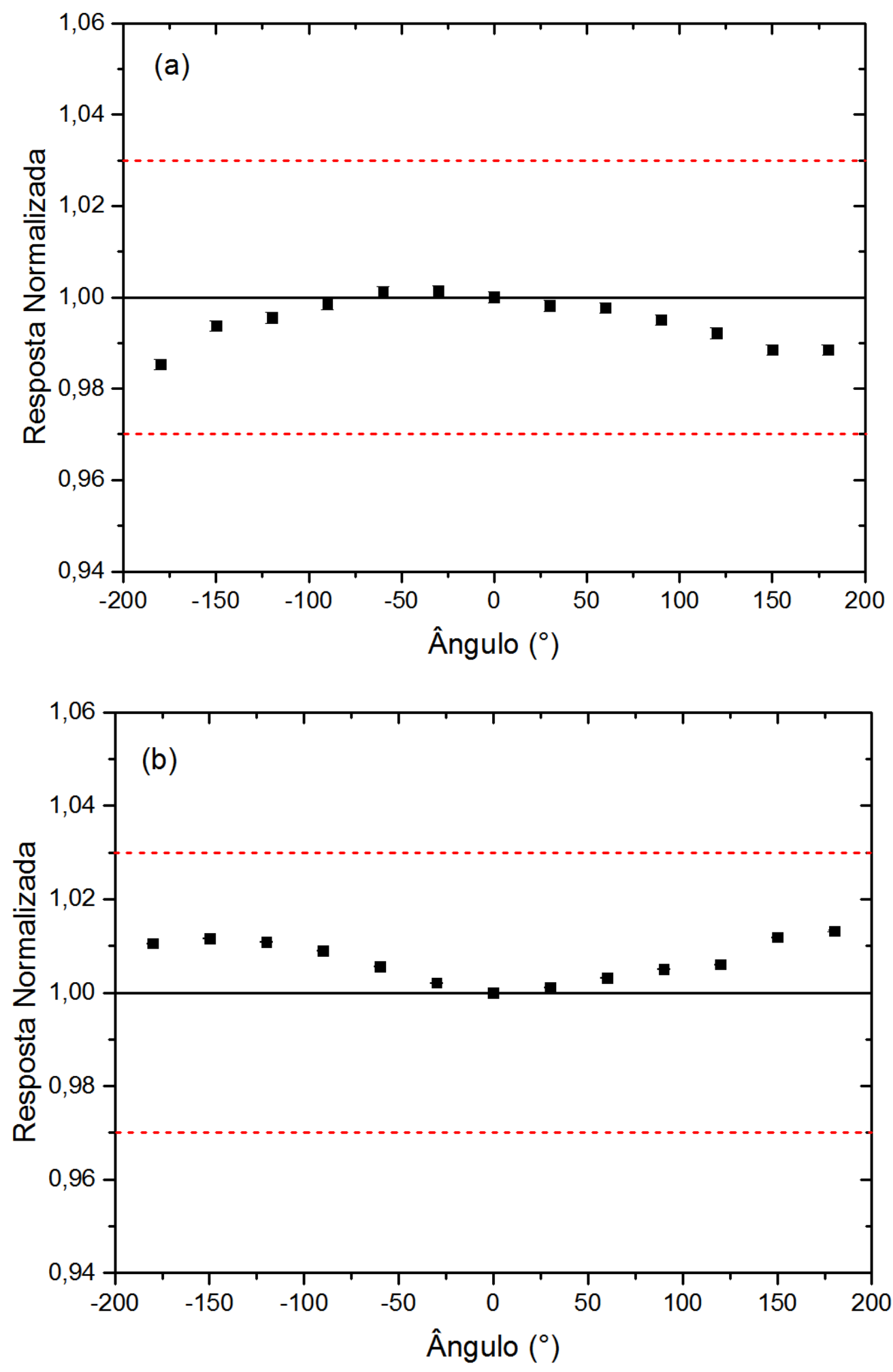

Figura 5.33: Dependência angular, para a qualidade de referência (RQT 9) dos feixes padronizados de radiação $X$ para CT no $\mathrm{LCl}$ e para as câmaras de ionização C6 (a) e C7 (b). A incerteza máxima das medições foi de 0,01 \%, não visível nos gráficos. 
Como é possível observar pelas figuras, os resultados obtidos encontramse dentro dos limites recomendados internacionalmente para dependência angular. Na Figura 5.33 é possível observar que as câmaras desenvolvidas, com comprimento de volume sensível de $30 \mathrm{~cm}$, apresentam a dependência angular dentro do limite (3\%) recomendado pela norma IEC (2005).

\subsubsection{Avaliação da Resposta em Função do Comprimento do Volume Sensível da Câmara de Ionização}

Este teste foi realizado com o intuito de avaliar a resposta em função do comprimento do volume sensível da câmara, ou seja, analisar se a quantidade de íons coletados ao longo do volume sensível é o mesmo ou se quando a medição se afasta do centro do volume sensível para ambas extremidades das câmaras o comportamento é o mesmo.

O teste de avaliação da resposta com o comprimento do volume sensível da câmara de ionização foi realizado para as câmaras que apresentam um comprimento de volume sensível de $30 \mathrm{~cm}$ (C6 e C7), utilizando a qualidade de radiação $X$ de referência de $C T$ do $L C l$ (RQT 9). O campo de radiação utilizado foi de $2 \mathrm{~cm}^{2}$ [abertura do colimador: $1 \mathrm{~cm}$ (eixo $\mathrm{x}$ ) $\times 2 \mathrm{~cm}$ (eixo y)]; para cada posição de irradiação no eixo $x$ foram obtidas dez medições de carga elétrica $(\mathrm{nC})$ durante $30 \mathrm{~s}$. Os resultados obtidos foram normalizados para a medição obtida no centro da câmara de ionização. A resposta deste teste será dada em resposta normalizada versus posição; a Figura 5.34 mostra um esquema da câmara de ionização com as posições de irradiação. A Figura 5.35 apresenta o resultado deste teste para as câmaras C6 e C7.

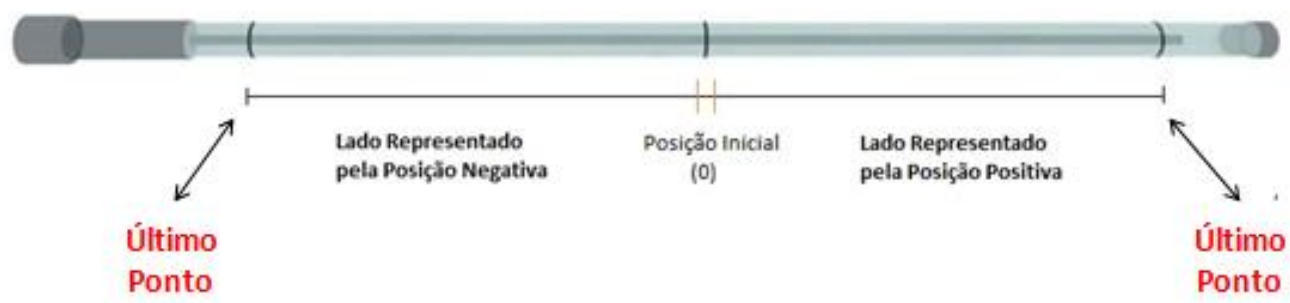

Figura 5.34: Esquema das posições utilizadas para o teste de avaliação da resposta em função do comprimento do volume sensível das câmaras de ionização C6 e C7. 

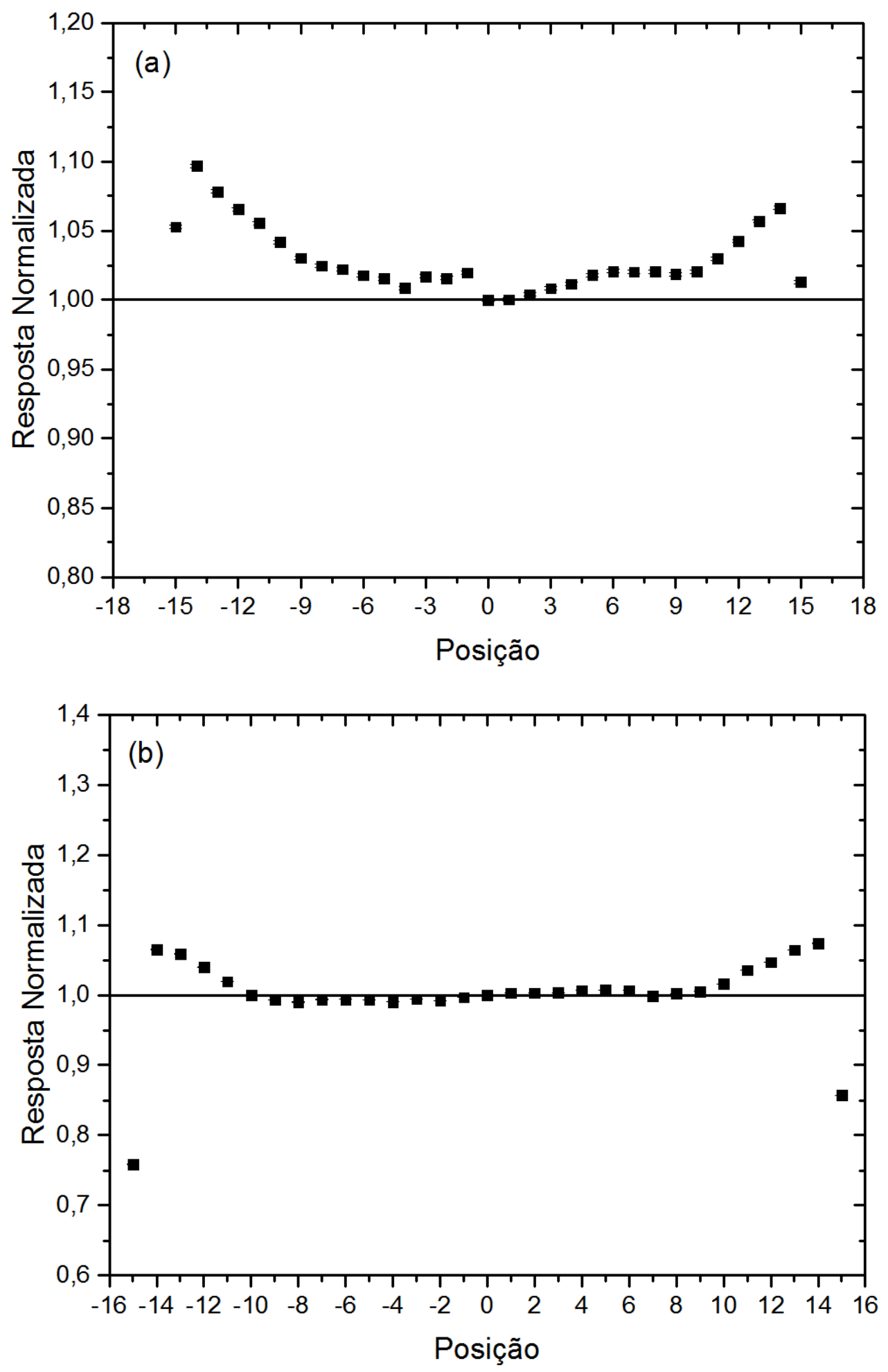

Figura 5.35: Avaliação da resposta em função da posição no comprimento do volume sensível, para a qualidade de referência (RQT 9) dos feixes estabelecidos de radiação $\mathrm{X}$ para $\mathrm{CT}$ no $\mathrm{LCl}$, com campo de irradiação de $2 \mathrm{~cm}^{2}$; a incerteza máxima das medições foi de 0,01\%, não visível nos gráficos, para as câmaras de ionização: (a) C6 e (b) C7. 
Este teste foi realizado com a intenção de se observar se a resposta obtida para a parte da câmara de ionização irradiada apresenta uma resposta semelhante em relação à região central. Para este estudo, partiu-se do centro para ambos os lados com passo de $1 \mathrm{~cm}$; sendo assim, foram realizadas 15 medições de carga elétrica $(\mathrm{pC})$ para cada lado e para a posição central, que foi utilizada para a normalização dos resultados.

Como se pode observar pela Figura 5.35, para a câmara C6, a resposta obtida para os pontos, quando se afastam do centro, varia bastante apesar de eles serem semelhantes para ambos os lados. Para a câmara $\mathrm{C} 7$, é possível observar que a resposta da câmara foi mais uniforme para um maior comprimento de volume sensível; somente no final da câmara pode-se ver uma maior variação na resposta; isso se deve ao final do comprimento do volume sensível e à presença da tampa da câmara de ionização ser de material isolante e, portanto, interferindo na resposta obtida. 


\section{Testes Realizados em Feixes Clínicos}

Como uma aplicação das câmaras de ionização desenvolvidas, foram realizados testes em dois hospitais, sendo eles: Hospital Veterinário da Faculdade de Medicina Veterinária e Zootecnia da Universidade de São Paulo (FMVZ/USP) em um tomógrafo Philips de 16 canais e no Hospital Israelita Albert Einstein (HIAE) em dois tomógrafos da Toshiba Aquilion, sendo um de 64 canais e outro de 320 canais. As câmaras de ionização utilizadas foram: C1, $\mathrm{C} 5$ e $\mathrm{C} 7$.

O intuito de se testar estas câmaras nestes feixes foi o de avaliar se as câmaras que foram desenvolvidas neste trabalho, C5 e C7, estão de acordo com as recomendações da ANVISA (2005) para o cálculo de dose absorvida. Utilizou-se a câmara C1 para auxiliar na comparação, uma vez que esta é uma câmara comercial, e foi utilizada como sistema de referência no decorrer de todo o presente trabalho.

Os testes realizados foram: determinação da taxa de kerma no ar e do CTDI. Para o cálculo da taxa de kerma no ar, a câmara de ionização ficou posicionada no centro do gantry; a técnica escolhida (parâmetros) foi a tensão de $120 \mathrm{kV}$, corrente de $100 \mathrm{~mA}$ e tempo de irradiação de $1 \mathrm{~s}$; e a abertura do colimador foi diferente para cada tomógrafo utilizado (Tabela 6.1). Para estas condições, foram realizadas três medições de carga $(\mathrm{nC})$ para cada câmara de ionização. Estas câmaras também foram expostas à radiação $X$ com capa $e$ sem capa protetora, para que fosse possível analisar a diferença entre as suas respostas e a influência do uso da capa. A Figura 6.1 mostra o arranjo do posicionamento das câmaras para este teste.

Tabela 6.1 Abertura do colimador para os tomógrafos utilizados

\begin{tabular}{ccc}
\hline Hospital & Número de Canais & $\begin{array}{c}\text { Campo de Radiação } \\
\left(\mathbf{m m}^{\mathbf{2}}\right)\end{array}$ \\
\hline FMVZ/USP & 16 & 24 \\
HIAE & 64 & 32 \\
HIAE & 320 & 32 \\
\hline
\end{tabular}




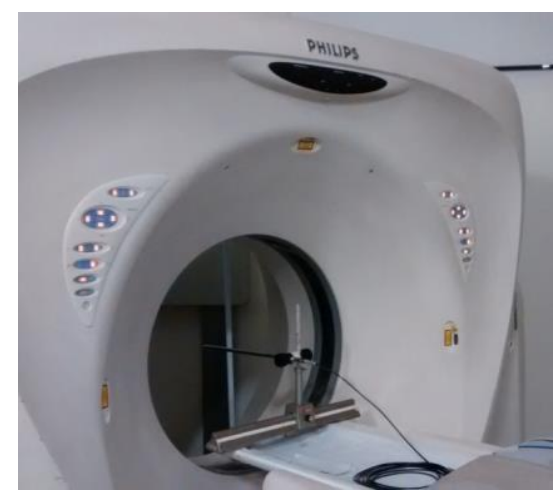

(a)

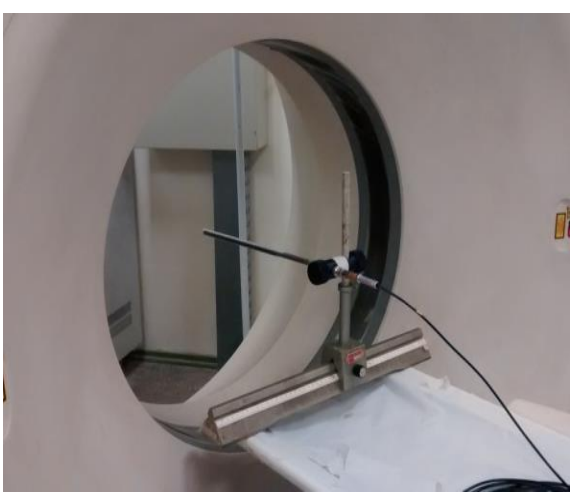

(b)

Figura 6.1: Posicionamento da câmara de ionização $C 7$ para a determinação da taxa de kerma no ar no tomógrafo clínico Philips: (a) imagem geral e (b) imagem focada no posicionamento da câmara no centro do gantry.

Para a determinação do CTDI, a técnica aplicada na irradiação foi a mesma que para a determinação da taxa de kerma no ar; a única diferença é que para a obtenção desta grandeza, a câmara de ionização foi posicionada dentro do simulador de PMMA; obrigatoriamente, ela precisa da capa para ela não ficar deslocada dentro do simulador e interferir no resultado a ser obtido. A Figura 6.2 mostra o arranjo experimental para o posicionamento da câmara de ionização no simulador e no centro do gantry.

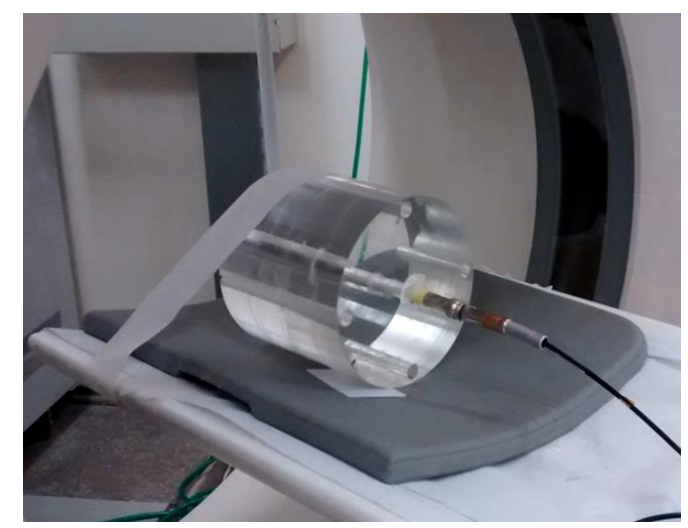

Figura 6.2: Arranjo experimental para o posicionamento das câmaras no simulador na posição central do tomógrafo clínico Philips

Para a obtenção do CTDI, as três câmaras foram irradiadas dentro dos simuladores de cabeça e de abdômen. Para a câmara $\mathrm{C}$, foram utilizados dois simuladores de cabeça e dois de abdômen encostados, para que todo o comprimento de volume sensível da câmara de ionização ficasse no interior do 
simulador. Foram realizadas três medições de $1 \mathrm{~s}$ na posição central e nas posições da periferia (3h, 6h, 9h e 12 h). Quando as câmaras foram utilizadas dentro do simulador, fez-se a escolha de protocolo de cabeça e abdômen no tomógrafo para que ele pudesse fornecer o CTDI nominal, para a comparação com o valor obtido, fazendo-se uso da câmara de ionização. As imagens da fatia fornecida pelo tomógrafo onde a câmara de ionização se encontra no momento da irradiação podem ser vistas na Figura 6.3 para a cabeça e para o abdômen. Estas imagens foram realizadas somente no interior do simulador de PMMA.

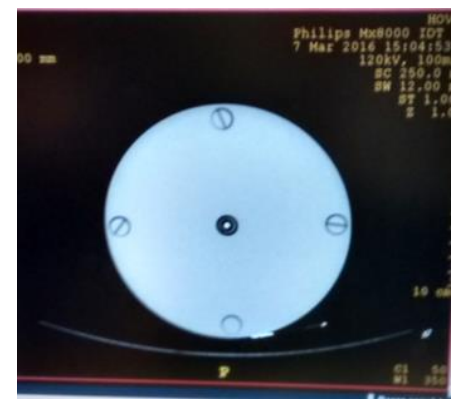

(a)

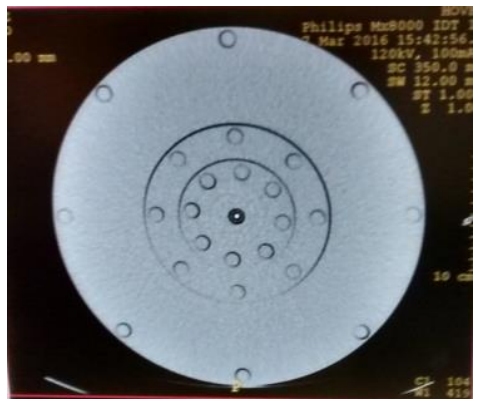

(b)

Figura 6.3: Imagens da câmaras de ionização na posição central no interior do simulador: (a) cabeça e (b) abdômen

A seguir serão apresentados os resultados obtidos para os testes descritos. As Tabelas 6.2 e 6.3 mostram os resultados para a taxa de kerma no ar das câmaras C1, C5 e C7 sem e com a capa protetora. A Tabela 6.4 apresenta os dados obtidos para o CTDI para as câmaras de ionização quando elas se localizam no simulador de cabeça e de abdômen no Hospital Israelita Albert Einstein.

Tabela 6.2: Índice de kerma ar no ar obtido com as câmaras $C 1$, $C 5$ e C7, sem capa e com capa, para os feixes do tomógrafo do Hospital FMVZ/USP para o campo de radiação de $24 \mathrm{~mm}^{2}$

\begin{tabular}{ccc}
\hline Câmara de & \multicolumn{2}{c}{ CTDI } \\
\cline { 2 - 3 } lonização & Sem Capa & Com Capa \\
\hline C1 & $14,758 \pm 0,003$ & $16,714 \pm 0,003$ \\
C5 & $19,166 \pm 0,003$ & $19,178 \pm 0,003$ \\
C7 & $23,937 \pm 0,003$ & $23,716 \pm 0,003$ \\
\hline
\end{tabular}


Tabela 6.3 Índice de kerma ar no ar obtido com as câmaras C1, C5 e C7, sem capa e com capa, para os feixes do tomógrafo do Hospital HIAE para o campo de radiação de $32 \mathrm{~mm}^{2}$

\begin{tabular}{ccccc}
\hline Câmara & \multicolumn{3}{c}{ CTDI (mGy) } \\
\cline { 2 - 5 } de & \multicolumn{2}{c}{ 64 Canais } & \multicolumn{2}{c}{ 320 Canais } \\
\cline { 2 - 5 } lonização & Sem Capa & Com Capa & Sem Capa & Com Capa \\
\hline C1 & $31,621 \pm 0,004$ & $31,903 \pm 0,004$ & $22,648 \pm 0,005$ & $22,981 \pm 0,005$ \\
C5 & $38,827 \pm 0,004$ & $38,385 \pm 0,004$ & $28,800 \pm 0,005$ & $28,975 \pm 0,005$ \\
C7 & $53,264 \pm 0,004$ & $53,512 \pm 0,004$ & $38,284 \pm 0,005$ & $38,476 \pm 0,005$ \\
\hline
\end{tabular}

Tabela 6.4 Índice de dose em tomografia computadorizada (CTDI) obtido para as câmaras $\mathrm{C} 1, \mathrm{C} 5$ e C7, para os simuladores de cabeça e abdômen no Hospital HIAE para os tomógrafos de 64 e 320 canais no campo de radiação de $32 \mathrm{~mm}^{2}$

\begin{tabular}{ccc}
\hline $\begin{array}{c}\text { Câmara de } \\
\text { lonização }\end{array}$ & $\begin{array}{c}\text { Cabeça } \\
\text { (mGy) }\end{array}$ & $\begin{array}{c}\text { Abdômen } \\
\text { (mGy) }\end{array}$ \\
\hline \multicolumn{3}{c}{ 64 Canais } \\
\hline C1 & $16,30 \pm 0,02$ & $9,90 \pm 0,02$ \\
C5 & $20,52 \pm 0,02$ & $12,11 \pm 0,02$ \\
C7 & $32,37 \pm 0,02$ & $21,51 \pm 0,02$ \\
\hline C1 & 320 Canais \\
C5 & 16,30 $\pm 0,01$ & $7,24 \pm 0,01$ \\
C7 & $36,47 \pm 0,01$ & $9,21 \pm 0,01$ \\
\hline
\end{tabular}


Tabela 6.5 Diferença percentual (\%) entre o CTDI obtido e o nominal para o simuladores de cabeça e de abdômen para as câmaras C1, C5 e C7 no Hospital HIAE para os tomógrafos de 64 e 320 canais no campo de radiação de $32 \mathrm{~mm}^{2}$

\begin{tabular}{ccc}
\hline $\begin{array}{c}\text { Câmara de } \\
\text { lonização }\end{array}$ & $\begin{array}{c}\text { Cabeça } \\
(\%)\end{array}$ & $\begin{array}{c}\text { Abdômen } \\
(\%)\end{array}$ \\
\hline \multicolumn{3}{c}{ 64 Canais } \\
C1 & 19,7 & 17,5 \\
C7 & 1,08 & 0,930 \\
\hline \multicolumn{3}{c}{ 320 Canais } \\
\hline C1 & 21,3 & 79,2 \\
C5 & 5,51 & 12,7 \\
C7 & 76,2 & 120 \\
\hline
\end{tabular}

Por meio destes resultados, é possível observar que as câmaras C1 e C5, que apresentam um comprimento de volume sensível de $10 \mathrm{~cm}$, responderam melhor, em comparação à câmara $\mathrm{C} 7$ que tem $30 \mathrm{~cm}$ de comprimento de volume sensível. A câmara de ionização de $10 \mathrm{~cm}$ que foi construída neste trabalho teve um desempenho melhor que a câmara comercial como se pode observar pela Tabela 6.5.

Para a câmara com comprimento de volume sensível de $30 \mathrm{~cm}$, os resultados obtidos não foram satisfatórios, por mais que esta câmara tenha sido testada em um tomógrafo que permita uma abertura de irradiação maior. Os testes foram realizados em modo axial, como recomendado pela ANVISA; portanto o campo de radiação máximo que se conseguiu utilizar foi de $32 \mathrm{~mm}^{2}$, ou seja, insignificante (aproximadamente $10 \%$ do volume sensível da câmara foi irradiado) se comparado ao comprimento do volume sensível desta câmara. Então, obedecendo às recomendações da ANVISA não é possível observar a real vantagem desta câmara de ionização. 


\section{Conclusões}

Os resultados obtidos para os testes de caracterização das câmaras de ionização utilizadas nesse trabalho encontram-se dentro dos limites recomendados internacionalmente, exceto para o caso do efeito de polaridade para as câmaras de ionização que apresentam comprimentos de volume sensível de $3 \mathrm{~cm}$ e $1 \mathrm{~cm}$, e para alguns casos em que o campo de radiação foi reduzido para $40 \mathrm{~mm}^{2}$. Porém, este fato não interfere no desempenho das câmaras de ionização. Para o teste de linearidade da resposta das câmaras, 0 ajuste linear foi obtido e, realizando-se uma aproximação, todos estão próximos de 1 , independentemente do campo de radiação em que foram obtidos.

As câmaras de ionização desenvolvidas (C5, C6 e C7) apresentaram resultados ótimos, verificando-se que a sua construção foi realizada com sucesso e que esta nova configuração com materiais de baixo custo não interfere nos níveis de qualidade internacional deste tipo de equipamento dosimétrico.

Também foi possível observar que ambas as câmaras com comprimento de volume sensível de $30 \mathrm{~cm}$, que foram desenvolvidas nesse trabalho, apresentaram respostas semelhantes e dentro dos limites recomendados internacionalmente, o que prova que a metodologia de desenvolvimento e construção são reprodutíveis e que o fato de se utilizar materiais nacionais de baixo custo não interfere no funcionamento deste tipo de equipamento dosimétrico.

As câmaras de ionização testadas nos feixes clínicos foram capazes de obter o índice de kerma no ar e o índice de dose em tomografia computadorizada (CTDI). Pode-se concluir que os resultados obtidos para as câmaras de ionização com comprimento de volume sensível de $10 \mathrm{~cm}$ (C1 e C5) foram bem melhores se comparados com os resultados da câmara $\mathrm{C} 7$ (30 $\mathrm{cm}$ de comprimento de volume sensível). Para esta última, os resultados não foram satisfatórios, pois pela recomendação da norma da ANVISA a realização dos testes deve ser em modo axial e o maior campo de radiação fornecido era pequeno em relação ao comprimento do volume sensível da 
câmara de ionização. Esta câmara de ionização teria que ser testada em outro modo (sem ser axial), com a finalidade de se obter respostas diferentes para este estudo, e para que se possa justificar a sua vantagem em relação a câmaras de ionização com volume sensíveis menores. 


\section{Referências}

ANVISA, AGÊNCIA NACIONAL DE VIGILÂNCIA SANITÁRIA. Diretrizes de Proteção Radiológica em Radiodiagnóstico Médico e Odontológico. Ministério da Saúde. Brasília, (Portaria 453), 1998.

ANVISA, AGÊNCIA NACIONAL DE VIGILÂNCIA SANITÁRIA. Radiodiagnóstico Médico: Desempenho de Equipamentos e Segurança. Brasília: Ministério da Saúde, 2005.

ATTIX, F.H., Introduction to Radiological Physics and Radiation Dosimetry. Willey-VCH Verlag, Wisconsin, 2004.

BOAG, J.W. Ionization Chambers. In: KASE, K.R.; BJARNGARD, B.E.; ATTIX, F.H. The Dosimetry of Ionization Radiation. Orlando, FL: Academic Press Inc., v. 2, p. 169-243, 1987.

BOONE, J M. The trouble with CTDI $_{100}$. Medical Physics, v.34, n.4, p.1364-1371, 2007.

BUSHONG, S.C. Ciência Radiológica para Tecnólogos. Elsevier. Rio de Janeiro, 2010.

COSTA, A. M. ; CALDAS, L. V. E. Câmara de ionização de placas paralelas para radiação $X$ de radiografia convencional e mamografia. Radiologia Brasileira, v. 41, p. 39-43, 2008.

DIAS, S. K. ; CALDAS, L. V. E. Development of an extrapolation chamber for the calibration for beta-ray applicators. IEEE Transactions on Nuclear Science, v. 45, n.3, p. 1666-1669, 1998. 
DIXON, R. L. Restructuring CT dosimetry-A realistic strategy for the future. Requiem for the pencil chamber. Medical Physics, v. 33, n. 10, p.3973-3976, 2006.

DIXON, R. L., BALLARD, A. C. Experimental validation of a versatile system of CT dosimetry using a conventional ion chamber: Beyond CTDI ${ }_{100}$. Medical Physics, v. 34, n. 8, p.3399-3413, 2006.

EUR, EUROPEAN COMMISSION. European Guidelines on Quality Criteria for Computed Tomography. Luxemburgourg,(EUR 16262 EN), 1997.

FEARON, T. CT dose parameters and their limitations. Pediatric Radiology, v. 32, n. 2, p.246-249, 2002.

FDA, FOOD AND DRUG ADMINISTRATION. Performance Standard for Diagnostic X-Ray Systems. Rockville, MD. Computed tomography (CT) equipament, 21 CFR 1020.33. (4-1-97 Editon), 1997.

GELEIJNS, J., ARTELLS, M. S., BRUIN, P. W., MATTER, R., MURAMATSU, Y., MCNITTGRAY, M. F. Computed tomography dose assessment for a $160 \mathrm{~mm}$ wide, 320 detector row, cone beam CT scanner. Physics in Medicine and Biology, v.54, n.10, p.3141-3159, 2010.

IAEA, INTERNATIONAL ATOMIC ENERGY AGENCY. Calibration of Dosemeters used in Radiotherapy. Relatório Técnico IAEA TRS 374, IAEA, Vienna, 1994.

IAEA, INTERNATIONAL ATOMIC ENERGY AGENCY. Calibration of Radiation Protection Monitoring Instruments. Relatório Técnico IAEA SRS 16, IAEA, Vienna, 2000.

IAEA, INTERNATIONAL ATOMIC ENERGY AGENCY. Dosimetry in Diagnostic Radiology: an International Code of Practice. Relatório Técnico IAEA TRS 457, IAEA, Vienna, 2007. 
ICRU, INTERNATIONAL COMMISSION ON RADIATION UNITS AND MEASUREMENTS. Fundamental Quantities and Units for lonizing Radiation. Relatório Técnico, ICRU Report 60, ICRU, Bethesda, Maryland, 1998.

IEC, INTERNATIONAL ELECTROTECHNICAL COMMISSION. Medical Electrical Equipment-Dosimeters with Ionization Chambers and/or Semi-Conductor Detectors as used in X-Ray Diagnostic Imaging. Relatório Técnico, IEC 61674, IEC, Genéve, 1997.

IEC, INTERNATIONAL ELECTROTECHNICAL COMMISSION: Medical Diagnostic X-Ray Equipment. Radiation Conditions for Use in the Determination of Characteristics. Relatório Técnico, (IEC 61267), $2^{\text {nd }}$ ed. IEC, Genève, 2005.

INMETRO, INSTITUTO NACIONAL DE METROLOGIA, NORMALIZAÇÃO E QUALIDADE INDUSTRIAL. Avaliação de Dados de Medição - Guia para a Expressão de Incerteza de Medição. ISO GUM, Rio de Janeiro, 2008.

KNOLL, G.F. Radiation Detection and Measurement. $2^{\text {nd }}$ ed., New York, N.Y.: John Wiley \& Sons, 1989

LEITZ, W.; AXELSSON, B.; SZENDRO, G. Computed-tomography dose assessment - a pratical approach. Radiation Protection Dosimetry., v.57, n. 2, p. 377-380, 1995.

MAIA, A. F.; CALDAS, L. V. E. A new extended-length parallel-plate ionization chamber. Physics in Medicine and Biology,v. 50, p. 3837-3847, 2005.

MAIA, A. F. Padronização de Feixes e Metodologia Dosimétrica em Tomografia Computadorizada. Tese (Doutorado), Instituto de Pesquisas Energéticas e Nucleares / Universidade de São Paulo, São Paulo, 2005. 
MORI, S., NISHIZAWA, K., OHNO, M., ENDO, M. Conversion factor for CT dosimetry to assess patient dose using a 256-slice CT scanner. The British Journal of Radiology. v. 79, p. 888-892, 2006.

NAGEL, H.D. Radiation Exposure in Computed Tomography Fundamentals, influencing Parameters, Dose Assessment, Optimization, Scanner Data, Terminology. $2^{\text {nd }}$ ed., Frankfurt: COCIR, cap. 2, Fundamentals of CT dosimetry, 2000.

NAKONECHNY, K. D., FALLONE, B. G., RATHEE, S. Novel methods of measuring single scan dose profiles and cumulative dose in CT. Medical Physics, v. 32, n.1, p. 98-109, 2005.

NEVES, L. P.; PERINI, A. P. ; CALDAS, L. V. E. Development and characterization of a new cylindrical ionization chamber for dosimetry of ${ }^{60} \mathrm{Co}$ beams. IEEE Transactions on Nuclear Science, v. 60, p. 712-715, 2013.

NEVES, L. P. Desenvolvimento e Caracterização de Câmaras de lonização Cilíndricas como Sistemas de Referência para Dosimetria de Feixes de Radiação de Fótons. Tese (Doutorado) - Instituto de Pesquisas Energéticas e Nucleares / Universidade de São Paulo, São Paulo, 2013.

OLIVEIRA, M. L. ; CALDAS, L. V. E. A special mini-extrapolation chamber for calibration of ${ }^{90} \mathrm{Sr}+{ }^{90} \mathrm{Y}$ sources. Physics in Medicine and Biology, v. 50, n.12, p. 2929-2936, 2005.

OKUNO, E.; YOSHIMURA, E. M. Física das Radiações. Oficina de Textos, São Paulo, 2010.

PERISINAKIS, K., DAMILAKIS, J., TZEDAKIS, A., PAPADAKIS, A., THEOCHAROPOULOS, N., GOURTSOYIANNIS, N. Determination of the weighted CT dose index in modern multi-detector CT scanners. Physics in Medicine and Biology, v.52,p.6485-6495, 2007. 
PODGORSAK, E.B. Radiation Oncology Physics: A Handbook for Teachers and Students. Relatório técnico, International Atomic Energy Agency, Vienna, 2005.

RAJAN, K.N.G. Advanced Medical Radiation Dosimetry. New Delhi: Prentice-Hall of India, 1992.

TOSHIBA, Manual de Operação para Tomógrafo Computadorizado TOSHIBA, modelo: Aquilion Prime (TSX- 302르), TOSHIBA Medical System Corporation, 2010. 